\title{
$\frac{((-)))}{40 e n}$
}

AUTARQUIA ASSOCIADA À UNIVERSIDADE DE SÃO PAULO

\section{ESTABELECIMENTO DE UM MÉTODO DOSIMÉTRICO PARA AVALIAÇÃO DA EXPOSIÇÃO À RADIAÇÃO ULTRAVIOLETA}

CLAUDIA CARLA GRONCHI

Tese apresentada como parte dos requisitos de obtenção do Grau de Doutor em Ciências na Área de Tecnologia Nuclear - Aplicações

Orientadora:

Dra. Linda V. E. Caldas

São Paulo 


\section{$\frac{((-)))}{40 e n}$}

AUTARQUIA ASSOCIADA À UNIVERSIDADE DE SÃO PAULO

\section{ESTABELECIMENTO DE UM MÉTODO DOSIMÉTRICO PARA AVALIAÇÃO DA EXPOSIÇÃO À RADIAÇÃO ULTRAVIOLETA}

CLAUDIA CARLA GRONCHI

Tese apresentada como parte dos requisitos de obtenção do Grau de Doutor em Ciências na Área de Tecnologia Nuclear - Aplicações

Orientadora:

Dra. Linda V. E. Caldas

São Paulo 2009 
Aos meus pais Dionísio (em memória)

e Marta, ao meu marido Rogério e a minha filha Vanessa. 


\section{AGRADECIMENTOS}

À Deus, pelo seu amor incondicional sempre presente na minha vida.

À FUNDACENTRO, por autorizar a minha participação no programa de pósgraduação e pelos recursos cedidos, sem os quais não seria possível a realização desta pesquisa.

Ao IPEN por me dar a possibilidade e disponibilizar os recursos financeiros e materiais para o desenvolvimento deste projeto.

À Dra. Linda V. E. Caldas, pela orientação firme e positiva, pelo total apoio, por acreditar e vibrar com cada resultado alcançado, pela liberdade e confiança que depositou em mim durante todo o desenvolvimento deste trabalho.

À Dra. Sonia G. P. Cecatti, um obrigada muito especial, não só pelo apoio e incentivo na realização deste projeto, mas pela nossa amizade e por tudo o que realizamos durante os anos em que trabalhamos juntas.

À M.Sc. Teresa Cristina Nathan Outeiro Pinto pelo seu apoio, confiança, paciência, compreensão e amizade, que foram fundamentais durante todo o processo.

À Dra. Maria Inês Teixeira, pelas sugestões no exame de qualificação.

À Dra. Letícia L. C. Rodrigues e à Dra. Sonia H. Tatumi pelas sugestões e incentivos feitos no seminário de área, que me deram muita força e inspiração para concluir o trabalho. 
À Dra. Alcinéa M. A. Santos e ao Dr. Carlos Sérgio da Silva, pela aprovação dos trâmites necessários na FUNDACENTRO, pelo apoio e incentivo ao longo de todo trabalho.

Aos colegas de trabalho da FUNDACENTRO Engํㅜ Francisco Kulcsar Neto e Dr. Irlon de Ângelo da Cunha, pela atenção e pelas informações que foram muito importantes na fase final deste trabalho.

Ao M.Sc. Gelson P. dos Santos, pela paciência, atenção e disponibilidade em irradiar as amostras.

Ao Sr. Claudinei T. Cescon, pela disponibilidade em me atender nos momentos de reparos e ajustes dos equipamentos do LCl.

Ao Sr. Valdir de S. Carvalho e Sr. Rafael E. Diniz, por disponibilizarem o uso da fonte de radiação beta e pela irradiação das amostras.

Ao Dr. Vitor Vívolo e à Dra. Maria da Penha A. Potiens, pela atenção prestada no decorrer do desenvolvimento deste trabalho.

Aos engenheiros do CTR, Sra. Elizabeth S. R. Somessari e Sr. Carlos G. Silveira, pela atenção e agilidade na irradiação das amostras.

Aos colegas de pós-graduação M.Sc. Eric A. B. da Silva e Patrícia L. Antonio, pela paciência, atenção e disponibilidade em me ajudar nos momentos solicitados.

A Sra. Donata C. O. Zanin, pela atenção, pelo apoio administrativo, pela simpatia e principalmente pela paciência, que foram fundamentais no decorrer deste trabalho.

Ao Sr. José C. Sabino da Divisão de Projetos e Fabricação do IPEN, pela atenção e disponibilidade na realização de usinagem de peças. 
Aos Srs. Idacir Mantovanni, Ismael A. Silva e Antonio M. Melo da Divisão de Projetos e Fabricação do IPEN, pela atenção e disponibilidade na realização de soldagem de peças nos processos de soldas elétrica e TIG.

À Srta. Patrícia G. P. Cecatti, pelas fotos e ilustrações das figuras.

Ao meu marido Rogério, pela paciência, pelo apoio, pelos incentivos constantes e vibrações positivas, imprescindíveis durante todo o decorrer deste estudo.

À minha querida filha Vanessa, alegre, determinada, e esperta, que vive intensamente cada minuto, fonte da minha inspiração. Obrigada pela compreensão, pelo amor e carinho.

À Laís, pela paciência, compreensão e carinho.

Aos meus cunhados Cristiane e Sacha Darke e a minha sogra Eloisa, que se empenharam na aquisição e no transporte dos filtros Hoya, parte fundamental do meu trabalho. Um obrigada muito especial.

À minha mãe Marta, pelo exemplo de vida e determinação.

A todos os meus familiares, que de alguma maneira me apoiaram durante todo esse tempo.

A todos que direta e indiretamente me ajudaram na execução deste trabalho. 
Quero aportar meu grão de areia para a praia do conhecimento humano banhada pelo mar da consciência universal.

(Juan Ribaut) 


\title{
ESTABELECIMENTO DE UM MÉTODO DOSIMÉTRICO PARA AVALIAÇÃO DA EXPOSIÇÃO À RADIAÇÃO ULTRAVIOLETA
}

\author{
Claudia Carla Gronchi
}

\section{RESUMO}

Um método dosimétrico para avaliação da exposição à radiação ultravioleta foi estabelecido com os detectores $\mathrm{Al}_{2} \mathrm{O}_{3}: \mathrm{C}$ InLight e com o sistema leitor OSL microStar e software, da Landauer, associados às técnicas de Luminescência Opticamente Estimulada (OSL) e Luminescência Opticamente Estimulada Fototransferida (PTOSL). As etapas principais do trabalho foram: caracterização dos detectores $\mathrm{Al}_{2} \mathrm{O}_{3}: \mathrm{C}$ InLight, sem pré-condicionamento, em relação às fontes de RUV solar e artificial, utilizando a técnica OSL; caracterização dos detectores $\mathrm{Al}_{2} \mathrm{O}_{3}: \mathrm{C}$ InLight, pré-condicionados, em relação às fontes de RUV solar e artificial, utilizando a técnica PTOSL; e aplicações práticas dos detectores $\mathrm{Al}_{2} \mathrm{O}_{3}: \mathrm{C}$ InLight, sem pré-condicionamento e pré-condicionados, em locais de exposição à RUV solar e RUV artificial proveniente de processos de soldagens elétrica e TIG (Tungsten Inert Gas). Os detectores $\mathrm{Al}_{2} \mathrm{O}_{3}: \mathrm{C}$ InLight apresentaram respostas OSL e PTOSL satisfatórias em relação aos parâmetros: comprimento de onda, tempo de iluminação UV, irradiância, exposição radiante e dependência angular, quando expostos à RUV. Esses detectores mostraram estimulação máxima OSL e PTOSL para o comprimento de onda de $330 \mathrm{~nm}$, o que os torna uma opção viável para detecção e dosimetria da radiação na faixa UVA. 


\title{
ESTABLISHMENT OF A DOSIMETRY METHOD FOR THE EXPOSURE EVALUATION TO THE ULTRAVIOLET RADIATION
}

\author{
Claudia Carla Gronchi
}

\begin{abstract}
A dosimetric method for the exposure evaluation to ultraviolet radiation was established with $\mathrm{Al}_{2} \mathrm{O}_{3}: \mathrm{C}$ InLight detectors and an OSL microStar reader and software, of Landauer, associated to the techniques of Optically Stimulated Luminescence (OSL) and Phototransferred Optically Stimulated Luminescence (PTOSL). The main phases of this work were: characterization of the $\mathrm{Al}_{2} \mathrm{O}_{3}: \mathrm{C}$ InLight detectors, without pre-conditioning, exposed to ultraviolet radiation (RUV) of solar and artificial sources, using the OSL technique; characterization of the $\mathrm{Al}_{2} \mathrm{O}_{3}: \mathrm{C}$ InLight detectors, pre-conditioned, exposed to $\mathrm{RUV}$ solar and artificial sources, using the PTOSL technique; practical applications of the $\mathrm{Al}_{2} \mathrm{O}_{3}: \mathrm{C}$ InLight detectors to the solar and artificial RUV, originating from TIG (Tungsten Inert Gas) and electric welding. The $\mathrm{Al}_{2} \mathrm{O}_{3}: \mathrm{C}$ InLight detectors presented satisfactory OSL and PTOSL responses in relation to the parameters: wavelength, UV illumination time, irradiance, radiance exposure and angular dependence to the RUV. Those detectors presented maximum OSL and PTOSL stimulation for the wavelength of $330 \mathrm{~nm}$, showing that they are may be useful for UVA radiation detection and dosimetry.
\end{abstract}




\section{SUMÁRIO}

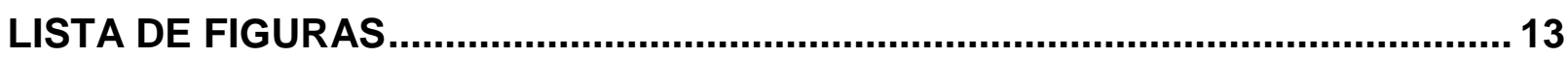

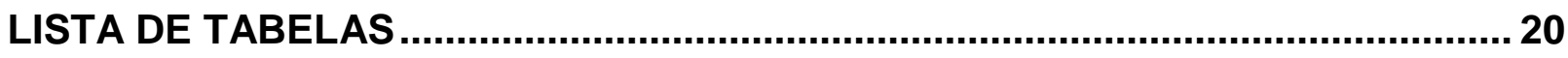

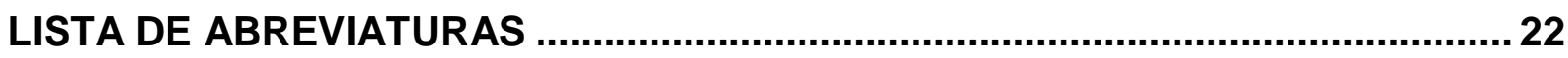

1. INTRODUÇÃO

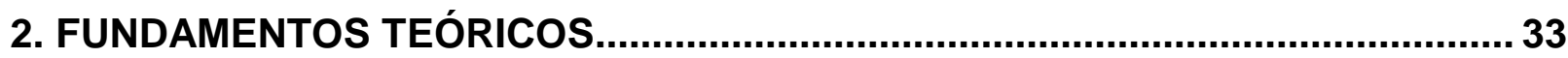

2.1 LUMINESCÊNCIA OPTICAMENTE ESTIMULADA (OSL) …........................................... 33

2.1.1 Óxido de alumínio dopado com carbono $\left(\mathrm{Al}_{2} \mathrm{O}_{3}: \mathrm{C}\right)$...................................... 37

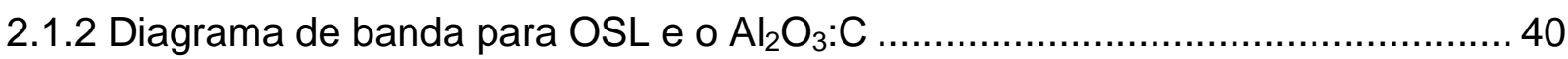

2.1.3 Luminescência opticamente estimulada fototransferida (PTOSL) ..................... 42

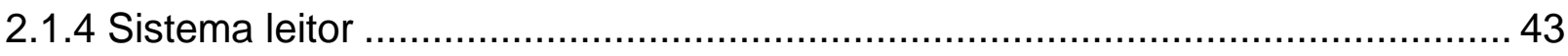

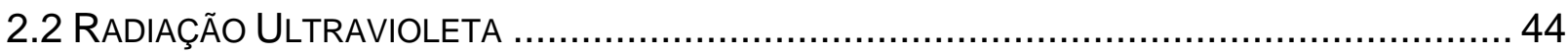

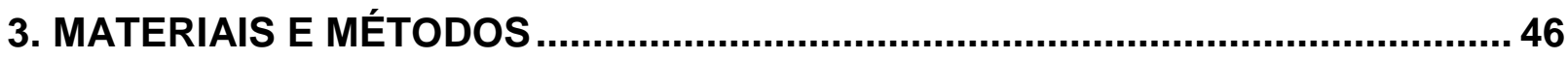

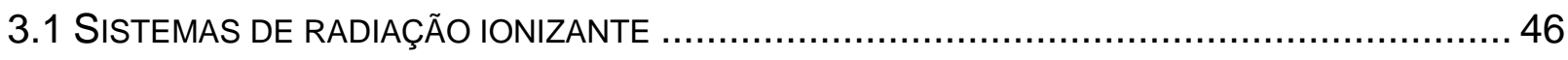

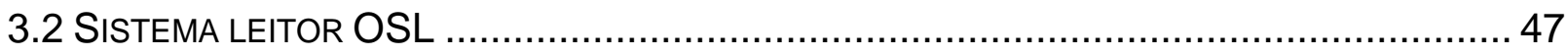

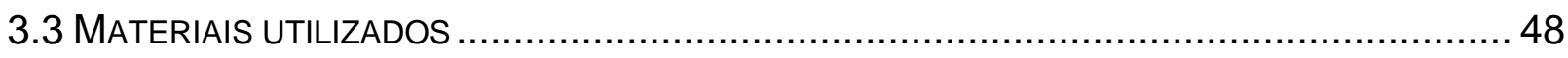

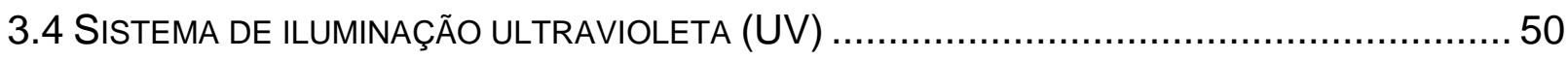

3.5 SISTEMA DE MEDIÇÃO DA RADIAÇÃO ULTRAVIOLETA (RUV) .....................................52

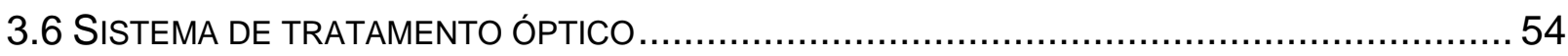

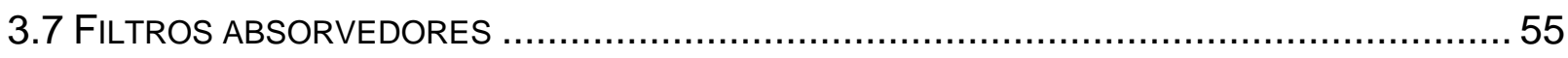

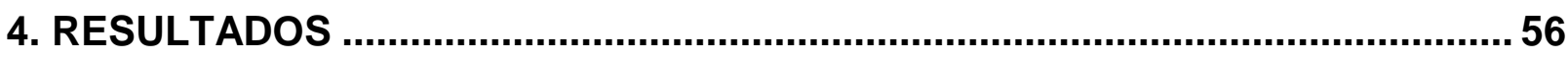

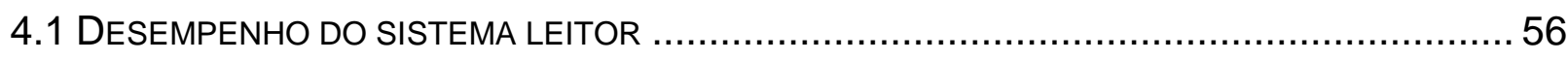

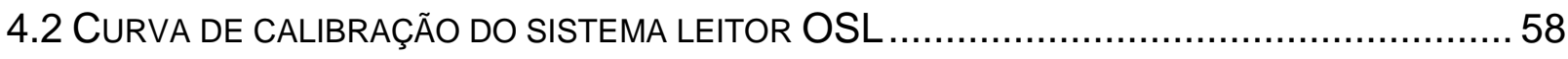


4.3 CARACTERIZAÇÃO INICIAL DOS DETECTORES $\mathrm{AL}_{2} \mathrm{O}_{3}: \mathrm{C}$ INLIGHT DOT ..........................59

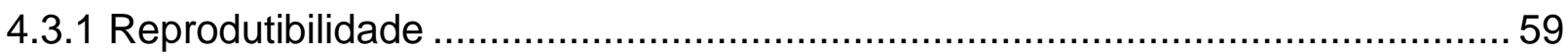

4.3.2 Resposta OSL em função da dose absorvida (radiação gama) ......................... 59

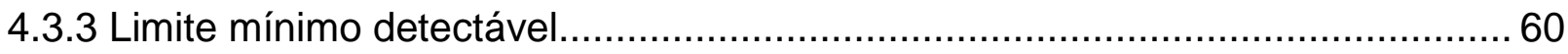

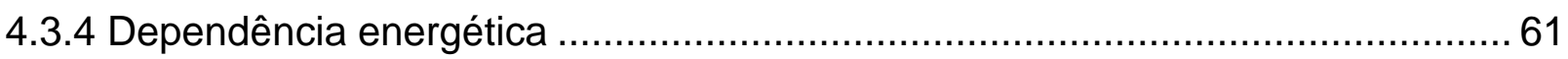

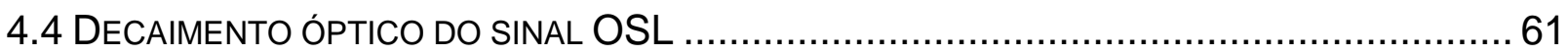

4.4.1 Exposição dos detectores $\mathrm{Al}_{2} \mathrm{O}_{3}: \mathrm{C}$ à luz fluorescente .....................................62

4.4.2 Exposição dos detectores InLight Dot à luz solar............................................ 65

4.5 CaracterizaÇÃo dos detectores $\mathrm{AL}_{2} \mathrm{O}_{3}: \mathrm{C}$ SEM PRÉ-CONDICIONAMENTOS

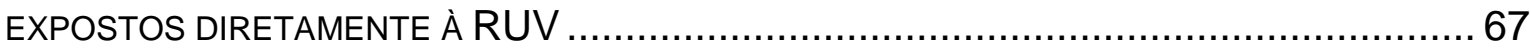

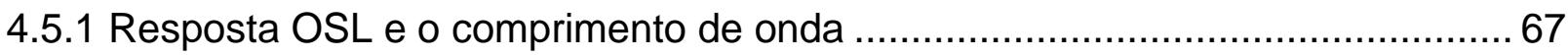

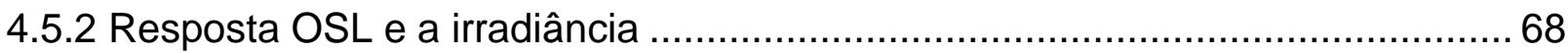

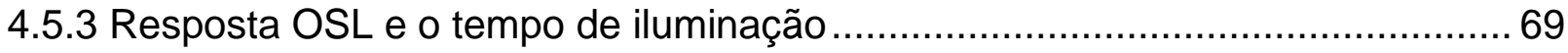

4.5.4 Resposta OSL e a exposição radiante ........................................................ 70

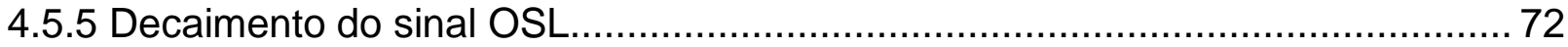

4.6 CARACTERIZAÇÃO DOS DETECTORES $\mathrm{AL}_{2} \mathrm{O}_{3}:$ :C UTILIZANDO A TÉCNICA PTOSL ..............76

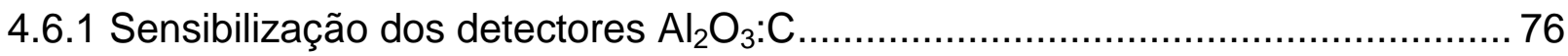

4.6.2 Tratamento óptico e o tempo de iluminação UV ................................................ 78

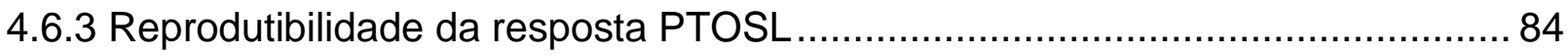

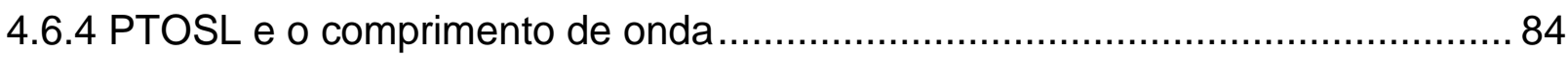

4.6.5 PTOSL e o tempo de iluminação UV ........................................................... 85

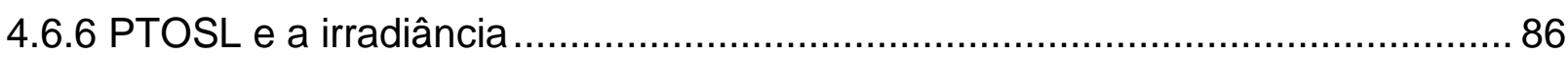

4.6.7 PTOSL e a exposição radiante …………………................................... 8 .

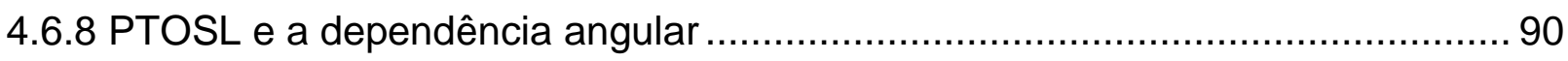

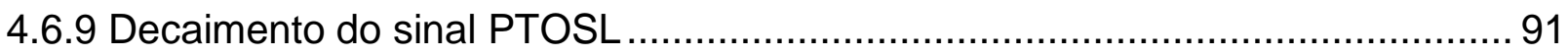

4.6.10 Limite mínimo detectável dos detectores $\mathrm{Al}_{2} \mathrm{O}_{3}: \mathrm{C}$ de RUV ............................92 
4.7 APLICAÇÕES PRÁTICAS DOS DETECTORES $\mathrm{AL}_{2} \mathrm{O}_{3}: \mathrm{C}$ INLIGHT

4.7.1 Aplicações práticas dos detectores $\mathrm{Al}_{2} \mathrm{O}_{3}: \mathrm{C}$ InLight (sem précondicionamentos) expostos diretamente à RUV.

4.7.1.1 Exposição dos detectores $\mathrm{Al}_{2} \mathrm{O}_{3}: \mathrm{C}$ InLight (sem pré-condicionamentos) à RUV solar.

4.7.1.2 Exposição dos detectores $\mathrm{Al}_{2} \mathrm{O}_{3}: \mathrm{C}$ InLight (sem pré-condicionamentos) à RUV proveniente do processo de solda elétrica.

4.7.1.3 Exposição dos detectores $\mathrm{Al}_{2} \mathrm{O}_{3}: \mathrm{C}$ InLight (sem pré-condicionamentos) à RUV proveniente do processo de solda TIG.

4.7.2 Aplicações práticas dos detectores $\mathrm{Al}_{2} \mathrm{O}_{3}: \mathrm{C}$ InLight, pré-condicionados, utilizando a técnica PTOSL.

4.7.2.1 Exposição dos detectores $\mathrm{Al}_{2} \mathrm{O}_{3}: \mathrm{C}$ InLight (pré-condicionados) à RUV solar

4.7.2.2 Exposição dos detectores $\mathrm{Al}_{2} \mathrm{O}_{3}: \mathrm{C}$ InLight, pré-condicionados, à RUV proveniente do processo de solda elétrica.

4.7.2.3 Exposição dos detectores $\mathrm{Al}_{2} \mathrm{O}_{3}: \mathrm{C}$ InLight, pré-condicionados, à RUV proveniente do processo de solda TIG.

4.7.2.3.1 Exposição dos detectores $\mathrm{Al}_{2} \mathrm{O}_{3}: \mathrm{C}$ InLight, pré-condicionados, à RUV proveniente do processo de solda TIG durante $5 \mathrm{~min}$.

4.7.2.3.2 Exposição dos detectores $\mathrm{Al}_{2} \mathrm{O}_{3}: \mathrm{C}$ InLight, pré-condicionados, à RUV proveniente do processo de solda TIG durante $20 \mathrm{~min}$.

5. CONCLUSÕES

APÊNDICE A PROCEDIMENTOS BÁSICOS PARA UTILIZAÇÃO DO LEITOR OSL MICROSTAR SYSTEM E SOFTWARE DA LANDAUER E DOS DETECTORES $\mathrm{AL}_{2} \mathrm{O}_{3}: \mathrm{C}$ INLIGHT DOT E INLIGHT.

APÊNDICE B PROCEDIMENTO PARA UTILIZAÇÃO DO SISTEMA LEITOR OSL MICROSTAR E DOS DETECTORES $\mathrm{AL}_{2} \mathrm{O}_{3}$ :C INLIGHT DOT E INLIGHT DA LANDAUER, SEM PRÉCONDICIONAMENTO, EXPOSTOS A UMA FONTE DE RADIAÇÃO ULTRAVIOLETA. 
APÊNDICE C PROCEDIMENTO PARA UTILIZAÇÃO DO SISTEMA LEITOR OSL MICROSTAR E OS DETECTORES $\mathrm{AL}_{2} \mathrm{O}_{3}: \mathrm{C}$ INLIGHT DOT E INLIGHT DA LANDAUER PRÉ- CONDICIONADOS E EXPOSTOS À UMA FONTE DE RADIAÇÃO ULTRAVIOLETA. ... 131

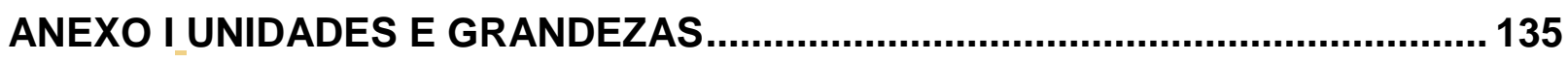

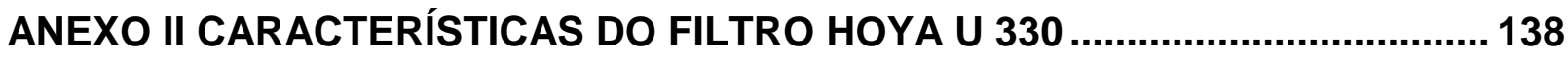

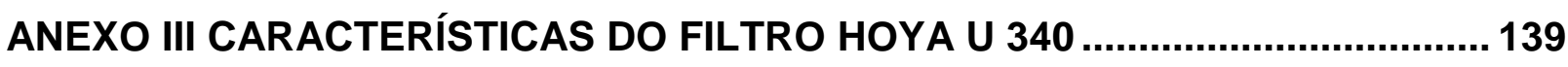

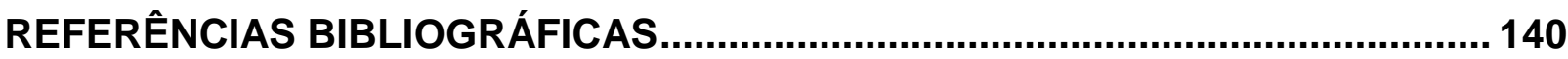




\section{LISTA DE FIGURAS}

FIGURA 2.1 - Curva de decaimento OSL do $\mathrm{Al}_{2} \mathrm{O}_{3}: \mathrm{C}$ com comprimento de onda na faixa de 420 e $550 \mathrm{~nm}$ (16 mW.cm-2) após irradiação com $60 \mathrm{mGy}\left({ }^{90} \mathrm{Sr}+{ }^{90} \mathrm{Y}\right)$.

FIGURA 2.2 - Representação gráfica dos principais modos de estimulação OSL.

FIGURA 2.3 - Estrutura simplificada do cristal de $\mathrm{Al}_{2} \mathrm{O}_{3}$. 39

FIGURA 2.4 - Configuração de uma carga compensada de um centro $\mathrm{F}^{+}$por um íon de carbono bivalente.

FIGURA 2.5 - Modelo de diagrama de bandas representando a armadilha dosimétrica principal (MDT), a armadilha profunda de elétron (DET), a armadilha profunda de buraco (DHT), e os centros $\mathrm{Fe} \mathrm{F}^{+}$. As transições do elétron principal e do buraco durante o estágio de irradiação com raios beta são retratados: (1) criação do par elétron-buraco, (2) captura do elétron pela MDT, (3) captura do elétron pela DET, (4) recombinação do elétron e do buraco no centro $\mathrm{F}^{+}$, (5) captura do buraco pelo centro $\mathrm{F}$, (6) captura do buraco pela DHT, (7) recombinação do elétron e do buraco na DHT.

FIGURA 2.6 - Esquema simplificado de um sistema OSL com fonte de estimulação óptica.

FIGURA 2.7 - Espectro eletromagnético da radiação. 45

FIGURA 3.1 - Leitor OSL microStar System e software da Landauer 48

FIGURA 3.2 - Invólucro (a) e a lâmina (b) do detector $\mathrm{Al}_{2} \mathrm{O}_{3}: \mathrm{C}$ InLight 49

FIGURA 3.3 - Adaptador (a) e o detector $\mathrm{Al}_{2} \mathrm{O}_{3}: \mathrm{C}$ InLight Dot aberto (b) 49

FIGURA 3.4 - Detector $\mathrm{Al}_{2} \mathrm{O}_{3}: \mathrm{C}$ InLight Dot fechado e encaixado no adaptador 49 
FIGURA 3.5 - Lâmpada de Hg, HBO 200 W da OSRAM acoplada ao Mercury Light Source SP-200, da Bausch \& Lomb, do sistema de iluminação UV.

FIGURA 3.6 - Base e suporte de amostra com o detector $\mathrm{Al}_{2} \mathrm{O}_{3}: \mathrm{C}$ InLight Dot (a) e com o detector $\mathrm{Al}_{2} \mathrm{O}_{3}: \mathrm{C}$ InLight (b). 51

FIGURA 3.7 - Sistema de irradiação ultravioleta. (a) trilho, (b) base para o suporte de amostra e sensor UV, (c) sensor UV, (d) seletor de comprimento de onda, (e) monocromador, (f) base para a lâmpada UV e colimador do feixe de luz UV. 52

FIGURA 3.8 - Radiômetro da DELTA OHM, modelo DO 9721, e sensor UV. 53

FIGURA 3.9 Sensores UVA, UVB e UVC, da Delta OHM. 53

FIGURA 3.10 - Sensor de nível de iluminamento (a) e de temperatura (b), da Delta OHM. 54

FIGURA 3.11 - Caixa de luz fluorescente para tratamento óptico dos detectores $\mathrm{Al}_{2} \mathrm{O}_{3}: \mathrm{C}$ para sua reutilização. 54

FIGURA 3.12 - Filtros HOYA U-330 (a) e U-340 (b) 55

FIGURA 4.1 - Desempenho do leitor OSL microStar System: Contagem DARK 57

FIGURA 4.2 - Desempenho do leitor OSL microStar System: Contagem CAL. 57

FIGURA 4.3 - Desempenho do leitor OSL microStar System: Contagem LED. 58

FIGURA 4.4 - Curva de calibração do leitor OSL microStar System usando dosímetros $\mathrm{Al}_{2} \mathrm{O}_{3}: \mathrm{C}$ InLight pré-irradiados.

FIGURA 4.5 - Curva de dose-resposta OSL dos detectores $\mathrm{Al}_{2} \mathrm{O}_{3}: \mathrm{C}$ Inlight Dot para radiação gama $\left({ }^{60} \mathrm{Co}\right)$.

FIGURA 4.6 - Decaimento do sinal OSL dos detectores $\mathrm{Al}_{2} \mathrm{O}_{3}: \mathrm{C}$ InLight Dot préirradiados com radiação beta em função do tempo de exposição a 260 lux de luz fluorescente (luz ambiente). A incerteza máxima das medições foi de $5,3 \%$. 63

FIGURA 4.7 - Decaimento do sinal OSL dos detectores $\mathrm{Al}_{2} \mathrm{O}_{3}: \mathrm{C}$ InLight Dot préirradiados com radiação beta em função do tempo de exposição 
a 26.0000 lux de luz fluorescente (caixa de luz). A incerteza máxima das medições foi de $5,1 \%$.

FIGURA 4.8 - Decaimento do sinal OSL dos detectores $\mathrm{Al}_{2} \mathrm{O}_{3}: \mathrm{C}$ InLight Dot préirradiados com 15 mGy de radiação beta em função do tempo de exposição a 260 lux, 17.000 lux e 26.000 lux de luz fluorescente. A incerteza máxima das medições foi de 5,0\%. 64

FIGURA 4.9 - Decaimento do sinal OSL dos detectores $\mathrm{Al}_{2} \mathrm{O}_{3}: \mathrm{C}$ InLight Dot não irradiados e pré-irradiados com 15 mGy em função do tempo de exposição à luz solar.

FIGURA 4.10 - Detalhes da curva de decaimento do sinal OSL entre 0 e 60 min (a) e entre 0 e 10 min (b), que mostram a ativação inicial da resposta OSL dos detectores InLight Dot não irradiados e expostos à luz solar. 66

FIGURA 4.11 - Resposta OSL dos detectores $\mathrm{Al}_{2} \mathrm{O}_{3}: \mathrm{C}$ InLight em função do comprimento de onda de luz do sistema de RUV. A incerteza máxima das medições foi de $6,8 \%$.

FIGURA 4.12 - Resposta OSL dos detectores $\mathrm{Al}_{2} \mathrm{O}_{3}: \mathrm{C}$ InLight em função da irradiância da fonte de luz do sistema de RUV.

FIGURA 4.13 - Resposta OSL dos detectores $\mathrm{Al}_{2} \mathrm{O}_{3}: \mathrm{C}$ InLight em função do tempo de iluminação UV.

FIGURA 4.14 - Resposta OSL dos detectores $\mathrm{Al}_{2} \mathrm{O}_{3}: \mathrm{C}$ InLight para $\mathrm{O}$ comprimento de onda de $330 \mathrm{~nm}$ em função da exposição radiante. 71

FIGURA 4.15 - Resposta OSL dos detectores $\mathrm{Al}_{2} \mathrm{O}_{3}: \mathrm{C}$ InLight para 0 comprimento de onda de $340 \mathrm{~nm}$ em função da exposição radiante. 71

FIGURA 4.16 - Decaimento do sinal OSL dos detectores $\mathrm{Al}_{2} \mathrm{O}_{3}: \mathrm{C}$ InLight, expostos a diferentes irradiâncias (RUV), em função do tempo pós-iluminação UV. 
FIGURA 4.17 - Perda percentual do sinal OSL em função do tempo pósiluminação UV dos detectores $\mathrm{Al}_{2} \mathrm{O}_{3}: \mathrm{C}$ InLight, expostos a diferentes irradiâncias (RUV).

FIGURA 4.18 - Decaimento do sinal OSL em função do tempo pósiluminação UV dos detectores $\mathrm{Al}_{2} \mathrm{O}_{3}: \mathrm{C}$ InLight, expostos a diferentes intervalos de tempo de iluminação UV. 74

FIGURA 4.19 - Perda percentual do sinal OSL em função do tempo pósiluminação UV dos detectores $\mathrm{Al}_{2} \mathrm{O}_{3}: \mathrm{C}$ InLight, expostos a diferentes intervalos de tempo de iluminação UV. 75

FIGURA 4.20 - Curva de decaimento óptico dos detectores $\mathrm{Al}_{2} \mathrm{O}_{3}: \mathrm{C}$ InLight em função do tempo de iluminação a 26.000 lux, para diferentes doses absorvidas de pré-irradiação $\left({ }^{60} \mathrm{Co}\right)$.

FIGURA 4.21 - Perda percentual do sinal OSL dos detectores $\mathrm{Al}_{2} \mathrm{O}_{3}: \mathrm{C}$ InLigth em função das doses de iluminação a 26.000 lux, para diferentes doses absorvidas de pré-irradiação $\left({ }^{60} \mathrm{Co}\right)$. 78

FIGURA 4.22 - Resposta OSL dos detectores $\mathrm{Al}_{2} \mathrm{O}_{3}: \mathrm{C}$ InLight tratados opticamente durante 10 min em função do tempo de iluminação UV (26.000 lux). 80

FIGURA 4.23 - Resposta OSL dos detectores $\mathrm{Al}_{2} \mathrm{O}_{3}: \mathrm{C}$ InLight tratados opticamente durante $20 \mathrm{~min}$ em função do tempo de iluminação UV (26.000 lux).

FIGURA 4.24 - Resposta PTOSL dos detectores $\mathrm{Al}_{2} \mathrm{O}_{3}: \mathrm{C}$ InLight tratados opticamente durante $30 \mathrm{~min}$ em função do tempo de iluminação UV (26.000 lux).

FIGURA 4.25 - Resposta PTOSL dos detectores $\mathrm{Al}_{2} \mathrm{O}_{3}: \mathrm{C}$ InLight tratados opticamente durante $60 \mathrm{~min}$ em função do tempo de iluminação UV (26.000 lux).

FIGURA 4.26 - Resposta PTOSL dos detectores $\mathrm{Al}_{2} \mathrm{O}_{3}: \mathrm{C}$ InLight tratados opticamente durante $90 \mathrm{~min}$ em função do tempo de iluminação UV (26.000 lux). 
FIGURA 4.27 - Resposta PTOSL dos detectores $\mathrm{Al}_{2} \mathrm{O}_{3}: \mathrm{C}$ InLight tratados opticamente durante 120 min em função do tempo de iluminação UV (26.000 lux).

FIGURA 4.28 - Resposta PTOSL dos detectores $\mathrm{Al}_{2} \mathrm{O}_{3}: \mathrm{C}$ InLight em função do comprimento de onda da RUV. A incerteza máxima das medições foi de $5,2 \%$.

FIGURA 4.29 - Resposta PTOSL dos detectores $\mathrm{Al}_{2} \mathrm{O}_{3}: \mathrm{C}$ InLight em função do tempo de iluminação UV, para o comprimento de onda de $330 \mathrm{~nm}$.

FIGURA 4.30 - Resposta PTOSL dos detectores $\mathrm{Al}_{2} \mathrm{O}_{3}: \mathrm{C}$ InLight em função da irradiância da fonte do sistema de RUV.

FIGURA 4.31 - Curva de calibração dos detectores $\mathrm{Al}_{2} \mathrm{O}_{3}: \mathrm{C}$ InLight, précondicionados, para o comprimento de onda de $330 \mathrm{~nm}$ em função da exposição radiante. 88

FIGURA 4.32 - Curva de calibração dos detectores $\mathrm{Al}_{2} \mathrm{O}_{3}: \mathrm{C}$ InLight, précondicionados, para o comprimento de onda de $340 \mathrm{~nm}$ em função da exposição radiante.

FIGURA 4.33 - Resposta PTOSL dos detectores $\mathrm{Al}_{2} \mathrm{O}_{3}: \mathrm{C}$ InLight em função do ângulo de incidência do feixe de iluminação UV.

FIGURA 4.34 - Conjunto (cartão+lâmina+filtro) para uso nas aplicações práticas. 94

FIGURA 4.35 - Resposta OSL dos detectores $\mathrm{Al}_{2} \mathrm{O}_{3}: \mathrm{C}$ InLight sem précondicionamentos, com filtro HOYA U330, em função do tempo de exposição à RUV solar. 95

FIGURA 4.36 - Posição do conjunto (cartão+lâmina+filtro) na máscara de proteção do soldador durante 2 min de soldagem elétrica. 98

FIGURA 4.37 - Posição dos conjuntos (cartão+lâmina+filtro), nos tripés, expostos à RUV durante 2 min de soldagem elétrica. 
FIGURA 4.38 - Resposta OSL dos detectores $\mathrm{Al}_{2} \mathrm{O}_{3}: \mathrm{C}$ InLight, sem précondicionamentos, após exposição à RUV, durante 2 min de soldagem elétrica.

FIGURA 4.39 - Posição dos conjuntos (cartão+lâmina+filtro), nos tripés, expostos à RUV durante 5 min de soldagem TIG.

FIGURA 4.40 - Resposta OSL dos detectores $\mathrm{Al}_{2} \mathrm{O}_{3}: \mathrm{C}$ InLight, sem précondicionamentos, após exposição direta à RUV durante 5 min de soldagem TIG.

FIGURA 4.41 - Resposta OSL dos detectores $\mathrm{Al}_{2} \mathrm{O}_{3}: \mathrm{C}$ InLight, précondicionados, com filtro HOYA U 330, em função do tempo de exposição à RUV solar.

FIGURA 4.42 - Posição do conjunto (cartão + lâmina + filtro) no protetor facial do soldador, durante 2 min de soldagem elétrica.

FIGURA 4.43 - Posição dos conjuntos (cartão + lâmina + filtro) nos tripés, durante 2 min de soldagem elétrica.

FIGURA 4.44 - Resposta OSL dos detectores $\mathrm{Al}_{2} \mathrm{O}_{3}: \mathrm{C}$ InLight após o tratamento óptico e resposta PTOSL após exposição à RUV durante 2 min de soldagem elétrica.

FIGURA 4.45 - Ganho percentual da resposta PTOSL dos detectores $\mathrm{Al}_{2} \mathrm{O}_{3}: \mathrm{C}$ InLight expostos à RUV da soldagem elétrica durante $2 \mathrm{~min}$.

FIGURA 4.46 - Posição do conjunto (cartão + lâmina + filtro) no protetor facial do soldador, durante 5 min de soldagem TIG.

FIGURA 4.47 - Posição dos conjuntos (cartão + lâmina + filtro) nos tripés, durante 5 min de soldagem TIG.

FIGURA 4.48 - Respostas OSL e PTOSL dos detectores $\mathrm{Al}_{2} \mathrm{O}_{3}: \mathrm{C}$ InLight após o tratamento óptico e exposição à RUV durante 5 min de soldagem TIG, respectivamente. 
FIGURA 4.49 - Ganho percentual da resposta PTOSL dos detectores $\mathrm{Al}_{2} \mathrm{O}_{3}: \mathrm{C}$ InLight expostos à RUV do processo de solda TIG durante $5 \mathrm{~min}$.

FIGURA 4.50 - Posição do conjunto (cartão + lâmina + filtro) no protetor facial durante o processo de solda TIG de $20 \mathrm{~min}$.

FIGURA 4.51 - Posição dos conjuntos (cartão + lâmina + filtro) nos tripés durante o processo de solda TIG de $20 \mathrm{~min}$.

FIGURA 4.52 - Resposta OSL dos detectores $\mathrm{Al}_{2} \mathrm{O}_{3}: \mathrm{C}$ InLight após o tratamento óptico e resposta PTOSL após exposição à RUV do processo de soldagem TIG realizado em $20 \mathrm{~min}$.

FIGURA 4.53 - Ganho percentual da resposta PTOSL dos detectores $\mathrm{Al}_{2} \mathrm{O}_{3}: \mathrm{C}$ InLight expostos à RUV do processo de solda TIG realizado em 20 min. 


\section{LISTA DE TABELAS}

TABELA 4.1 - Dependência energética dos detectores $\mathrm{Al}_{2} \mathrm{O}_{3}: \mathrm{C}$ InLight Dot, para radiação gama, irradiados com 0,3 mGy.

TABELA 4.2 - Resposta OSL e PTOSL dos detectores $\mathrm{Al}_{2} \mathrm{O}_{3}: \mathrm{C}$ InLight em função do tempo de tratamento óptico e do tempo de iluminação UV.

TABELA 4.3 Respostas PTOSL dos detectores $\mathrm{Al}_{2} \mathrm{O}_{3}: \mathrm{C}$ InLight imediatamente após a iluminação UV e após $720 \mathrm{~h}$.

TABELA 4.4 - Posição e distância dos conjuntos (cartão+lâmina+filtro) durante 2 min de soldagem elétrica.

TABELA 4.5 - Posição e distância dos conjuntos (cartão+lâmina+filtro) durante 5 min de soldagem TIG.

TABELA 4.6 - Respostas OSL dos detectores $\mathrm{Al}_{2} \mathrm{O}_{3}: \mathrm{C}$ InLight da Landauer com filtros HOYA U 330 após o tratamento térmico e após exposição ao sol.

TABELA 4.7 - Posição e distância dos conjuntos (cartão+lâmina+filtro) durante o processo de solda elétrica.

TABELA 4.8 - Resposta OSL e PTSOL dos detectores $\mathrm{Al}_{2} \mathrm{O}_{3}: \mathrm{C}$ InLight, précondicionados, após o tratamento óptico e exposição à RUV durante 2 min de soldagem elétrica.

TABELA 4.9 - Valores das exposições radiantes obtidas nas posições dos detectores \#18, \#19 e \# 20

TABELA 4.10 - Posição e distância dos conjuntos (cartão+lâmina+filtro) durante 5 min de soldagem TIG 
TABELA 4.11 - Resposta OSL e PTSOL dos detectores $\mathrm{Al}_{2} \mathrm{O}_{3}: \mathrm{C}$ InLight após o tratamento óptico e exposição à RUV proveniente da solda TIG realizada durante $5 \mathrm{~min}$.

TABELA 4.12 - Valores de exposições radiantes obtidas nas posições dos detectores \#22, \#23 e \#25

TABELA 4.13 - Posição e distância dos conjuntos (cartão + lâmina + filtro) durante o processo de soldagem TIG

TABELA 4.14 - Resposta OSL e PTOSL dos detectores $\mathrm{Al}_{2} \mathrm{O}_{3}: \mathrm{C}$ InLight, précondicionados, após o tratamento óptico e exposição à RUV proveniente do processo de solda TIG realizado em $20 \mathrm{~min}$

TABELA 4.15 - Valores de exposições radiantes obtidas nas posições dos detectores \#26, \#27 e \#28 e \#29. 


\section{LISTA DE ABREVIATURAS}

CIE International Commission Illumination

CNEN Comissão Nacional de Energia Nuclear

CTR Centro de Tecnologia das Radiações

GMR Gerência de Metrologia das Radiações

IARC International Agency for Research on Cancer

ICNIRP International Commission on Non-ionizing Radiation Protection

ICRP International Commission on Radiological Protection.

ICRU International Commission on Radiation Units and Measurements.

INCA Instituto Nacional do Câncer

IPEN Instituto de Pesquisas Energéticas e Nucleares

LCI Laboratório de Calibração de Instrumentos

NPL National Physical Laboratory

PTB Physikalisch-Technische Bundesanstalt

UPI Urals Polytechnical Institute

WHO World Health Organization 


\section{INTRODUÇÃO}

$\mathrm{Na}$ medicina, o uso da radiação ultravioleta (RUV) teve início no século XVIII com o médico dinamarquês $\mathrm{N}$. Finsen no tratamento da lupus vulgaris [OKUNO e VILELA, 2005]. A partir daí foram realizados vários estudos sobre os efeitos benéficos da radiação ultravioleta ao homem proveniente do sol e de fontes artificiais [WEELDEN e col., 1988; DIFFEY e HART, 1997; GORDON e col., 1998; MacKIE, 2000; HINCE e col., 2000].

Com o passar do tempo, algumas preocupações começaram a surgir quando foram observados prejuízos à saúde do ser humano após exposições prolongadas a este tipo de radiação. Na década de 1940, o médico fisiologista $\mathrm{H}$. Blum fez uma correlação entre exposição à radiação ultravioleta e o desenvolvimento de câncer [OKUNO e VILELA, 2005].

O maior risco à saúde está associado aos hábitos pessoais de exposição ao sol que é a maior fonte natural de emissão de radiação ultravioleta. A maioria dos estudos relativos à exposição à luz solar está centrada em ciências médicas, proteção do meio ambiente e geologia [CESARINI, 2001; CORREA e col., 2003; HU e col., 2004].

A RUV solar que alcança a terra compreende 95\% de UVA (315$400 \mathrm{~nm}), 5 \%$ de UVB ( $280-315 \mathrm{~nm})$; e a UVC (200 - $280 \mathrm{~nm})$ é completamente filtrada pela atmosfera terrestre. A estratosfera é composta por uma camada de ozônio que absorve parte do espectro da RUV. O ozônio é o maior absorvedor da radiação UVC, e em menores proporções da radiação UVA e UVB. No entanto, variações na camada de ozônio nas últimas décadas influenciaram o alcance das RUVs na superfície da terra, especialmente as de curto comprimento de onda [DRISCOLL, 1996; BAKIRTZIS e col., 2000; MENNO e col., 2002]. 
No início, os cientistas atribuíram as variações na camada de ozônio à emissão na atmosfera de produtos químicos voláteis, os clorofluorcarbonos (CFCs), usados em refrigeradores e aerossóis. Atualmente, considera-se que as mudanças climáticas provocadas principalmente pela queima de combustíveis fósseis causam o chamado "efeito estufa" (resfriamento da calota atmosférica) e contribuem drasticamente para a redução na camada de ozônio da atmosfera terrestre.

Os trabalhadores da agricultura, mineração a céu aberto, construção civil e pesca, dentre outras atividades, estão expostos, dependendo da estação do ano, latitude e altitude da região em que desenvolvem suas tarefas, a altos índices de RUV. Em regiões próximas à linha do Equador, latitude $0^{\circ}$, a RUV solar é mais intensa.

O Brasil, devido a sua posição geográfica, é essencialmente de clima tropical, o que agrava o problema da exposição à RUV solar. Ao norte, o país é cortado pela linha do Equador e 7\% de suas terras encontram-se no hemisfério norte, próximas a latitudes de $0^{\circ}$ norte. Ao sul, é cortado pelo Trópico de Capricórnio, apresentando $93 \%$ de suas terras, com latitudes entre $0^{\circ}$ norte e $33^{\circ}$ sul.

Além da RUV solar, existe um número grande de fontes artificiais que emitem um espectro contínuo de radiação, que podem ser encontradas nos ambientes de trabalho. Entre as principais fontes artificiais, pode-se citar lâmpadas incandescentes de tungstênio, lâmpadas de mercúrio (baixa, média e alta pressão), lâmpadas de mercúrio com halogenetos, lâmpadas de hidrogênio e deutério, solda a arco, solda a arco carbono, e lasers [WHO, 1994; MUNNOCH e col., 2000; SURAKKA e col., 2000; SWERDLOW, 2000; CHANG e col., 2006].

Doughty e Oblak [2005] relataram que a operação de solda a arco é a que tem maior potencial de emissão de RUV. Apesar dos trabalhadores usarem protetores faciais ou óculos de segurança contra a RUV, alguns removem esses equipamentos em ambientes escuros e confinados devido à falta de visão durante 
os processos de soldagem [DIXON e DIXON, 2004; KIM e col., 2007]. Além disso, os trabalhadores sem proteção adequada que desempenham atividades próximas à operação de soldagem estão sujeitos à RUV.

A exposição à RUV proveniente do sol e de fontes artificiais é considerada um risco para a saúde pública [NORVAL, 2002; CHANG e col., 2006].

Os efeitos potenciais da RUV no ser humano vêm sendo relatados pela comunidade científica internacional de maneira crescente e ampla, e as investigações epidemiológicas das doenças crônicas estão relacionadas principalmente aos olhos, à pele e ao sistema imunológico. A relação da RUV com o câncer está bem documentada e foi objeto de estudo da International Agency for Research on Cancer (IARC) e da World Health Organization (WHO) [IARC, 1992; WHO, 1995].

Estima-se que mais de 60.000 mortes por ano no mundo são devidas à exposição excessiva à RUV. Dentre este total, estima-se que 48.000 mortes são por melanomas e 12.000 por carcinomas de pele [WHO, 2006].

Em 2008, o Instituto Nacional do Câncer (INCA) publicou uma estimativa da incidência de câncer no Brasil. O número de casos novos de câncer de pele tipo não melanoma estimados para o ano de 2008 foi de 55.890 entre homens e 59.120 entre mulheres, correspondendo a um risco de 59 casos a cada 100 mil homens e 61 casos para cada 100 mil mulheres [INCA, 2008].

Segundo o INCA [2008], este tipo de câncer foi o mais incidente em homens na maioria das regiões do Brasil, com um risco estimado de 82/100.000 na região Sul, 68/100.000 na região Sudeste, 47/100.000 na região Nordeste e $27 / 100.000$ na região Norte, enquanto que na região Centro-Oeste $(45 / 100.000)$ foi o segundo mais frequente. Nas mulheres foi o mais frequente nas regiões Sul (82/100.000), Centro-Oeste (64/100.000), Nordeste (53/100.000) e Norte 
(28/100.000), enquanto que na região Sudeste $(64 / 100.000)$ foi o segundo mais frequente.

O melanoma possui letalidade elevada, porém sua incidência é baixa. Os dados de 2008 estimaram 2.950 casos novos em homens e 2.970 casos novos em mulheres, e as maiores taxas se encontraram na região Sul. Segundo o INCA, estes índices podem estar subestimados em função da retirada de muitas lesões suspeitas sem diagnósticos [INCA, 2008].

Os efeitos deletérios da RUV dependem da duração e da frequência da exposição, da intensidade da radiação solar em função da latitude, e da reação da pele segundo a constituição genética, como cor e fototipo.

Os efeitos podem ser: a) agudos, como queimadura solar e fototoxicidade induzida por medicamentos; b) a longo prazo, devido à exposição descontrolada e repetida que resulta no desenvolvimento de modificações actínicas ou dermatohelioses, como rugas, envelhecimento precoce, adelgaçamento irregular da epiderme e máculas hiperpigmentadas; c) lesões prémalignas como ceratoses solares; e d) malignas, como carcinomas basocelulares, carcinomas espinocelulares e melanomas. Há também a consequência do dano fotoquímico cumulativo aos olhos desprotegidos, resultando no escurecimento das lentes (envelhecimento) e formação de catarata. A alteração do sistema imunológico e da função de distribuição dos componentes do sistema imunológico causa uma incompetência imunológica seletiva [SHEEHAN e YOUNG, 2000; NORVAL, 2002; OKUNO e VILELA, 2005; KHAZOVA e col., 2006; CHANG e col., 2006; SGARBI e col., 2007].

Existem poucas publicações que relatam os efeitos da RUV em locais de trabalho [OKUNO, 1987; DIXON e DIXON, 2004; YEN e col., 2004].

A instrumentação necessária para monitoramento da exposição ocupacional à RUV constitui ainda um grande obstáculo, assim como a calibração e a intercomparação das medições desses instrumentos. Há muitas diferenças 
entre os tipos de equipamentos, fabricantes e modelos, não existindo uma padronização global dos detectores de radiação UV como um conjunto de equipamentos idênticos para a realização de medidas de intercomparação [WEBB, 2000; CHANG e col., 2006].

Webb, da Universidade de Manchester, encontrou problemas ao utilizar diferentes detectores nas medições de RUV solar, e constatou que a sua padronização é uma tarefa difícil, uma vez que não há um instrumento padrão com o qual possa ser realizada uma comparação. Além disso, segundo Webb, o nível de padronização de fontes para irradiância espectral usada para calibração de espectroradiômetros e os outros detectores é ainda um fator limitante [MARIUTTI, 2000; WEBB, 2000].

Os laboratórios de calibração, nos diferentes países, possuem técnicas individuais, o que dificulta a realização de intercomparação e a calibração absoluta dos instrumentos de monitoração de RUV. De acordo com R. Lambe, da National Physical Laboratory (NPL), existem grandes incertezas apresentadas pelos laboratórios de padronização secundária em função das diferenças nos padrões utilizados [MARIUTTI, 2000].

Schreder e col. [2004] realizaram um estudo de intercomparação de fontes monocromáticas para determinação da resposta relativa espectral de radiômetros com filtros na faixa eritemal, e verificaram que as diferenças estão relacionadas com as incertezas nas medições e com a resposta espectral dos equipamentos.

Segundo Los e Gröbner [2005], a falta de um padrão de procedimento de calibração para radiômetros introduz muitas incertezas nas medidas destes equipamentos.

Meinander e col. [2006] observaram discrepâncias inesperadas na intercomparação de espectroradiômetros de alta qualidade. As razões espectrais das irradiâncias mostraram variações de 2 a 9 \%. 
Hülsen e Gröbner [2007] realizaram a calibração de alguns radiômetros por meio de uma comparação com um espectroradiômetro de referência com a finalidade de caracterizar a resposta espectral e angular destes equipamentos. A maioria deles teve uma incerteza de aproximadamente $7 \%$ na resposta espectral e $0,9 \%$ a $7,2 \%$ de incerteza na resposta angular.

Com a falta de uma padronização dos equipamentos de medição de radiação ultravioleta e do alto custo na sua aquisição [WEATHERHEAD e WEBB, 1997; LOS e GRÖBNER, 2005; MEINANDER e col., 2006], o uso de material luminescente tornou-se uma opção viável para medição da RUV, por possuir características apropriadas para a dosimetria dessas radiações e com baixo custo de investimento [CALDAS, 1973; LAS, 1975; POTIENS e CAMPOS, 1996; COLYOTT e col., 1997; COLYOTT e col., 1999; McKEEVER, 2001; GROSSI e CAMPOS, 2002; McKEEVER e MOSCOVITCH, 2003; BØTTER-JENSEN e col., 2003; WEST e col., 2006; PAGONIS e col., 2008].

O material luminescente mais estudado como detector de RUV é o óxido de alumínio dopado com carbono $\left(\mathrm{Al}_{2} \mathrm{O}_{3}: \mathrm{C}\right)$ [COLYOTT e col., 1999; SONO e McKEEVER, 2002; BØTTER-JENSEN, e col., 2003; WEST e col., 2006].

A dosimetria RUV, assim como os efeitos da iluminação UV no material luminescente $\mathrm{Al}_{2} \mathrm{O}_{3}: \mathrm{C}$, vêm sendo relatadas há muito tempo por pesquisadores que realizam seus estudos por meio das técnicas de termoluminescência (TL), termoluminescência fototransferida (PTTL), luminescência opticamente estimulada (OSL) e luminescência opticamente estimulada fototransferida (PTOSL).

Oster e col. [1994] estudaram os efeitos da RUV solar em cristais de $\mathrm{Al}_{2} \mathrm{O}_{3}: \mathrm{C}$ utilizando o método PTTL. Notaram que este material tem uma alta sensibilidade à dose extremamente baixa de RUV, o que o torna um material muito interessante para dosimetria UV. 
O fenômeno PTTL em $\mathrm{Al}_{2} \mathrm{O}_{3}$ : $\mathrm{C}$ utilizando uma fonte de RUV com vários comprimentos de onda foi observado por Colyott e col. [1996]. Verificaram que o sinal PTTL é linearmente proporcional ao tempo de iluminação e proporcional à dose aplicada no intervalo de 6 mGy a 40 Gy.

De acordo com McKeveer e col. [1996], o detector $\alpha-\mathrm{Al}_{2} \mathrm{O}_{3}$ : C é um material de alta sensibilidade para a dosimetria termoluminescente, mas quando exposto à luz sofre um desvanecimento forte. Em função disso, eles pesquisaram e concluíram que o uso da POSL em $\mathrm{Al}_{2} \mathrm{O}_{3}: \mathrm{C}$ é uma ferramenta dosimétrica viável, pois foram observadas tanto uma alta sensibilidade como facilidade na medição de doses baixas para dosimetria individual.

Para Pradhan e col. [1996], o $\mathrm{Al}_{2} \mathrm{O}_{3}: \mathrm{C}$ exibe resposta termoluminescente alta à RUV. Além disso, a curva de emissão TL tem comportamento similar à resposta à radiação ionizante deste detector, o que o torna um material interessante para compreensão do processo TL. Em função da alta sensibilidade TL à RUV, não foi observada PTTL nos detectores $\mathrm{Al}_{2} \mathrm{O}_{3}: \mathrm{C}$ pré-irradiados para doses acima de $60 \mathrm{mGy}$ de radiação beta e dose de 0,27 Gy de partículas alfa. Além disso, não observaram redução no sinal TL destes detectores pré- irradiados após exposição à RUV.

Colyott e col. [1997] desenvolveram um dosímetro para RUV integrado com resposta centrada em $307 \mathrm{~nm}$, utilizando PTTL em detectores de $\alpha-\mathrm{Al}_{2} \mathrm{O}_{3}: \mathrm{C}$. $\mathrm{O}$ dosímetro apresentou resposta linear em função da dose e baixa dependência à temperatura na região de 273 a $323 \mathrm{~K}$, e pode ser utilizado no ar e na água.

Colyott e col. [1999] observaram que a avaliação do dosímetro UVB desenvolvido por Colyott e col. [1997] pode ser feita pelas técnicas TL e OSL. Observaram que o método OSL de detecção leva vantagem nas propriedades de fototransferência do $\mathrm{Al}_{2} \mathrm{O}_{3}$ : C na região UVB $(280-320 \mathrm{~nm})$. O dosímetro apresentou resposta linear de várias ordens de magnitude, nenhuma dependência com a temperatura e excelente resposta angular. 
Cordoba e col. [1999] realizaram testes com o detector $\mathrm{Al}_{2} \mathrm{O}_{3}: \mathrm{C}$, sem pré-tratamento térmico e sem pré-irradiação, expondo-o à UVB solar e utilizando a técnica TL. Concluíram que este detector pode ser usado como dosímetro para UVB solar com sensibilidade para a faixa entre 285 e $295 \mathrm{~nm}$.

Noh e col. [2001] investigaram a resposta TL dos detectores de $\mathrm{CaF}_{2}:$ Dy (TLD-200); $\mathrm{CaF}_{2}: \mathrm{Mn}$ (TLD- 400); $\mathrm{Al}_{2} \mathrm{O}_{3}$ (TLD- 500); $\mathrm{CaSO}_{4}: \mathrm{Dy}$ (TLD-900), e o LiF: Mg, Cu, P (TLD-100H e TLD-700H) em relação à radiação ultravioleta utilizando uma lâmpada de deutério. Observaram alta e baixa sensibilidades dos detectores TLD -500 e TLD-400, respectivamente. Os detectores de TLD - 900 e TLD-200 mostraram menos sensibilidade da resposta TL do que no caso de TLD 500, mas apresentaram resposta linear à RUV, indicando-os para o uso em RUV solar.

Sono e McKeever [2002] relataram um estudo realizado com diferentes materiais $\mathrm{TL}\left(\mathrm{Al}_{2} \mathrm{O}_{3}: \mathrm{C}, \mathrm{CaF}_{2}: \mathrm{Cu}, \mathrm{MgO}\right.$ e $\left.\mathrm{MgO}: \mathrm{Cu}\right)$ utilizando o método PTTL. $\mathrm{A}$ combinação de todos os resultados, como alta sensibilidade, reprodutibilidade, curva de dose-resposta à RUV e curva de resposta em função do comprimento de onda, indicou que os materiais $\mathrm{Al}_{2} \mathrm{O}_{3}: \mathrm{C}$ e $\mathrm{CaF}_{2}: \mathrm{Cu}$ são os mais atrativos para a dosimetria UV.

Yukihara e col. [2003] descreveram detalhadamente as mudanças na sensibilidade e no pico principal $\mathrm{TL}$ do $\mathrm{Al}_{2} \mathrm{O}_{3}: \mathrm{C}$ com a dose, o tipo de radiação e tratamentos térmicos. Verificaram que este material dosimétrico quando iluminado com UV cria preferencialmente elétrons livres sensibilizando a amostra.

A resposta $\mathrm{OSL}$ do $\mathrm{Al}_{2} \mathrm{O}_{3}: \mathrm{C}$ em função das doses altas foi verificada por Yukihara e col. [2004]. Notaram que o decaimento do sinal OSL é muito mais rápido quando a dose aumenta.

West e col. [2006] estudaram a resposta OSL do detector $\alpha-\mathrm{Al}_{2} \mathrm{O}_{3}: \mathrm{C}$ (comercialmente disponível) à luz solar. Observaram o desvanecimento do sinal OSL em um curto período de tempo de exposição direta à luz solar. 
Um modelo cinético quantitativo aplicável para o material dosimétrico $\mathrm{Al}_{2} \mathrm{O}_{3}: \mathrm{C}$ foi relatado por Pagonis e col. [2008], no qual descreveram a resposta termoluminescente deste material à iluminação UV para o comprimento de onda de $206 \mathrm{~nm}$.

A Luminescência Opticamente Estimulada (OSL - Optically Stimulated Luminescence), utilizada em datação geológica e arqueológica [WINTLE, 1997; TATUMI e col., 2006] e na dosimetria das radiações ionizantes, é uma técnica que está sendo objeto de estudo em conjunto com $\circ \quad \mathrm{Al}_{2} \mathrm{O}_{3}: \mathrm{C}$ na dosimetria da radiação ultravioleta [COLYOTT e col., 1999; WEST e col., 2006; SMETANA e col., 2008].

O objetivo principal deste trabalho é estabelecer um método dosimétrico para avaliação da exposição à RUV utilizando os detectores de $\mathrm{Al}_{2} \mathrm{O}_{3}: \mathrm{C}$ da Landauer e as técnicas de Luminescência Opticamente Estimulada (OSL) e Luminescência Opticamente Estimulada Fototransferida (PTOSL).

Os objetivos específicos deste trabalho são:

- Caracterizar os detectores $\mathrm{Al}_{2} \mathrm{O}_{3}: \mathrm{C}$ InLight Dot em relação à reprodutibilidade, à curva de dose-resposta, à dependência energética e ao limite mínimo de detecção, utilizando fonte de radiação gama e a técnica OSL;

- Caracterizar os detectores $\mathrm{Al}_{2} \mathrm{O}_{3}: \mathrm{C}$ InLight Dot em relação ao decaimento do sinal OSL, utilizando fonte de radiação beta e a técnica OSL;

- Caracterizar os detectores $\mathrm{Al}_{2} \mathrm{O}_{3}: \mathrm{C}$ InLight, sem pré-condicionamento, em relação ao comprimento de onda, ao tempo de iluminação UV, à irradiância, à exposição radiante e ao decaimento do sinal OSL, utilizando fontes de RUV solar e artificial e a técnica OSL;

- Caracterizar os detectores $\mathrm{Al}_{2} \mathrm{O}_{3}: \mathrm{C}$ InLight, pré-condicionados, em relação ao comprimento de onda, ao tempo de iluminação UV, à irradiância, à exposição radiante, à dependência angular, ao limite mínimo de detecção e ao decaimento do sinal PTOSL, utilizando fonte de radiação gama, fontes de RUV solar e artificial, e a técnica PTOSL; 
- Realizar aplicações práticas dos detectores $\mathrm{Al}_{2} \mathrm{O}_{3}: \mathrm{C}$ InLight, sem précondicionamento e pré-condicionados, em locais de exposição à RUV solar e RUV artificial provenientes de processos de soldagens elétrica e TIG (Tungsten Inert Gas), para avaliar a possibilidade da utilização destes detectores em dosimetria da exposição à RUV.

- Elaborar os procedimentos para utilização do leitor OSL microStar System e software da Landauer e dos detectores $\mathrm{Al}_{2} \mathrm{O}_{3}: \mathrm{C}$ InLight Dot e InLight 


\section{FUNDAMENTOS TEÓRICOS}

\subsection{Luminescência Opticamente Estimulada (OSL)}

A luminescência opticamente estimulada (OSL) é um dos fenômenos de estimulação de matéria condensada pela radiação ionizante bastante conhecido e tornou-se uma excelente ferramenta prática na dosimetria das radiações [AKSELROD e col., 2007] Durante muitos anos a termoluminescência (TL) era a técnica dosimétrica mais popular usando detectores passivos de baixo custo como LiF:Mg,Ti; CaF:Mn; CaSO $: \mathrm{Dy} ; \mathrm{Li}_{2} \mathrm{~B}_{4} \mathrm{O}_{7}$; dentre outros [McKEEVER e col.1995].

A técnica OSL despertou interesse e importância para aplicações dosimétricas devido a vários fatores [McKEEVER e col., 1996; BØTTER-JENSEN e col., 2003]:

a) o desenvolvimento e a introdução do primeiro sistema de monitoramento pessoal comercial baseado na OSL do óxido de alumínio dopado com carbono;

b) a intensa atividade de pesquisa em OSL aplicada à datação por luminescência e dosimetria retrospectiva;

c) a disponibilidade de diodos de alta intensidade de luz emitida e laser de estado sólido, de baixo custo, para serem utilizados como fontes de estimulação óptica, levando à pesquisa em novas aplicações de OSL.

A principal diferença entre a OSL e a termoluminescência (TL) é que a estimulação óptica é utilizada no lugar da estimulação térmica para liberar as cargas armadilhadas, mas os princípios físicos da OSL são parecidos com os da TL. 
As principais vantagens da OSL quando comparadas com a TL são [BØTTER-JENSEN, 2000; McKEEVER, 2001; BØTTER-JENSEN e col., 2003]:

- a OSL é normalmente medida próximo da temperatura ambiente, sendo um método menos destrutivo e potencialmente mais sensível do que a TL;

- o sinal OSL pode ser medido muitas vezes em uma mesma amostra. Uma medida TL envolve perda total do sinal;

- um sinal TL geralmente pode ser medido depois das medidas OSL da mesma amostra;

- a OSL mede elétrons armadilhados que são mais sensíveis à luz, o que é particularmente importante para datação geológica de amostras de sedimentos.

Outra vantagem a se ressaltar é o fato de que, em muitos materiais TL, a eficiência da luminescência diminui quando a temperatura da amostra aumenta. A OSL é normalmente medida à temperatura ambiente, ou próxima, evitando este tipo de problema, o que intrinsecamente torna maior a sensibilidade da OSL em relação à $T L$.

Por conveniência experimental, a OSL emitida durante a recombinação das cargas desarmadilhadas é geralmente medida em uma região espectral diferente daquela de excitação dos fótons. Enquanto que o sinal TL (durante 0 aquecimento) aparece como uma curva (curva de emissão) com vários picos de temperatura representando diferentes níveis de armadilhas, o sinal OSL (durante a exposição à luz de estimulação) decresce à medida que as cargas armadilhadas vão sendo esvaziadas (curva de decaimento) [BØTTERJENSEN, 2000].

A OSL foi sugerida, primeiramente, como uma ferramenta dosimétrica nas décadas de 1950 e 1960 por Antonov-Romanovskii e col. [1956]; Bräunlich e col., [1967]; Sanborn e Beard [1967]. Esta técnica é muito utilizada em datação geológica e arqueológica como um método de determinação da dose equivalente em materiais naturais [WINTLE, 1997; TATUMI e col., 2003; TATUMI e 
col., 2006]. Na área de dosimetria das radiações, este método foi introduzido por Huntley e col. [1985].

A OSL é a luminescência emitida por um semicondutor ou isolante irradiado durante a exposição à luz [BØTTER-JENSEN e col., 2003; McKEEVER e MOSCOVITCH, 2003].

Quando um material semicondutor ou isolante absorve energia de uma fonte de radiação ionizante, ocorre a excitação dos elétrons livres e dos buracos vazios, e subsequente armadilhamento destas espécies eletrônicas nos defeitos (estados armadilhados) dentro do material. Após a excitação, a amostra pode ser estimulada, de maneira que a energia absorvida induza a liberação de cargas carregadas de mesmo sinal, que são capazes de se recombinar com cargas carregadas de sinal oposto. A absorção da radiação e a excitação da carga conduzem a uma perturbação do sistema de um estado de equilíbrio termodinâmico para um estado metaestável. A subsequente absorção da energia externa pela carga armadilhada metaestável resulta num relaxamento estimulado e o sistema retorna à condição de equilíbrio. Durante o processo de relaxamento, ocorre a recombinação de cargas eletrônicas, e então, a luminescência é emitida. Em OSL a fonte de energia de estimulação é luz (UV, visível e infravermelho). A intensidade do sinal OSL é proporcional à dose de radiação absorvida [McKEVEER, 2001; BØTTER-JENSEN e col., 2003; AKSELROD e col., 2007].

Para o caso específico da OSL, a intensidade da luminescência emitida está relacionada com a taxa na qual o sistema retorna para o equilíbrio. Esta taxa é uma função da concentração de cargas armadilhadas (metaestáveis) e no caso mais simples a taxa é linearmente proporcional à concentração de cargas armadilhadas. Normalmente, monitora-se a intensidade da luminescência em função do tempo, resultando numa curva característica de luminescência versus tempo (FIG. 2.1). A integral da curva de luminescência versus tempo está relacionada com a concentração de cargas armadilhadas, que é proporcional à dose inicial da radiação absorvida [McKEEVER e col., 1996; BØTTER-JENSEN e col., 2003]. 
Os principais modos de estimulação óptica são a OSL contínua (CW OSL), a OSL de modulação linear (LM - OSL) e a OSL pulsada (POSL) (FIG. 2.2) [BØTTER-JENSEN e col., 2003; AKSELROD e col., 2007].

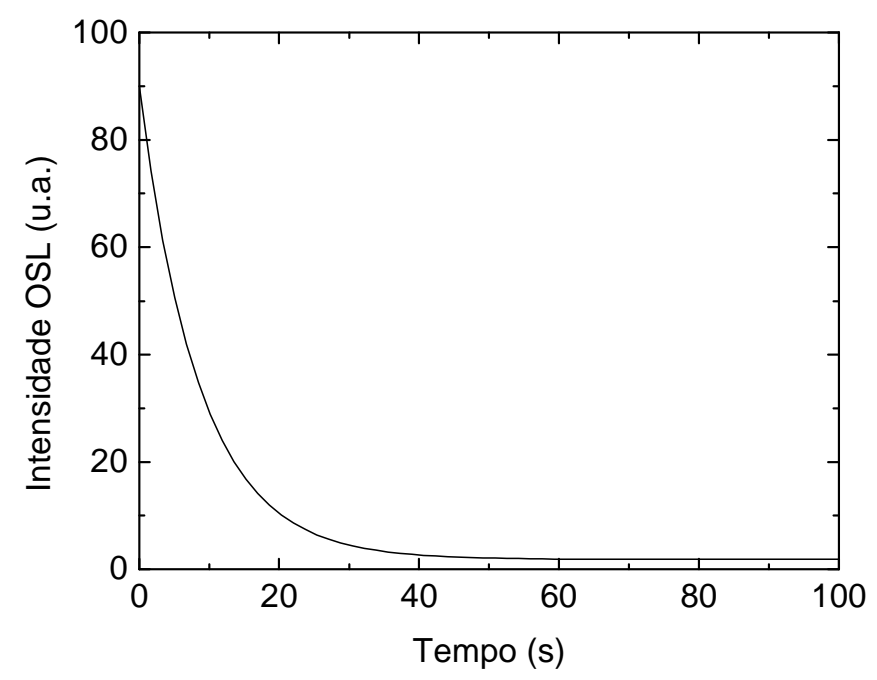

FIGURA 2.1 - Curva de decaimento OSL do $\mathrm{Al}_{2} \mathrm{O}_{3}: \mathrm{C}$ com comprimento de onda na faixa de 420 e $550 \mathrm{~nm}\left(16 \mathrm{~mW} . \mathrm{cm}^{-2}\right)$ após irradiação com $60 \mathrm{mGy}\left({ }^{90} \mathrm{Sr}+{ }^{90} \mathrm{Y}\right)$ [BØTTER-JENSEN e col., 2003].

Nas medições de CW - OSL, a luminescência é continuamente monitorada durante a estimulação óptica até todas as armadilhas carregadas terem sido esvaziadas. Neste caso, a luz de estimulação é separada da luz emitida por filtros, que são usados para discriminar entre a luz de estímulo e a luz emitida. Na LM - OSL a intensidade da estimulação óptica aumenta linearmente em função do tempo enquanto a OSL é medida para um determinado comprimento de onda fixo. $\mathrm{Na}$ POSL, as medidas da luminescência são detectadas somente após o fim da ação de estimulação [McKEEVER, 2001; BØTTER-JENSEN e col., 2003; McKEEVER e col., 2004; AKSELROD e col., 2007]. Este método usa menos filtração do que a CW-OSL, expõe o material irradiado a uma fonte de luz pulsada e detecta simultaneamente a luminescência emitida entre pulsos [McKEEVER e col., 2004]. 


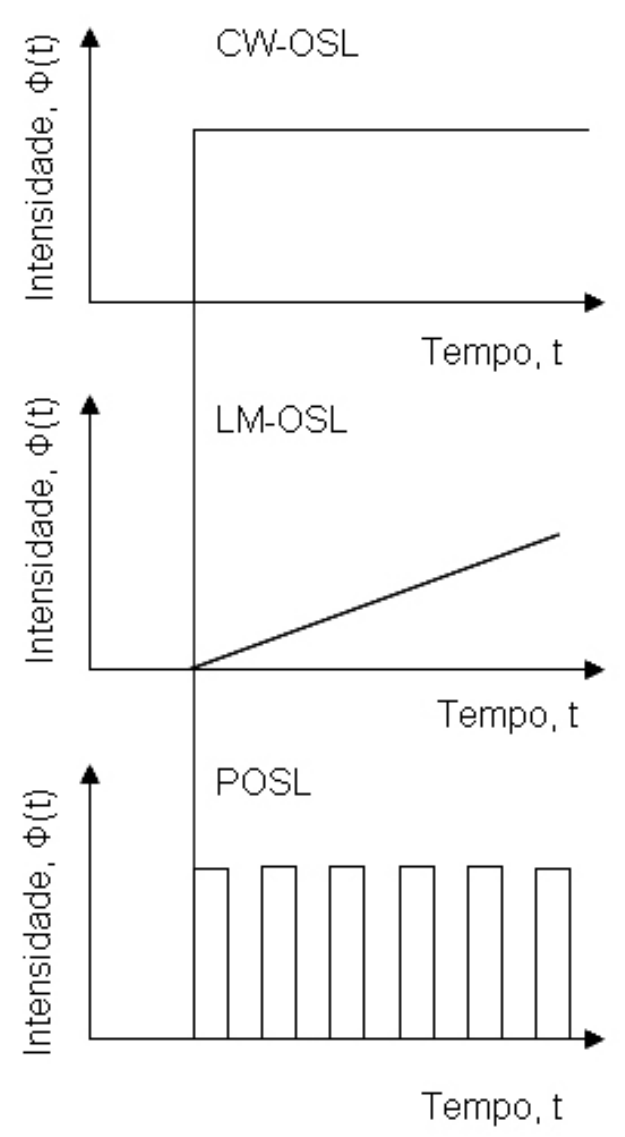

FIGURA 2.2 - Representação gráfica dos principais modos de estimulação OSL [BØTTER-JENSEN e col., 2003; AKSELROD e col. 2007].

\subsection{1 Óxido de alumínio dopado com carbono $\left(\mathrm{Al}_{2} \mathrm{O}_{3}: \mathrm{C}\right)$}

As principais características dosimétricas necessárias para que um material tenha uma boa resposta de OSL são (BØTTER-JENSEN e col., 2003; AKSELROD e col., 2007):

- alta sensibilidade à radiação;

- alta eficiência de estimulação óptica;

- baixo número atômico;

- baixo decaimento do sinal (sinal de luminescência estável à temperatura ambiente). 
A introdução do $\mathrm{Al}_{2} \mathrm{O}_{3}: \mathrm{C}$ como material para dosimetria termoluminescente foi feita por Akselrod e col. [1990], que possibilitou a realização de medições de alta sensibilidade, particularmente para exposições de tempo curto em dosimetria ambiental [BØTTER-JENSEN e col., 2003].

$\mathrm{O}$ uso do material luminescente $\mathrm{Al}_{2} \mathrm{O}_{3}: \mathrm{C}$ na dosimetria OSL provou ser mais vantajoso do que na dosimetria TL. Com a técnica OSL e a sua alta sensibilidade óptica pode-se obter respostas rápidas e medições totalmente ópticas das doses absorvidas [McKEEVER e col., 1996].

$\mathrm{O} \mathrm{Al}_{2} \mathrm{O}_{3}: \mathrm{C}$ tem uma sensibilidade de 40 a 60 vezes maior do que o LiF (TLD-100), tornando-o um forte candidato para detectar doses baixas e para aplicações em exposições curtas [McKEEVER e col., 1995]. Em função da alta sensibilidade, $\circ \quad \mathrm{Al}_{2} \mathrm{O}_{3}: \mathrm{C}$ passou a ser um material potencial para dosimetria, utilizando-se a técnica da luminescência opticamente estimulada.

$\mathrm{O} \alpha-\mathrm{Al}_{2} \mathrm{O}_{3}: \mathrm{C}$ foi primeiramente desenvolvido e produzido pela Urals Polytechnical Institute (UPI) na forma de um cristal simples [AKSELROD e col., 1993]. Atualmente, dosímetros comerciais de cristais crescidos de $\mathrm{Al}_{2} \mathrm{O}_{3}: \mathrm{C}$ são produzidos pela Landauer Stillwater Crystal Growth Division [YUKIHARA e McKEEVER, 2008].

O óxido de alumínio é um composto químico formado por átomos de alumínio e oxigênio e sua fórmula química é $\mathrm{Al}_{2} \mathrm{O}_{3}$. $\mathrm{O}$ cristal de óxido de alumínio possui uma estrutura hexagonal fechada, levemente distorcida, composta por íons de $\mathrm{O}^{2-}$ e $\mathrm{Al}^{3+}$. Cada íon de $\mathrm{Al}^{3+}$ está ligado a 6 íons de $\mathrm{O}^{2-}$, conforme mostra a FIG. 2.3 [AKSELROD e col., 2007].

O óxido de alumínio crescido sob baixa pressão atmosférica de carbono é o material mais usado como dosímetro OSL. Na sua produção, os átomos de alumínio são substituídos por átomos de carbono e os átomos de oxigênio são retirados da estrutura criando defeitos pontuais, conhecidos como centros $\mathrm{F}$ e $\mathrm{F}^{+}$[AKSELROD e col., 2007]. Estes são os principais centros de 
luminescência do cristal $\mathrm{Al}_{2} \mathrm{O}_{3}: \mathrm{C}$ e são muito importantes para a dosimetria TL e OSL.

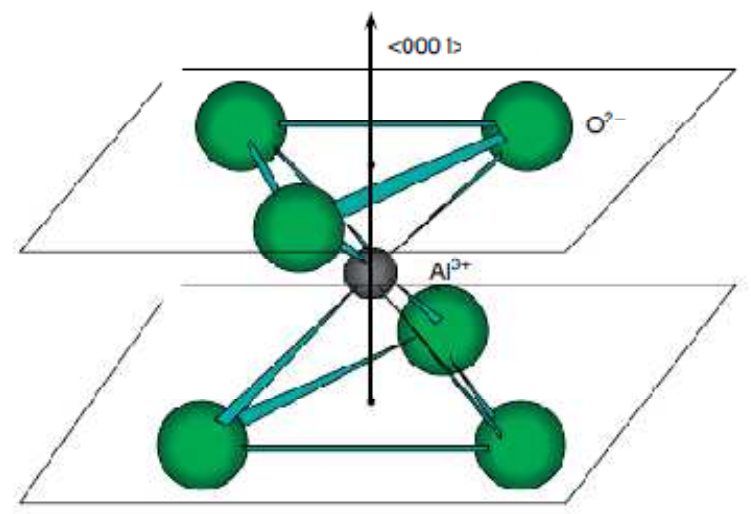

FIGURA 2.3 - Estrutura simplificada do cristal de $\mathrm{Al}_{2} \mathrm{O}_{3}$ [AKSELROD e col., 2007].

No cristal, o centro F é formado pela ocupação do buraco livre por dois elétrons livres devido à ausência do oxigênio, e o centro $\mathrm{F}^{+}$é formado pela ocupação do buraco livre por um elétron livre devido à ausência do oxigênio (FIG. 2.4) [AKSELROD e col., 2007].

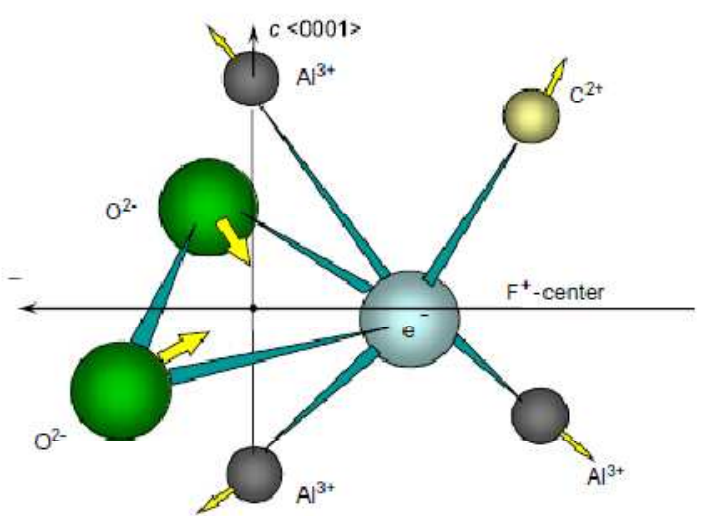

FIGURA 2.4 - Configuração de uma carga compensada de um centro $\mathrm{F}^{+}$por um íon de carbono bivalente [AKSELROD e col., 2007].

$O$ centro $F$ produz luminescência a $420 \mathrm{~nm}$ com meia vida de $35 \mathrm{~ms}$ e a emissão do centro $\mathrm{F}^{+}$está centrada em $330 \mathrm{~nm}$ com meia vida extremamente curta (menor que $7 \mathrm{~ns}$ ). Um aumento na concentração de $\mathrm{F}^{+}$causa um aumento 
significativo na sensibilidade OSL. Isto demonstra que a ausência de oxigênio na forma de centro $\mathrm{F}^{+}$é resultado da compensação de carga do íon do carbono bivalente que substitui o íon $\mathrm{Al}^{3+}$ [AKSELROD e col., 1990; AKSELROD e col., 2007].

\subsubsection{Diagrama de banda para OSL e o $\mathrm{Al}_{2} \mathrm{O}_{3}: \mathrm{C}$}

Um modelo geral de diagrama de banda (FIG. 2.5) [YUKIHARA e col., 2003] foi sugerido por Yukihara e McKeever [2006] para explicar o processo OSL nos detectores $\mathrm{Al}_{2} \mathrm{O}_{3}: \mathrm{C}$.

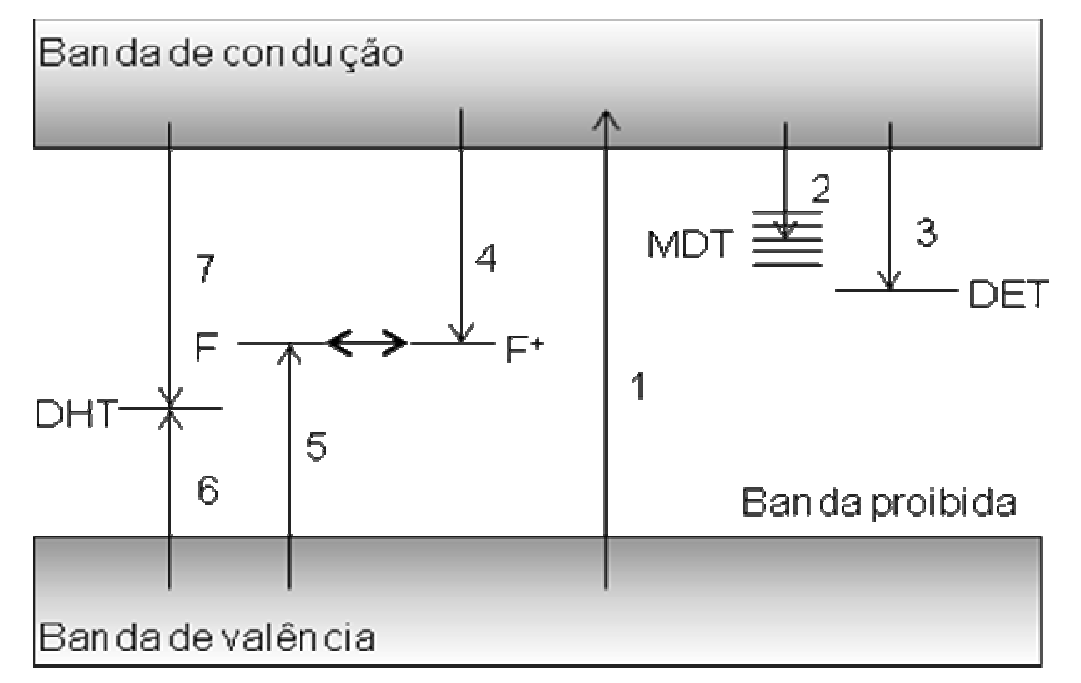

FIGURA 2.5 - Modelo de diagrama de bandas representando a armadilha dosimétrica principal (MDT), a armadilha profunda de elétron (DET), a armadilha profunda de buraco (DHT), e os centros $\mathrm{Fe} \mathrm{F}^{+}$. As transições do elétron principal e do buraco durante $\mathrm{o}$ estágio de irradiação com raios beta são retratados: (1) criação do par elétron-buraco, (2) captura do elétron pela MDT, (3) captura do elétron pela $\mathrm{DET}$, (4) recombinação do elétron e do buraco no centro $\mathrm{F}^{+}$, (5) captura do buraco pelo centro $F,(6)$ captura do buraco pela DHT, (7) recombinação do elétron e do buraco na DHT [YUKIHARA e col., 2003; YUKIHARA e McKEEVER, 2006]. 
A maior parte do comportamento básico da OSL pode ser explicada considerando somente os níveis associados com a armadilha dosimétrica principal (MDT) (pico TL a $450 \mathrm{~K}$ ) e os centros $\mathrm{F} \mathrm{e}^{+}$[YUKIHARA e col., 2003].

Durante a exposição à radiação ionizante dos detectores $\mathrm{Al}_{2} \mathrm{O}_{3}: \mathrm{C}$ são criados elétrons e buracos livres na banda de condução e valência, respectivamente (transição 1). Os elétrons são armadilhados na armadilha dosimétrica principal (MDT) (transição 2) ou recombinados com os centros $\mathrm{F}^{+}$(transição 4), criando um centro $\mathrm{F}$ em estado excitado $\left(\mathrm{F}^{+}+\mathrm{e}^{-} \rightarrow \mathrm{F}^{\star}\right)$, o qual produz luminescência no processo de relaxamento $\left(\mathrm{F}^{*} \rightarrow \mathrm{F}+\mathrm{hv} v_{420 \mathrm{~nm}}\right)$. Os buracos livres gerados durante as irradiações são capturados pelos centros $F$ (transição 5), aumentando a concentração dos centros $F^{+}\left(F+h^{+} \rightarrow F^{+}\right)$. Durante estimulação térmica ou óptica, elétrons são liberados da MDT e se recombinam com os centros $\mathrm{F}^{+}$criando um centro $\mathrm{F}$ excitado e resultando emissão de luz em $420 \mathrm{~nm}$ [YUKIHARA e col., 2003; YUKIHARA e McKEEVER, 2006].

As DETs vazias agem como competidores, capturando elétrons excitados para a banda de condução durante a irradiação ou iluminação, ou elétrons estimulados da MDT durante o estágio de recombinação. Como as DETs estão preenchidas, a competição torna-se menos importante e mais elétrons podem ser armadilhados na MDT durante a irradiação, resultando no aumento da sensibilidade [YUKIHARA e col., 2003].

Por outro lado, a DHT ocupada também age como competidor, concorrendo na captura de elétrons da banda de condução durante irradiação e aquecimento. As DHTs são preenchidas pelos buracos livres criados durante irradiação, as concentrações destes competidores aumentam e, além disso, para cada buraco capturado pela DHT, um centro $\mathrm{F}$ é convertido em centro $\mathrm{F}^{+}$, o que implica pouca disponibilidade de centros de recombinação. Portanto, com as DHTs preenchidas, o balanço oscila para a competição do processo de recombinação e a sensibilidade diminui [YUKIHARA e col., 2003]. 
As curvas de dose resposta e de sensibilidade são, portanto, os processos de recombinação. Para doses abaixo de 10 Gy e 20 Gy, elétrons são capturados pelos centros $\mathrm{F}^{+}$ou pelas MDTs e DETs, enquanto buracos são capturados pelos centros $F$ ou pelas DHTs, mas no geral as reações $F+h^{+} \rightarrow F^{+}$ e $\mathrm{F}^{+}+\mathrm{e}^{-} \rightarrow \mathrm{F}$ são balanceadas e a concentração dos centros $\mathrm{F}^{+}$não muda significativamente [YUKIHARA e col., 2003].

Quando as DETs são preenchidas, a diminuição na competição causa um pequeno aumento na sensibilidade. Para altas doses, as MDTs e as DETs começam a saturar, mas as DHTs ainda estão sendo preenchidas. Para doses acima de 10 a 20 Gy, somente a rota disponível para elétrons é para recombinar com os centros $\mathrm{F}^{+}\left(\mathrm{F}^{+}+\mathrm{e}^{-} \rightarrow \mathrm{F}\right)$, enquanto os buracos podem ainda ser armadilhados pelas DHTs. O resultado é uma diminuição na concentração dos centros $\mathrm{F}^{+}$e um aumento na concentração dos competidores (DHTs ocupadas), assim causando uma diminuição na sensibilidade [YUKIHARA e col., 2003].

\subsubsection{Luminescência opticamente estimulada fototransferida (PTOSL)}

O sinal da luminescência opticamente estimulada fototransferida (PTOSL) em amostras de $\mathrm{Al}_{2} \mathrm{O}_{3}: \mathrm{C}$ foi inicialmente sugerido por Colyott e col., [1999] para medir a dose de radiação ultravioleta na faixa UVB $(280 \mathrm{~nm}$ a $315 \mathrm{~nm})$.

A PTOSL envolve a produção de OSL pela fototransferência de cargas de armadilhas profundas para armadilhas rasas. Este fenômeno começa com o preenchimento das armadilhas profundas com uma pré-dose de radiação ionizante e um subsequente tratamento adequado (térmico ou óptico) das amostras esvazia as armadilhas rasas, permitindo o preenchimento destas armadilhas com a transferência de cargas provenientes das armadilhas profundas pela exposição à RUV [COLYOTT e col., 1999; SMETANA e col., 2008]. O sinal PTOSL é proporcional à exposição à luz, e à pré-dose de radiação inicial [BØTTER-JENSEN e col., 2003]. 


\subsubsection{Sistema leitor}

O leitor OSL constitui-se basicamente em um sistema de detecção da luz, uma fonte de estimulação óptica e um filtro de corte, conforme representação simplificada na FIG. 2.6 [BØTTER-JENSEN e col., 2003].

Neste sistema, a amostra é exposta em laboratório a uma fonte de luz fixa com comprimento de onda e intensidade apropriadas, e a luminescência estimulada do material durante o procedimento é monitorada em função do tempo de estimulação, usando um detector sensível (fotomultiplicadora). A integral da luminescência emitida durante o período de estimulação é uma medida que pode levar à determinação da dose absorvida [McKEEVER, 2001; BØTTER- JENSEN e col., 2003].

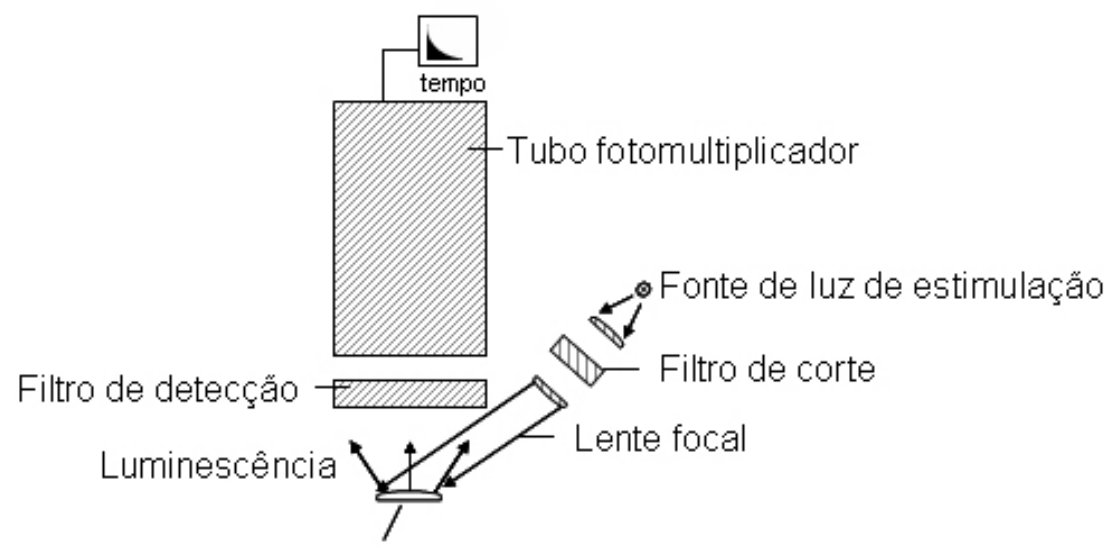

Amostra

FIGURA 2.6 - Esquema simplificado de um sistema OSL com fonte de estimulação óptica [BØTTER-JENSEN e col., 2003].

Dependendo do tipo do sistema detector, os seguintes modos de estimulação podem ser usados: CW-OSL, LM-OSL e POSL já descritos no item 2.1. Além disso, um sistema detector OSL pode usar as seguintes fontes de estimulação óptica:

- LED infravermelho

- Diodo de laser e infravermelho 
- LED verde

- LED azul

- Banda larga

O primeiro serviço comercial de dosimetria OSL baseado no $\mathrm{Al}_{2} \mathrm{O}_{3}: \mathrm{C}$ e na técnica OSL (Luxel ${ }^{\mathrm{TM}}$ ) foi introduzido pela Landauer Inc. em 1998 [YUKIHARA e MCKEEVER, 2008].

Recentemente, a Landauer introduziu o leitor portátil comercial OSL microStar $^{\mathrm{TM}}$ System projetado exclusivamente para uso com o sistema de dosímetros $\mathrm{Al}_{2} \mathrm{O}_{3}: \mathrm{C}$ InLight ${ }^{\mathrm{TM}}$ [YUKIHARA e McKEEVER, 2008]. Este leitor OSL possui 38 LEDs verdes com tempo de leitura OSL de 1s e opera no modo CW-OSL [PERKS e col., 2007].

No caso de doses baixas de radiação, este sistema leitor utiliza os 38 LEDs, resultando um sinal OSL mais alto devido à máxima estimulação; mas em contrapartida, apresenta uma depleção maior do sinal. Para doses altas de radiação, o sistema leitor utiliza somente 6 LEDs, resultando em um sinal OSL mais baixo e o grau de depleção do sinal é menor [JURSINIC, 2007].

A luminescência é detectada e medida pelo detector do tubo fotomultiplicador (PMT) com filtros HOYA B-370 [YUKIHARA e McKEEVER, 2008], utilizando-se um sistema de contagem de fótons de alta sensibilidade. Um algoritmo é aplicado à medição para determinação da dose. A luminescência emitida é proporcional à dose absorvida [LANDAUER, 2006].

\subsection{Radiação Ultravioleta}

A RUV é uma radiação não ionizante, que cobre uma pequena parte do espectro eletromagnético entre a luz visível e os raios $X$ (FIG. 2.7) [ICNIRP, 2007]. A radiação eletromagnética é geralmente caracterizada pelo comprimento de onda, pela frequência e pela energia do fóton. 


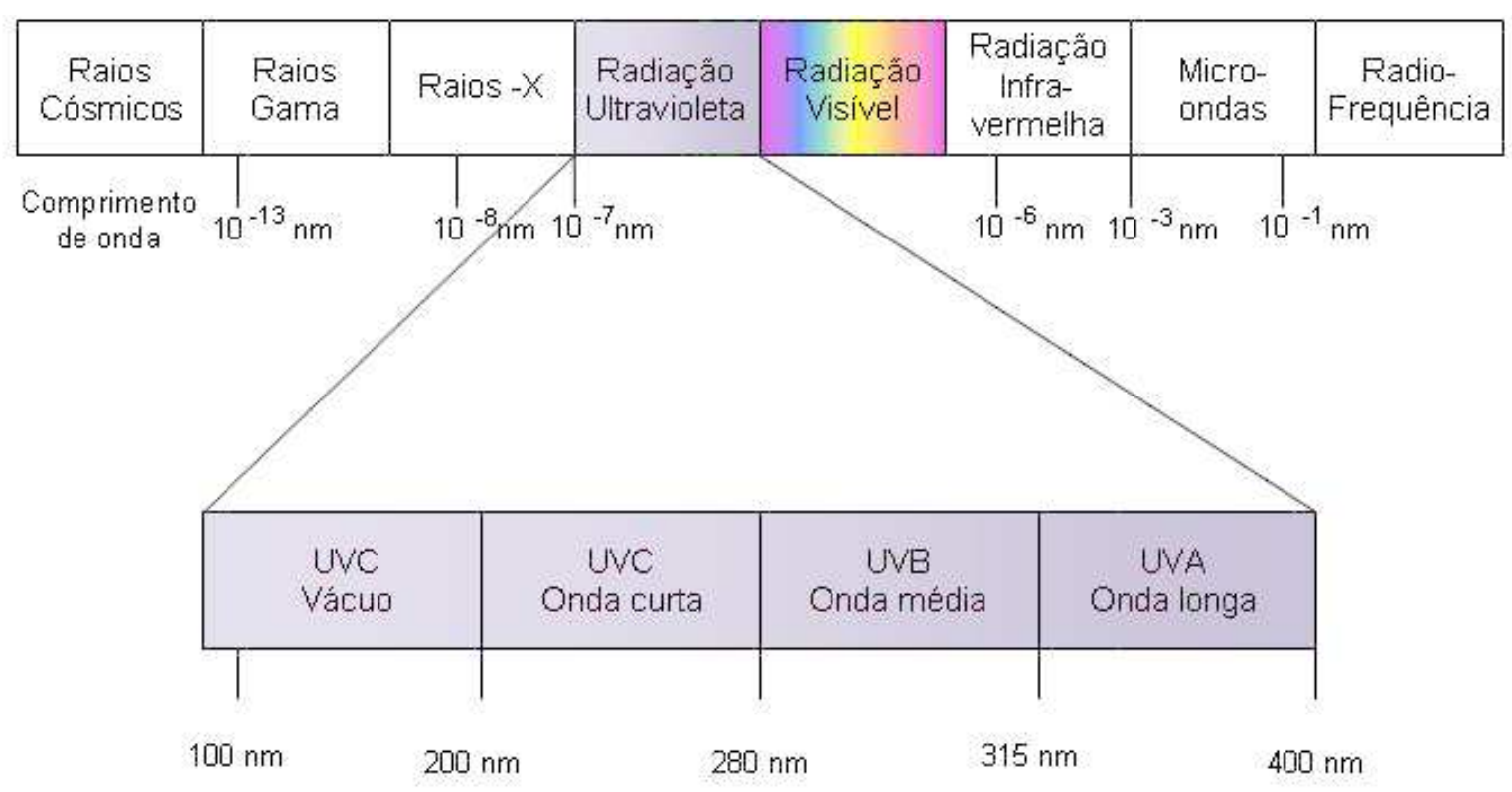

FIGURA 2.7 - Espectro eletromagnético da radiação [ICNIRP, 2007].

No espectro eletromagnético, a RUV compreende a faixa de comprimento de onda de 100 a $400 \mathrm{~nm}$. A classificação da RUV em UVA, UVB e UVC foi feita por dermatologistas e introduzida na década de 1930 pela International Commission on Illumination (CIE), sendo adotada formalmente a partir de 1970. A UVA compreende a faixa de comprimento de onda de $315 \mathrm{~nm}$ a $400 \mathrm{~nm}$, a UVB de $280 \mathrm{~nm}$ a $315 \mathrm{~nm}$, e a UVC de $200 \mathrm{~nm}$ a $280 \mathrm{~nm}$ [GRUIJL, 2000; OKUNO e VILELA, 2005].

O ANEXO I apresenta as grandezas e unidades dosimétricas e radiométricas. 


\section{MATERIAIS E MÉTODOS}

Nesta seção serão apresentados os equipamentos, o material OSL, os arranjos experimentais e os procedimentos utilizados para o estabelecimento de um método dosimétrico para avaliação da exposição à radiação ultravioleta.

\subsection{Sistemas de radiação ionizante}

As seguintes fontes de radiação ionizante do Laboratório de Calibração de Instrumentos (LCI) da Gerência de Metrologia das Radiações (GMR) foram utilizadas no desenvolvimento deste trabalho:

- Fonte de radiação gama, ${ }^{60} \mathrm{Co}$, em irradiador construído no IPEN, modelo CPIO - AO 0197/82, série IR-003, com uma taxa de exposição de $0,44 \mathrm{mC} \cdot \mathrm{kg}^{-1} \cdot \mathrm{h}^{-1}$ (abril/2009). As amostras foram posicionadas a uma distância de $125 \mathrm{~cm}$ da fonte, num campo de radiação com diâmetro de $14 \mathrm{~cm}$. Esta fonte foi utilizada nas irradiações das amostras com doses inferiores a $15 \mathrm{mGy}$.

- Fonte de teleterapia de ${ }^{60} \mathrm{Co}$, da Keleket Barnes Flexaray, EUA, modelo IS, com uma taxa de exposição de $8,46 \times 10^{-4} \mathrm{C} . \mathrm{kg}^{-1} \cdot \mathrm{h}^{-1}$ (abril/2009). As amostras foram posicionadas a uma distância de $100 \mathrm{~cm}$ da fonte, num campo de radiação de $10 \mathrm{~cm}$ de diâmetro. Esta fonte foi utilizada para irradiar as amostras com doses de 1 Gy para o estudo da PTOSL.

- Fonte de radioterapia de ${ }^{137} \mathrm{Cs}$, Gammatron/Siemens, Alemanha, com taxa de dose absorvida no ar de 11,10 Gy/h (abril/2009). As amostras foram posicionadas a uma distância de $125 \mathrm{~cm}$ da fonte. Esta fonte de radiação foi usada para o estudo da dependência energética das amostras. 
- Fonte de radiação beta de ${ }^{90} \mathrm{Sr}+{ }^{90} \mathrm{Y}$ do sistema padrão secundário da Buchler GmbH \& Co., Alemanha, com taxa de dose absorvida de 35,38 $\mu$ Gy.s ${ }^{-1}$ (abril/2009). Esta fonte possui certificado de calibração do Laboratório Padrão Primário Physikalisch - Technische Bundesanstalt (PTB), Alemanha. As amostras foram irradiadas a $30 \mathrm{~cm}$ de distância da fonte sobre um objeto simulador de Lucite com dimensões de $120 \mathrm{~mm} \times 120 \mathrm{~mm} \times 15 \mathrm{~mm}$. Esta fonte foi utilizada somente no desenvolvimento do estudo do decaimento do sinal OSL dos detectores $\mathrm{Al}_{2} \mathrm{O}_{3}: \mathrm{C}$.

A fonte de radiação do Centro de Tecnologia das Radiações (CTR), descrita a seguir, foi utilizada nas irradiações das amostras com doses superiores a 3 Gy:

- Irradiador de ${ }^{60} \mathrm{Co}$ do tipo Panorâmica, categoria II. A fonte é composta de apenas um lápis de ${ }^{60} \mathrm{Co} \mathrm{com} 20 \mathrm{~cm}$ de comprimento e $1 \mathrm{~cm}$ de diâmetro, com taxa de exposição de 50,72 C.kg-1.h ${ }^{-1}$ (abril/2009).

Todas as amostras expostas à radiação gama foram acondicionadas entre duas placas de polimetilmetacrilato (Lucite) de $3 \mathrm{~mm}$ de espessura para garantir as condições de equilíbrio eletrônico.

\subsection{Sistema leitor OSL}

O leitor OSL InLight microStar System e o software microStar de dosimetria da Landauer (FIG. 3.1) foram utilizados para as medidas OSL.

A avaliação OSL (leitura OSL) dos detectores processou-se pelo uso de diodos emissores de luz verde (LED) para estimular os detectores, e a luz emitida pelo material OSL foi detectada e medida por um tubo fotomultiplicador (PMT) usando um sistema de contagem de fótons de alta sensibilidade. As medidas OSL foram realizadas imediatamente após as irradiações, iluminações com RUV e radiação visível (ambiente e solar). 
Os resultados são os valores das médias e os desvios padrões de 10 leituras consecutivas para cada detector $\mathrm{Al}_{2} \mathrm{O}_{3}: \mathrm{C}$. A avaliação e a expressão das incertezas das medições foram feitas de acordo com as recomendações do Guia para a Expressão da Incerteza de Medição (ISO, 2003). As incertezas relacionadas nos resultados das medições são incertezas padrão, expressas como um desvio padrão $(1 \sigma, k=1)$.

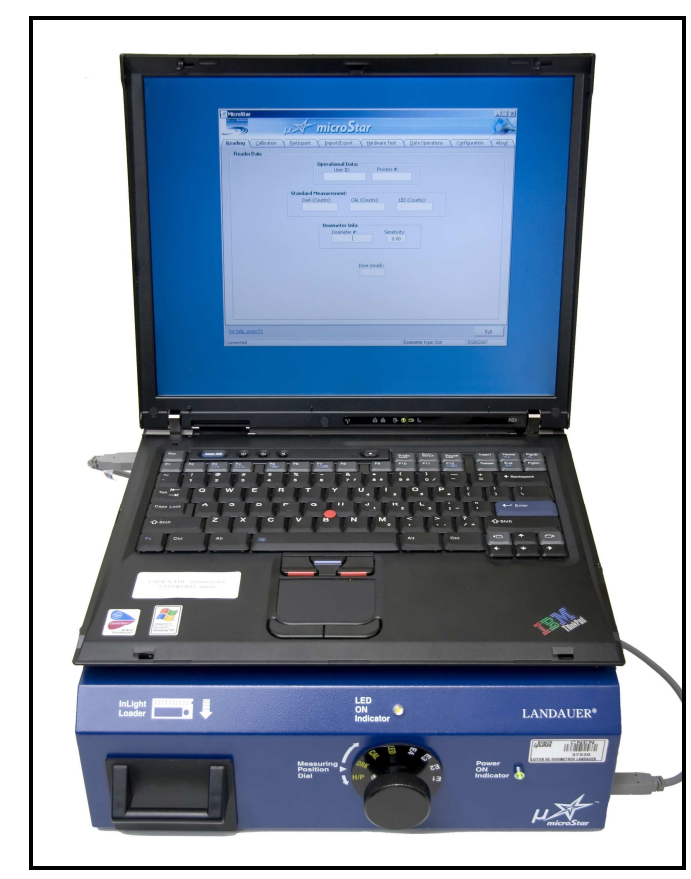

FIGURA 3.1 - Leitor OSL microStar System e software da Landauer

\subsection{Materiais utilizados}

Os materiais utilizados neste estudo foram os detectores $\mathrm{Al}_{2} \mathrm{O}_{3}: \mathrm{C}$ InLight e InLight Dot, da Landauer. O detector InLight é composto por uma lâmina (slide) com dimensões $46 \mathrm{~mm} \times 10 \mathrm{~mm} \times 1 \mathrm{~mm}$, contendo quatro pastilhas de $\mathrm{Al}_{2} \mathrm{O}_{3}: \mathrm{C}$ com diâmetros de $7 \mathrm{~mm}$, que se encaixa em um invólucro (case) de plástico preto com dimensões $48 \mathrm{~mm} \times 22 \mathrm{~mm} \times 5 \mathrm{~mm}$ (FIG. 3.2). Este invólucro contém uma janela aberta e filtros de alumínio, cobre e plástico. Somente a primeira pastilha de cada lâmina (quando dentro do invólucro fica posicionada onde está a janela aberta) foi usada para este estudo. 
$\mathrm{O}$ detector InLight Dot contém apenas uma pastilha de $\mathrm{Al}_{2} \mathrm{O}_{3}: \mathrm{C}$ com o mesmo diâmetro, acondicionada em plástico preto com dimensões $20 \mathrm{~mm} \times 10 \mathrm{~mm} \times 1 \mathrm{~mm}$. Um adaptador de plástico preto com as mesmas dimensões do invólucro do dosímetro InLight é usado para a leitura no microStar InLight System (FIG. 3.3 e FIG. 3.4). As pastilhas de $\mathrm{Al}_{2} \mathrm{O}_{3}: \mathrm{C}$ estão entre duas camadas de poliéster com espessura total de $0,3 \mathrm{~mm}$ nos dois tipos de detectores.

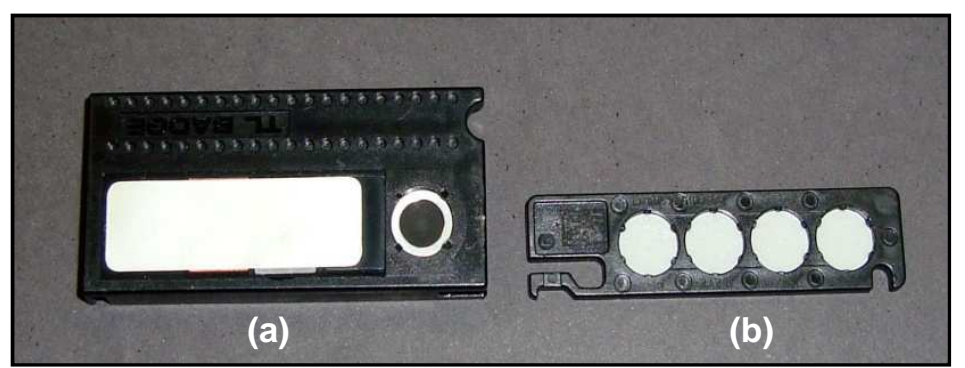

FIGURA 3.2 - Invólucro (a) e a lâmina (b) do detector $\mathrm{Al}_{2} \mathrm{O}_{3}: \mathrm{C}$ InLight

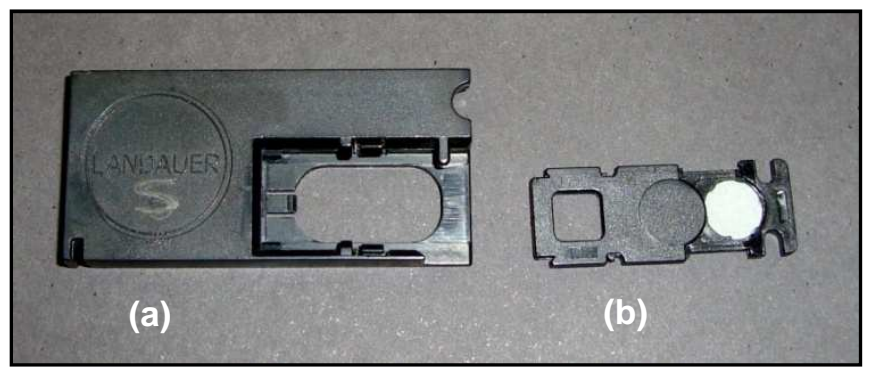

FIGURA 3.3 - Adaptador (a) e o detector $\mathrm{Al}_{2} \mathrm{O}_{3}: \mathrm{C}$ InLight Dot aberto (b)

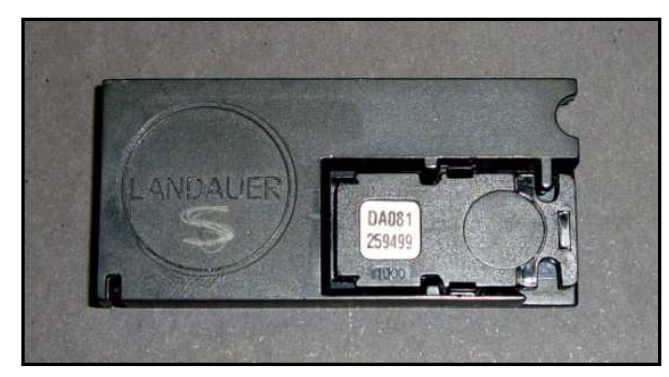

FIGURA 3.4 - Detector $\mathrm{Al}_{2} \mathrm{O}_{3}: \mathrm{C}$ InLight Dot fechado e encaixado no adaptador 
Os detectores InLight Dot foram utilizados no estudo inicial de sua caracterização em relação à fonte de radiação gama e no estudo do decaimento do sinal OSL, conforme descrição nos itens 4.3 e 4.4, respectivamente.

Como as pastilhas dos detectores InLight Dot e InLight possuem a mesma composição do material luminescente $\mathrm{Al}_{2} \mathrm{O}_{3}: \mathrm{C}$ e as mesmas dimensões, os detectores InLight passaram a ser utilizados como detectores InLight Dot, tendo em vista que somente a primeira pastilha deste detector foi usada. As leituras OSL destes detectores foram realizadas na planilha selecionada para detectores tipo Dot no software do leitor OSL microStar.

Os detectores InLight foram usados no estudo da caracterização dos detectores sem pré-condicionamento, no estudo da caracterização dos detectores pré-condicionados e nas aplicações práticas em locais de exposição à RUV solar e RUV artificial provenientes de processos de soldagens elétrica e TIG (Tungsten Inert Gas), conforme apresentados nos itens 4.5, 4.6 e 4.7, respectivamente.

\subsection{Sistema de iluminação ultravioleta (UV)}

O sistema de iluminação ultravioleta é composto por uma lâmpada de alta pressão de mercúrio (Hg), HBO $200 \mathrm{~W}$ da OSRAM (FIG. 3.5), acoplada ao Mercury Light Source SP-200, da Bausch \& Lomb, que está conectado ao monocromador de retículo, modelo GM 200, Bausch \& Lomb. A iluminação UV dos detectores $\mathrm{Al}_{2} \mathrm{O}_{3}: \mathrm{C}$ foi realizada dentro de um sistema fechado de madeira preta, para impedir a influência de luz externa, com dimensões $200 \mathrm{~cm} \times 80 \mathrm{~m} \times 65 \mathrm{~cm}$.

Para as irradiações das amostras neste sistema foi confeccionado em polimetilmetacrilato (Lucite) um conjunto contendo um trilho de $480 \mathrm{~mm}$ sobre o qual se encontra uma base deslizante de dimensões $90 \mathrm{~mm} \times 124 \mathrm{~mm} \times 50 \mathrm{~mm}$, onde se posiciona o suporte dos detectores $\mathrm{Al}_{2} \mathrm{O}_{3}: \mathrm{C}$ InLight Dot e InLight (FIG. 3.6 a e b) e os sensores UV (item c da FIG. 3.7). 


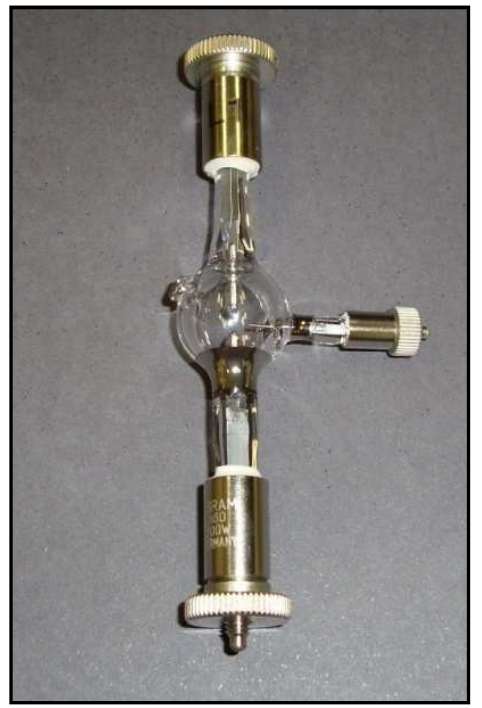

FIGURA 3.5 - Lâmpada de Hg, HBO 200 W da OSRAM acoplada ao Mercury Light Source SP-200, da Bausch \& Lomb, do sistema de iluminação UV.

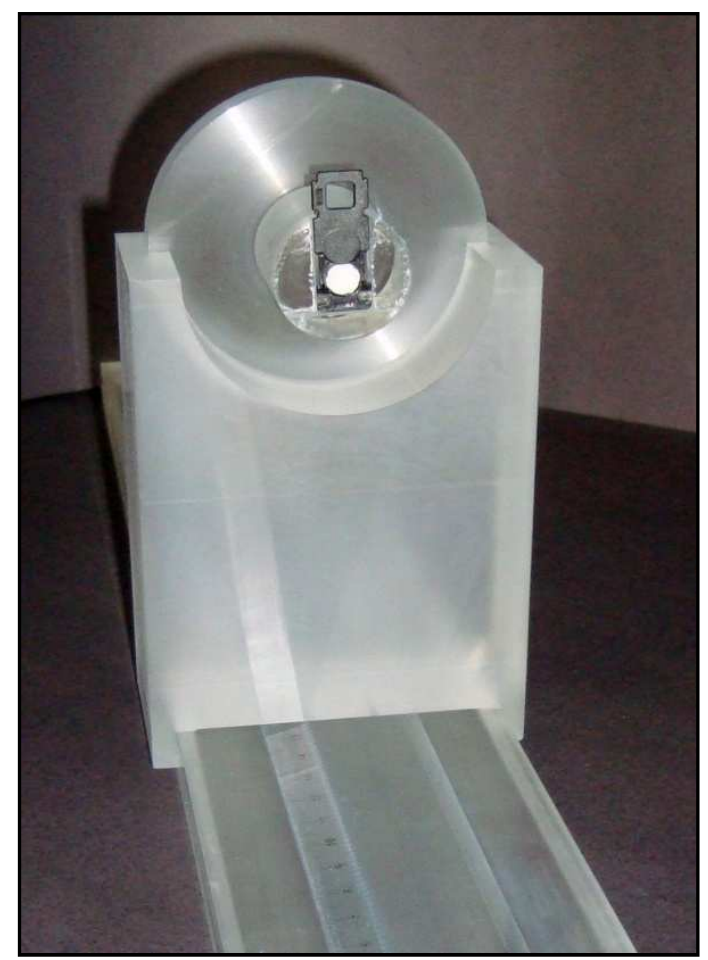

(a)

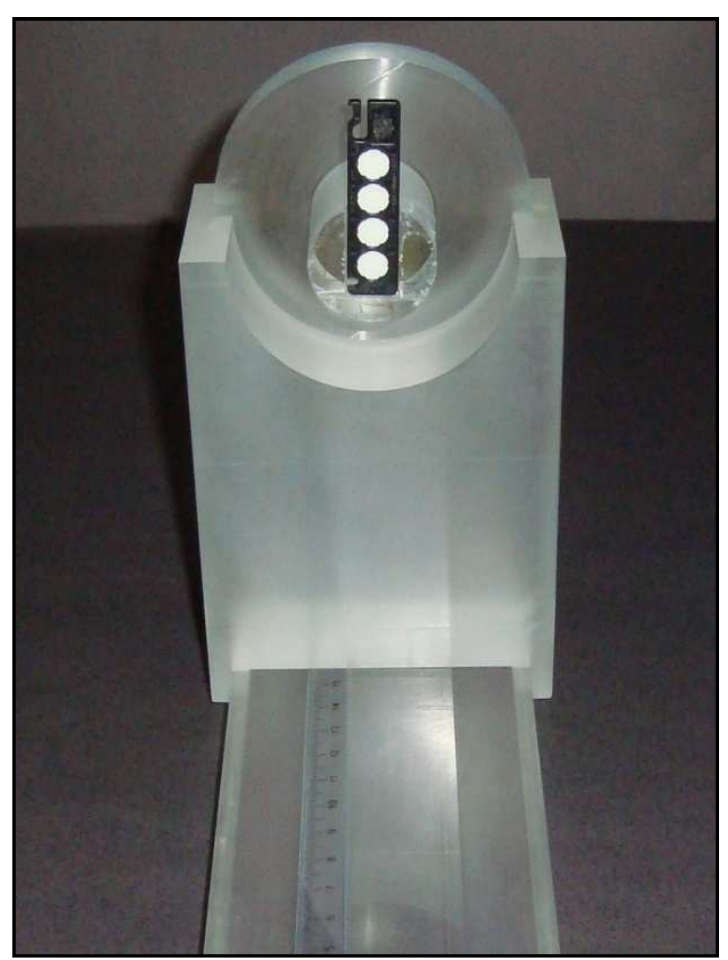

(b)

FIGURA 3.6 - Base e suporte de amostra com o detector $\mathrm{Al}_{2} \mathrm{O}_{3}: \mathrm{C}$ InLight Dot (a) e com o detector $\mathrm{Al}_{2} \mathrm{O}_{3}: \mathrm{C}$ InLight (b). 
Este suporte tem o mesmo formato e dimensões dos sensores de UV que compõem o conjunto do medidor de RUV usado neste estudo. O conjunto foi projetado e confeccionado de maneira que os centros do suporte da amostra e dos sensores, quando posicionados, ficassem à mesma altura do feixe de iluminação UV.

O ângulo de incidência do feixe de iluminação UV em relação à amostra foi mantido em zero grau, para garantir uma maior absorção da amostra. O sistema de iluminação ultravioleta é mostrado na FIG. 3.7.

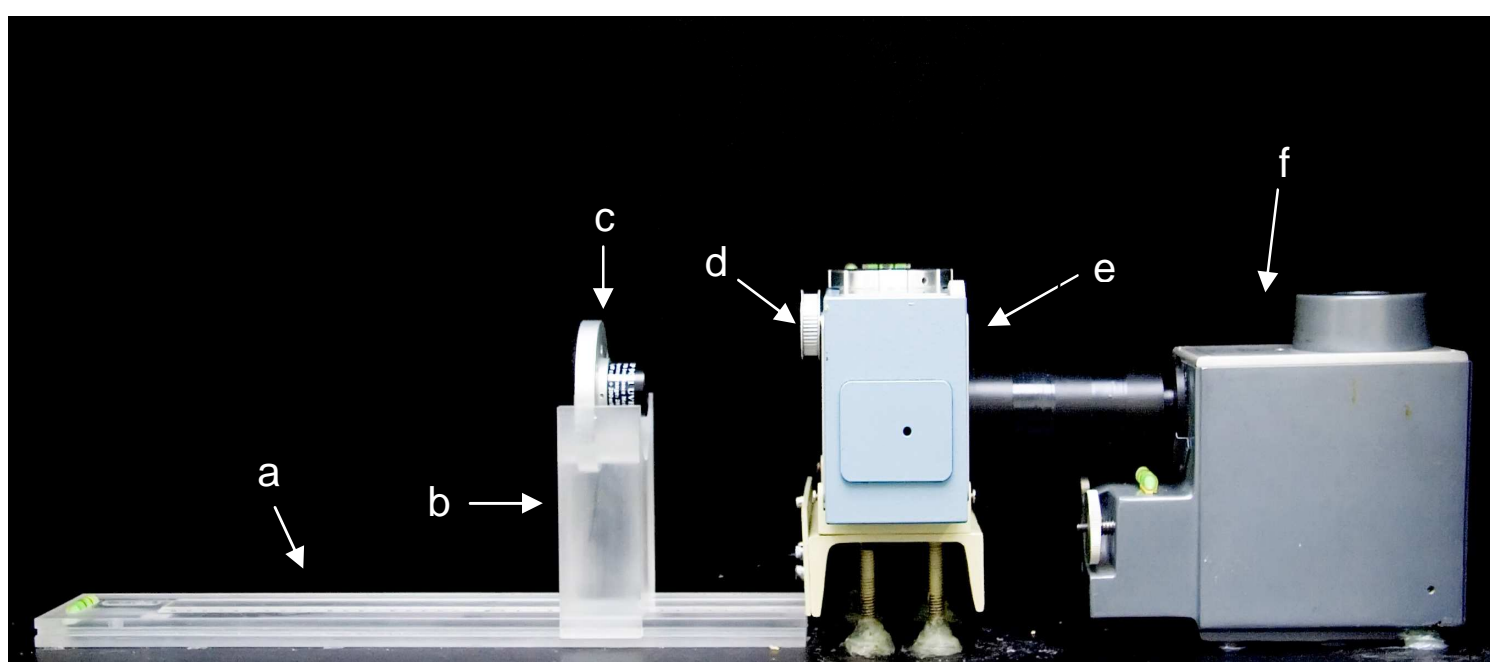

FIGURA 3.7 - Sistema de irradiação ultravioleta. (a) trilho, (b) base para o suporte de amostra e sensor UV, (c) sensor UV, (d) seletor de comprimento de onda, (e) monocromador, (f) base para a lâmpada UV e colimador do feixe de luz UV.

\subsection{Sistema de medição da radiação ultravioleta (RUV)}

As medições de irradiância em miliwatts por metro quadrado $\left(\mathrm{mW} . \mathrm{m}^{-2}\right) \mathrm{e}$ watts por metro quadrado $\left(\mathrm{W} . \mathrm{m}^{-2}\right)$ da lâmpada de UV foram realizadas com o radiômetro da DELTA OHM, modelo DO 9721 (FIG. 3.8) e sensores UVA, UVB, UVC (série LP9021) (FIG. 3.9).

Os sensores foram posicionados no suporte do sistema antes e depois de cada amostra iluminada com UV para verificação da irradiância. As medidas 
de irradiância foram registradas num microcomputador acoplado ao radiômetro com o auxílio de um software específico do equipamento. Este medidor possui ainda os sensores LP 9021 PHOT e TP 870A para medição do nível de iluminamento (em unidades de lux) e temperatura, respectivamente (FIG. 3.10).

O radiômetro e os sensores foram calibrados e inspecionados pelo fabricante Delta OHM. As instruções para calibração e periodicidade estão descritas no manual do equipamento [DELTA OHM, 2008].

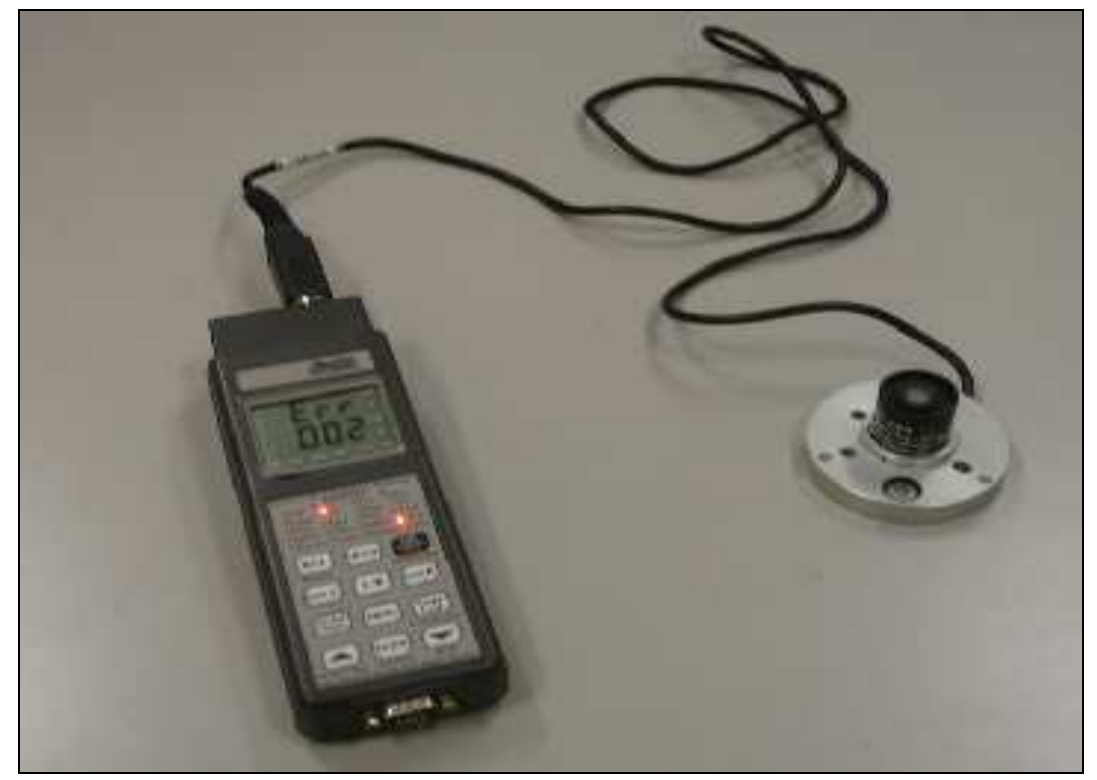

FIGURA 3.8 - Radiômetro da DELTA OHM, modelo DO 9721, e sensor UV.

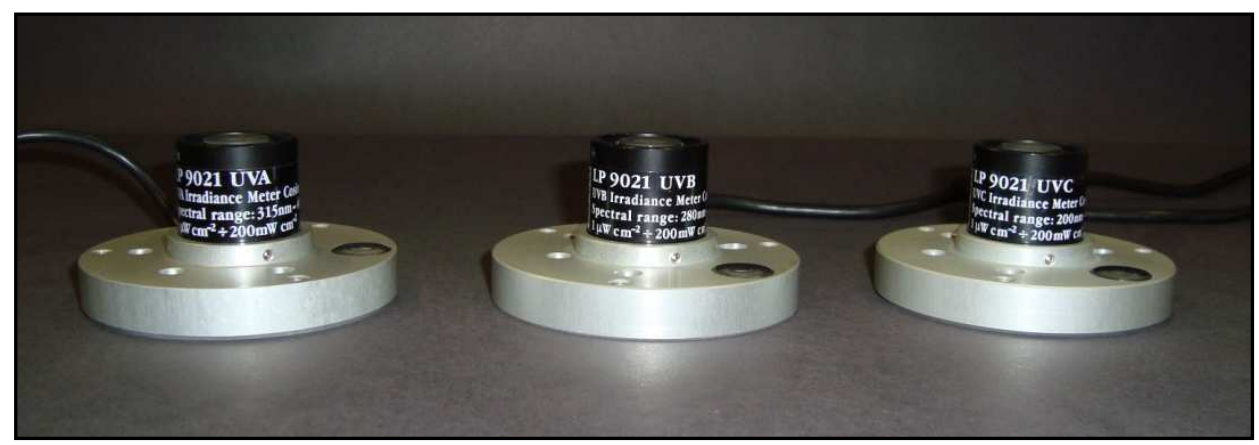

FIGURA 3.9 Sensores UVA, UVB e UVC, da Delta OHM. 


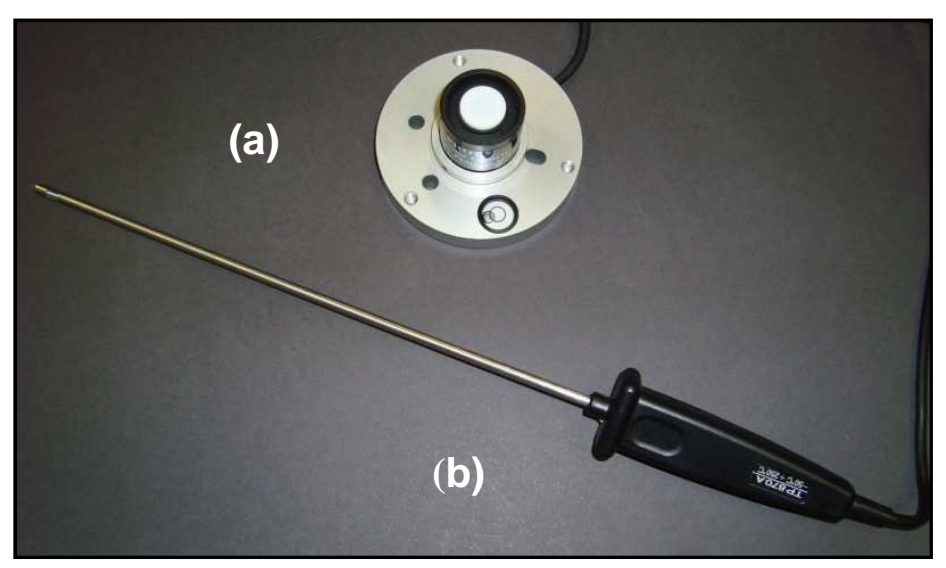

FIGURA 3.10 - Sensor de nível de iluminamento (a) e de temperatura (b), da Delta OHM.

\subsection{Sistema de tratamento óptico}

Para a reutilização, os detectores $\mathrm{Al}_{2} \mathrm{O}_{3}: \mathrm{C}$ foram "zerados"1 opticamente dentro de uma caixa de madeira branca, com dimensões $66 \times 21 \times 17 \mathrm{~cm}^{3}$, contendo duas lâmpadas fluorescentes, de $20 \mathrm{~W}$, marca Sylvânia, modelo F 16 W/78 (FIG. 3.11). A distância entre as lâmpadas e as amostras é de $9 \mathrm{~cm}$ e o nível de iluminamento dentro da caixa fechada foi de 26.000 lux.

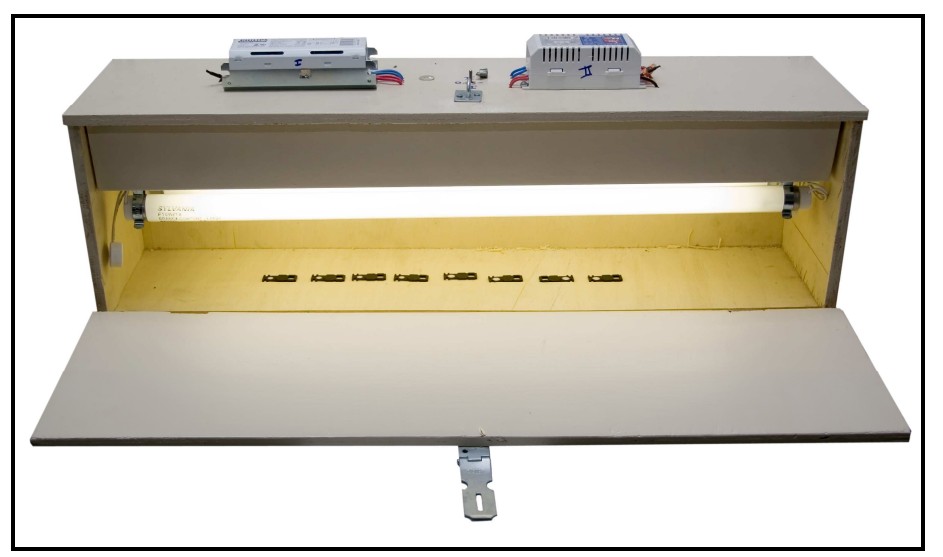

FIGURA 3.11 - Caixa de luz fluorescente para tratamento óptico dos detectores $\mathrm{Al}_{2} \mathrm{O}_{3}: \mathrm{C}$ para sua reutilização. 


\subsection{Filtros absorvedores}

Os filtros absorvedores de luz visível HOYA U 330 e U 340 da UQG Optics, com diâmetro de 12,5 mm e espessura de 2,5 mm (FIG. 3.12), foram usados nas aplicações práticas dos detectores $\mathrm{Al}_{2} \mathrm{O}_{3}: \mathrm{C}$ InLight (item 4.7) para que a luz visível do ambiente não interferisse no sinal OSL, em função da alta sensibilidade óptica deste material à radiação visível.

Os filtros HOYA U 330 e U 340 possuem transmitâncias máximas de $(85 \pm 5) \%$ para $330 \mathrm{~nm}$ e de $(75 \pm 5) \%$ para $340 \mathrm{~nm}$, respectivamente. As especificações dos filtros encontram-se nos ANEXOS II e III.

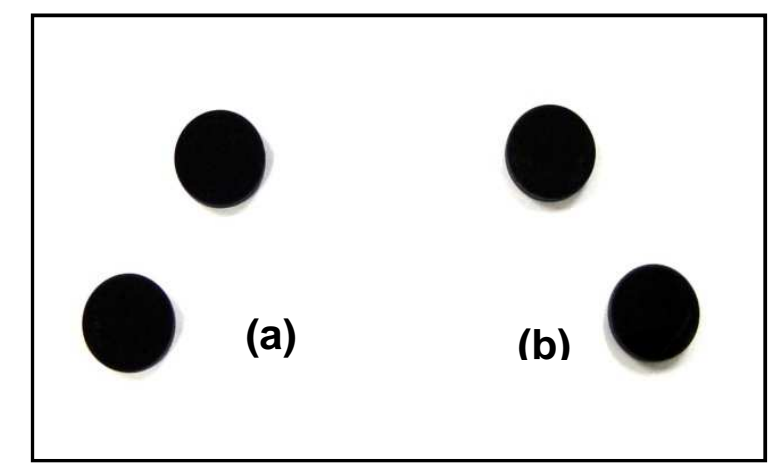

FIGURA 3.12 - Filtros HOYA U-330 (a) e U-340 (b) 


\section{RESULTADOS}

\subsection{Desempenho do sistema leitor}

O sistema leitor OSL microStar da Landauer possui 3 padrões (DARK, CAL e LED) que permitem o acompanhamento do seu desempenho durante o estudo. Esses padrões são selecionados por meio de um botão mecânico localizado no painel frontal do equipamento e os resultados das medições são mostrados em campos específicos do software da Landauer instalado no notebook acoplado ao sistema leitor, conforme mostra a FIG. 3.1. Essas medições são realizadas sem os detectores OSL.

O botão posicionado no padrão DARK permite a contagem de medidas do tubo fotomultiplicador (PMT) e indica a quantidade de ruído eletrônico inerente à PMT. No padrão CAL, a contagem de medidas da PMT indica a sua sensibilidade e consistência, e é realizada com o auxílio de uma pequena fonte de material radioativo de ${ }^{14} \mathrm{C}$ embutida em um cintilador plástico. No padrão LED a contagem das medidas da PMT mostra a intensidade do feixe de luz.

Para verificar o desempenho do sistema leitor foram realizadas 200 medições para cada padrão. As medições no padrão DARK não excederam o limite de 30 contagens [LANDAUER, 2006], conforme mostrado na FIG. 4.1.

As contagens nos padrões CAL e LED foram normalizadas para o valor médio das medições. Observa-se nas FIG. 4.2 e 4.3, que 90\% das medições no padrão CAL e 95\% das medições no padrão LED, respectivamente, estão dentro de $\pm 10 \%$ do valor médio estabelecido [LANDAUER, 2006]. 
As medições de cada padrão foram sempre realizadas após 10 leituras OSL. As medições mantiveram-se dentro dos resultados expostos.

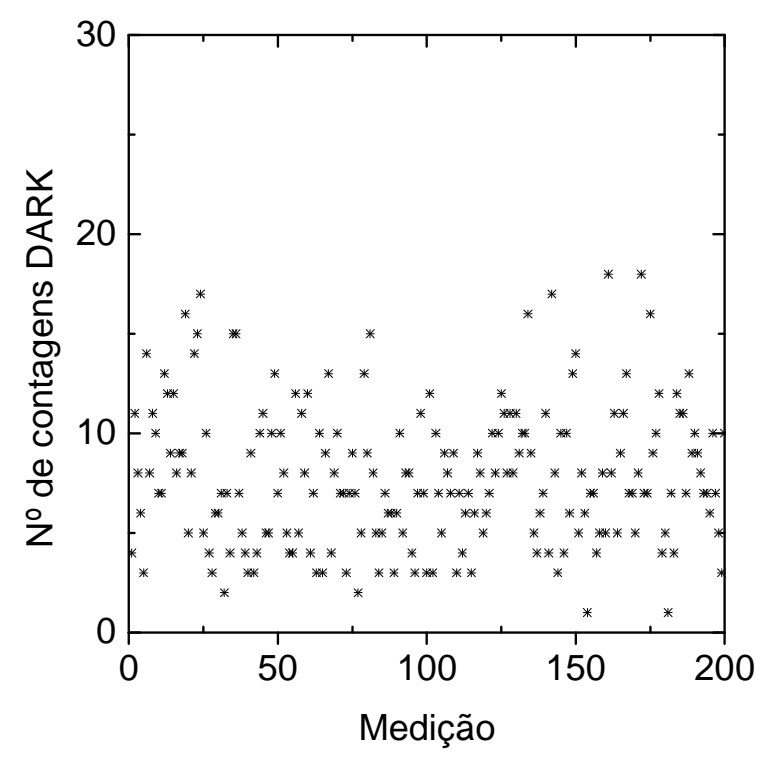

FIGURA 4.1 - Desempenho do leitor OSL microStar System: Contagem DARK

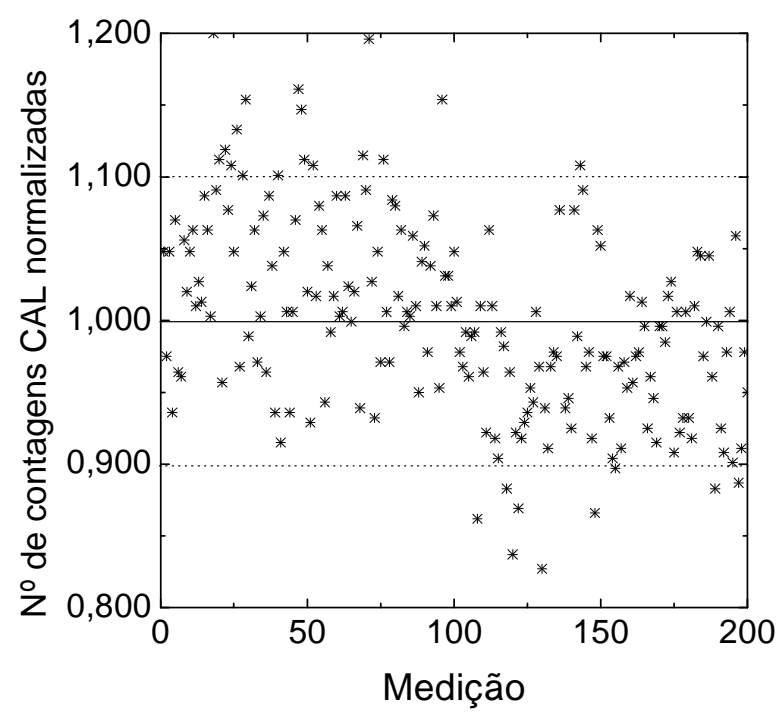

FIGURA 4.2 - Desempenho do leitor OSL microStar System: Contagem CAL. 


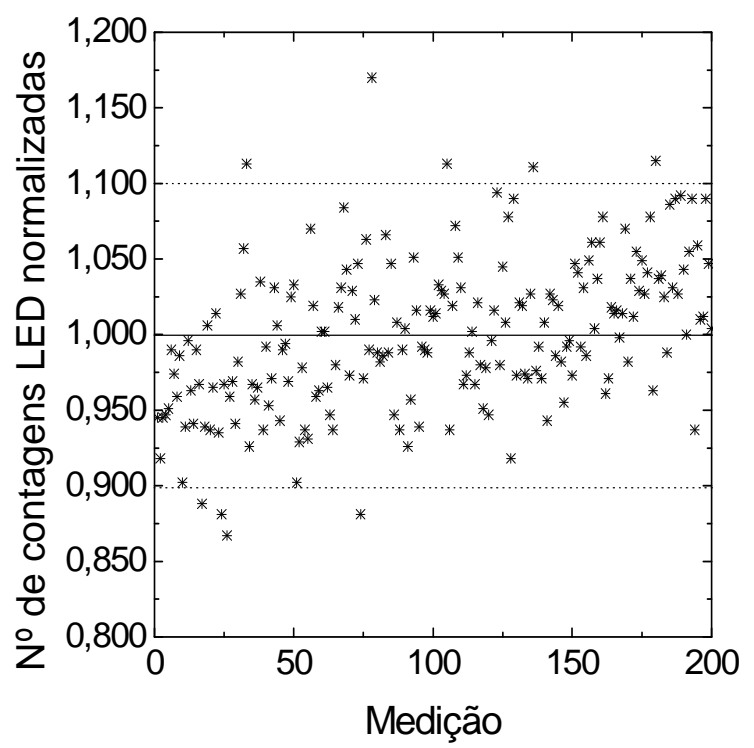

FIGURA 4.3 - Desempenho do leitor OSL microStar System: Contagem LED.

\subsection{Curva de calibração do sistema leitor OSL}

A curva de calibração do sistema leitor OSL microStar da Landauer foi determinada usando um conjunto de dosímetros InLigth pré-irradiados pelo fabricante com doses de ${ }^{137} \mathrm{Cs}$ de $5 \mathrm{mSv}, 100 \mathrm{mSv}, 500 \mathrm{mSv}$ e $5.000 \mathrm{mSv}$. A FIG. 4.4 mostra a linearidade da curva de calibração para o intervalo de dose absorvida em questão.

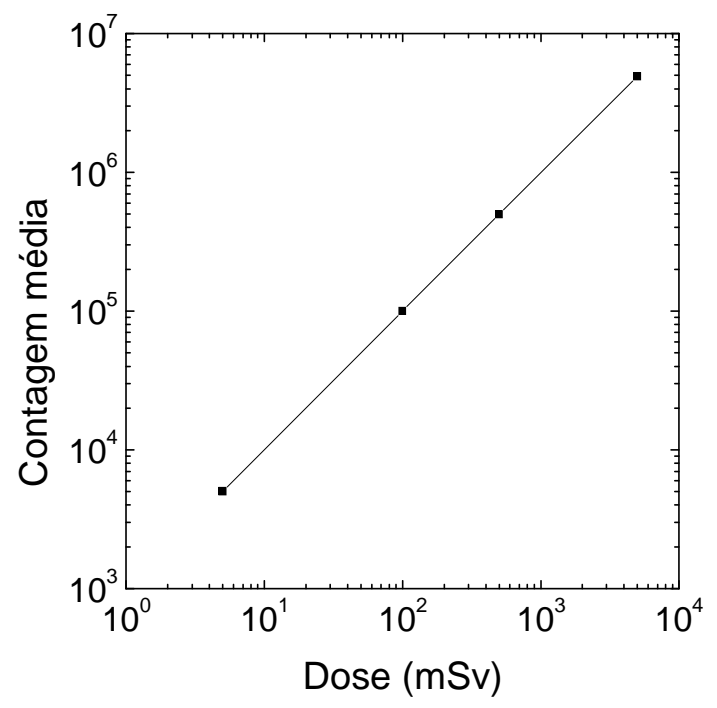

FIGURA 4.4 - Curva de calibração do leitor OSL microStar System usando dosímetros $\mathrm{Al}_{2} \mathrm{O}_{3}: \mathrm{C}$ InLight pré-irradiados. 
Este procedimento de calibração foi realizado a cada dois meses ou logo após um serviço de manutenção do sistema leitor OSL, seguindo as recomendações do fabricante [LANDAUER, 2006].

\subsection{Caracterização inicial dos detectores $\mathrm{Al}_{2} \mathrm{O}_{3}: \mathrm{C}$ InLight Dot}

A caracterização inicial dos detectores $\mathrm{Al}_{2} \mathrm{O}_{3}: \mathrm{C}$ foi realizada com fontes de radiação gama de ${ }^{60} \mathrm{Co}$ e ${ }^{137} \mathrm{Cs}$. As características estudadas da resposta OSL foram: reprodutibilidade, curva de dose-resposta, limite mínimo de detecção e dependência energética.

\subsubsection{Reprodutibilidade}

A reprodutibilidade da resposta OSL dos detectores $\mathrm{Al}_{2} \mathrm{O}_{3}: \mathrm{C}$ InLight Dot foi determinada utilizando um conjunto de dez detectores "zerados" e posicionados entre duas placas de Lucite de $3 \mathrm{~mm}$ de espessura cada, para garantir condição de equilíbrio eletrônico, e irradiados com doses de 1 Gy de fonte de radiação gama $\left({ }^{60} \mathrm{Co}\right)$; em seguida, foram tomadas as medidas OSL. Esse procedimento foi repetido 5 vezes consecutivas.

O desvio padrão percentual foi de 4,5\%, valor dentro do limite aceitável de 7,5\% recomendado pelo "Comitê de Avaliação dos Serviços de Monitoração Individual Externa" (CASMIE) [IRD, 1995]. O resultado obtido demonstra uma reprodutibilidade excelente destes detectores.

\subsubsection{Resposta OSL em função da dose absorvida (radiação gama)}

A curva de resposta OSL dos detectores $\mathrm{Al}_{2} \mathrm{O}_{3}: \mathrm{C}$ InLight Dot em função da dose absorvida foi resultado da irradiação de 23 detectores totalmente "zerados" com doses absorvidas entre 0,01 mGy e 120 Gy de fontes de radiação gama de ${ }^{60} \mathrm{Co}$ (sob condições de equilíbrio eletrônico). 
Estes detectores apresentaram linearidade entre 0,05 mGy e 20 Gy, e acima desta dose começaram a mostrar sinais de saturação (FIG. 4.5).

Resultados similares foram relatados por Yukihara e col. [2004] com os dosímetros $\mathrm{Al}_{2} \mathrm{O}_{3}: \mathrm{C}$ Luxel da Landauer e por Xinbo e col. [2008] com cristais de $\mathrm{Al}_{2} \mathrm{O}_{3}: \mathrm{C}$ e a técnica de termoluminescência. Yukihara e col. [2003] verificaram que para doses aproximadamente entre 10 e 20 Gy de radiação beta ocorreu uma queda na sensibilidade dos detectores $\mathrm{Al}_{2} \mathrm{O}_{3}: \mathrm{C}$, utilizando a técnica de termoluminescência.

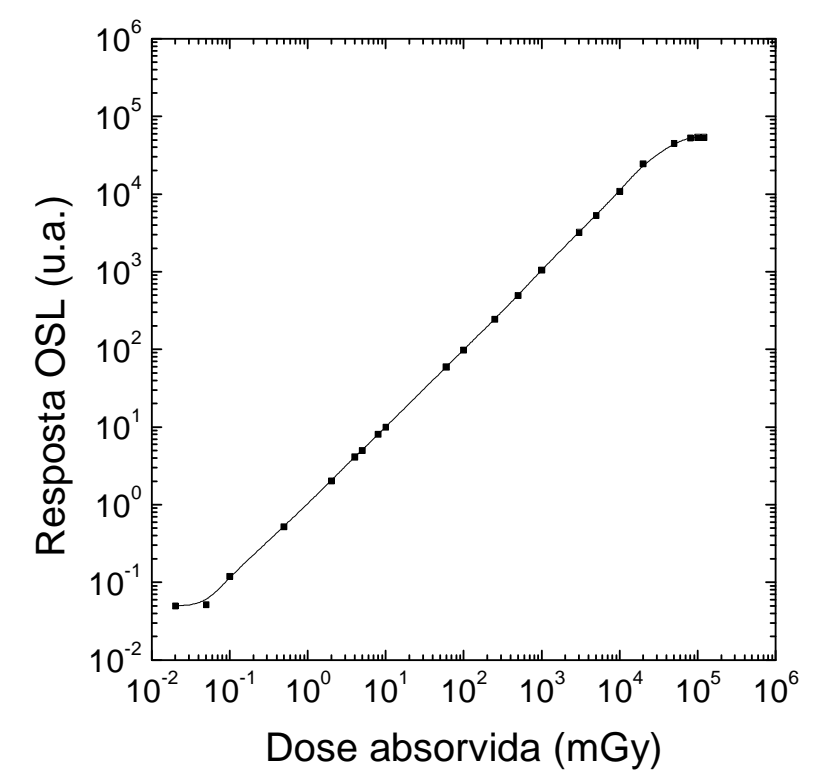

FIGURA 4.5 - Curva de dose-resposta OSL dos detectores $\mathrm{Al}_{2} \mathrm{O}_{3}: \mathrm{C}$ Inlight Dot para radiação gama $\left({ }^{60} \mathrm{Co}\right)$.

\subsubsection{Limite mínimo detectável}

O limite mínimo detectável dos detectores $\mathrm{Al}_{2} \mathrm{O}_{3}: \mathrm{C}$ InLight Dot é uma característica muito importante na dosimetria das radiações. Pode-se observar na FIG. 4.5, que o valor do limite mínimo detectável destes detectores para radiação gama $\left({ }^{60} \mathrm{Co}\right)$ foi de $50 \mu \mathrm{Gy}$, e está de acordo com o limite de $50 \mu \mathrm{Sv}$ estabelecido pelo fabricante [LANDAUER, 2006]. 


\subsubsection{Dependência energética}

A dependência energética dos detectores $\mathrm{Al}_{2} \mathrm{O}_{3}: \mathrm{C}$ InLight Dot foi verificada utilizando-se as fontes de radiação gama de ${ }^{137} \mathrm{Cs}(662 \mathrm{keV})$ e ${ }^{60} \mathrm{Co}(1,25 \mathrm{MeV})$. Os detectores foram irradiados neste caso com doses de 0,3 mGy de ${ }^{137} \mathrm{Cs} \mathrm{e}{ }^{60} \mathrm{Co}$, sob condições de equilíbrio eletrônico.

Foram tomadas dez medidas OSL consecutivas para cada detector irradiado com fontes de ${ }^{137} \mathrm{Cs}$ e ${ }^{60} \mathrm{Co}$ e os resultados obtidos são os valores médios das leituras OSL, conforme apresentado na TAB. 4.1.

Os detectores não apresentaram dependência energética da resposta OSL em relação às fontes de radiação estudadas, pois a diferença está dentro do limite de incerteza das medições (item 4.3.1).

Um estudo apresentado por Jursinic [2007] mostra que estes detectores não apresentaram dependência energética em relação a feixes de raios- $\mathrm{X}$ e de elétrons, de diferentes energias.

TABELA 4.1 - Dependência energética dos detectores $\mathrm{Al}_{2} \mathrm{O}_{3}: \mathrm{C}$ InLight Dot, para radiação gama, irradiados com $0,3 \mathrm{mGy}$.

\begin{tabular}{cc}
\hline $\begin{array}{c}\text { Fonte de radiação } \\
\text { gama }\end{array}$ & $\begin{array}{c}\text { Dose absorvida } \\
\text { (mGy) }\end{array}$ \\
\hline${ }^{137} \mathrm{Cs}(662 \mathrm{keV})$ & $0,320 \pm 0,010$ \\
\hline${ }^{60} \mathrm{Co}(1,25 \mathrm{MeV})$ & $0,310 \pm 0,011$ \\
\hline
\end{tabular}

\subsection{Decaimento óptico do sinal OSL}

Devido à alta sensibilidade do material $\mathrm{Al}_{2} \mathrm{O}_{3}: \mathrm{C}$ à luz [WEST e col., 2006], foi realizado um estudo para verificar o decaimento óptico do sinal OSL com os detectores InLight Dot em função da exposição à luz fluorescente e à luz solar. 


\subsubsection{Exposição dos detectores $\mathrm{Al}_{2} \mathrm{O}_{3}: \mathrm{C}$ à luz fluorescente}

O decaimento óptico em função da luz fluorescente ambiente do laboratório da GMR foi verificado com seis detectores $\mathrm{Al}_{2} \mathrm{O}_{3}: \mathrm{C}$ InLight Dot pré-irradiados com doses absorvidas de fonte de radiação beta $\left({ }^{90} \mathrm{Sr}+{ }^{90} \mathrm{Y}\right)$ entre $0,1 \mathrm{mGy}$ e $15 \mathrm{mGy}$.

Os detectores InLight Dot abertos foram posicionados numa bancada do laboratório e as pastilhas de $\mathrm{Al}_{2} \mathrm{O}_{3}: \mathrm{C}$ expostas a 260 lux provenientes de oito lâmpadas fluorescentes que iluminam uma área de aproximadamente $25 \mathrm{~m}^{2}$.

O nível de iluminamento foi obtido posicionando o sensor LP 9021 PHOT conectado ao radiômetro Delta OHM, no mesmo local dos detectores InLight Dot abertos no momento da exposição à luz fluorescente do ambiente. Os tempos de exposição a 260 lux variaram entre 30 e $1.800 \mathrm{~s}$.

A FIG. 4.6 mostra que a porcentagem de queda do sinal OSL dos detectores irradiados nos primeiros 5 min de exposição à luz variou entre $16 \% \mathrm{e}$ $24 \%$. Após $30 \mathrm{~min}$, a porcentagem de queda do sinal OSL variou entre $49 \%$ e $53 \%$.

O decaimento óptico do sinal OSL dos detectores $\mathrm{Al}_{2} \mathrm{O}_{3}: \mathrm{C}$ InLight Dot foi verificado também para um nível de iluminamento mais alto do que o do ambiente. Depois de "zerados", os seis detectores foram irradiados com doses absorvidas de radiação beta $\left({ }^{90} \mathrm{Sr}+{ }^{90} \mathrm{Y}\right)$ entre $0,1 \mathrm{mGy}$ e $15 \mathrm{mGy}$ e os detectores InLight Dot abertos foram posicionados dentro da caixa de luz (FIG. 3.11) com nível de iluminamento de 26.000 lux. O tempo de exposição à luz também variou neste caso de 30 a $1.800 \mathrm{~s}$.

A porcentagem de queda do sinal OSL dos detectores, nos 5 primeiros minutos de exposição, variou de $76 \%$ a $91 \%$. Após $30 \mathrm{~min}$, os detectores, independentemente das doses, estavam "zerados" (FIG. 4.7). 


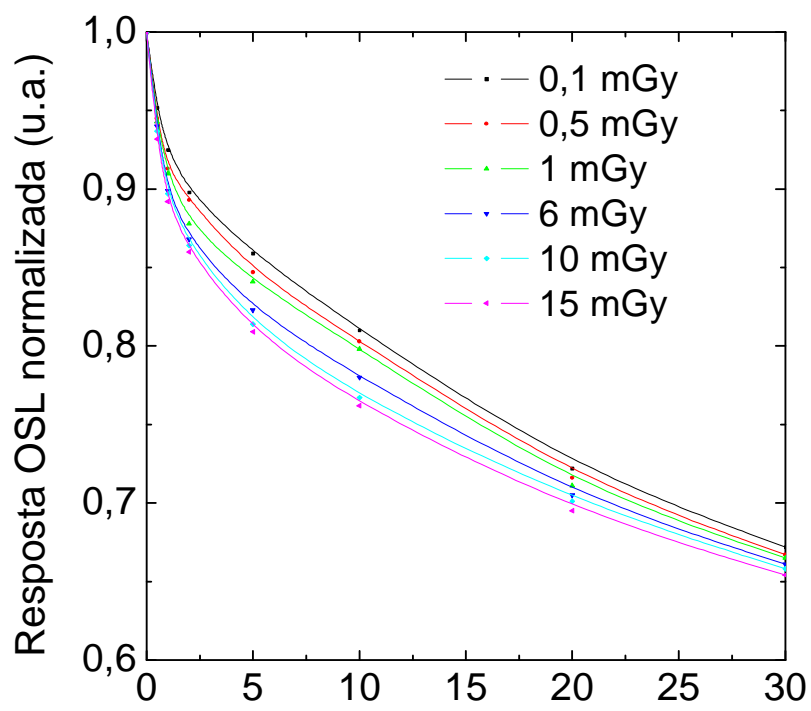

Tempo de exposição à luz fluorescente (min)

FIGURA 4.6 - Decaimento do sinal OSL dos detectores $\mathrm{Al}_{2} \mathrm{O}_{3}: \mathrm{C}$ InLight Dot préirradiados com radiação beta em função do tempo de exposição a 260 lux de luz fluorescente (luz ambiente). A incerteza máxima das medições foi de $5,3 \%$.

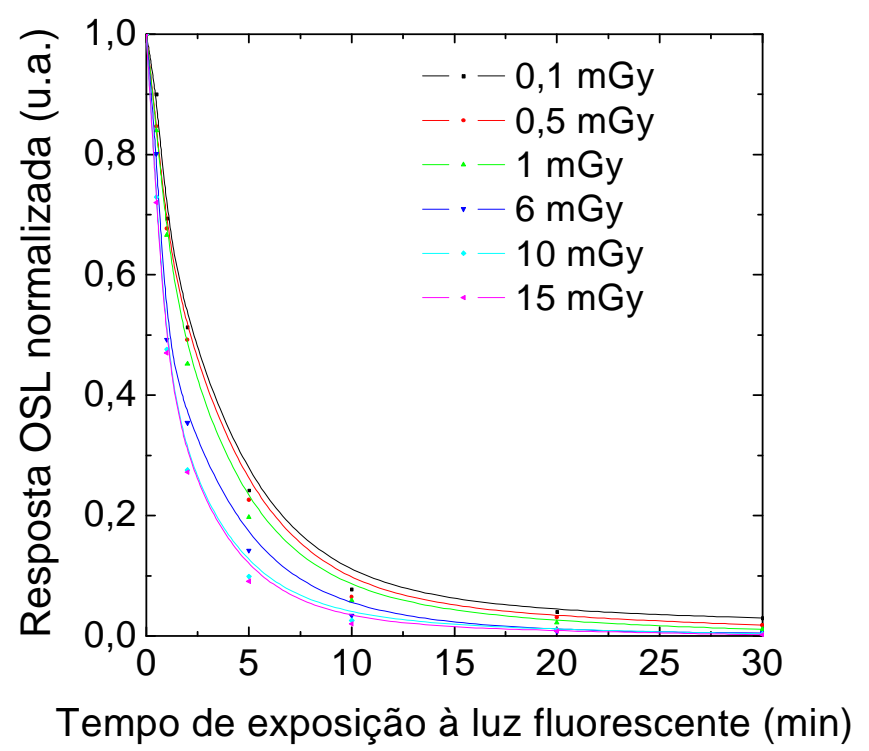

FIGURA 4.7 - Decaimento do sinal OSL dos detectores $\mathrm{Al}_{2} \mathrm{O}_{3}: \mathrm{C}$ InLight Dot préirradiados com radiação beta em função do tempo de exposição a 26.0000 lux de luz fluorescente (caixa de luz). A incerteza máxima das medições foi de $5,1 \%$. 
Em seguida, um detector $\mathrm{Al}_{2} \mathrm{O}_{3}: \mathrm{C}$ InLight Dot foi irradiado com dose de $15 \mathrm{mGy}$ de radiação de beta de ${ }^{90} \mathrm{Sr}+{ }^{90} \mathrm{Y}$ e o detector Dot aberto foi colocado dentro da caixa de luz com apenas uma lâmpada fluorescente ligada, fornecendo um nível de iluminamento de 17.000 lux. O tempo de exposição também variou de 30 a $1.800 \mathrm{~s}$.

A FIG 4.8 mostra uma comparação das curvas de decaimento do sinal OSL dos detectores pré-irradiados e expostos a 260 lux, 17.000 lux e 26.000 lux de luz fluorescente em função do tempo de exposição à luz. Verifica-se que o decaimento óptico do sinal OSL é mais rápido para exposição a 26.000 lux.

A exposição dos detectores InLight Dot à luz fluorescente em função do tempo foi consecutiva, isto é, ao final de cada tempo de exposição foram realizadas as leituras OSL e em seguida os detectores retornaram para local da exposição à luz dando sequência ao estudo. Todas as respostas OSL foram normalizadas para os valores das medições iniciais.

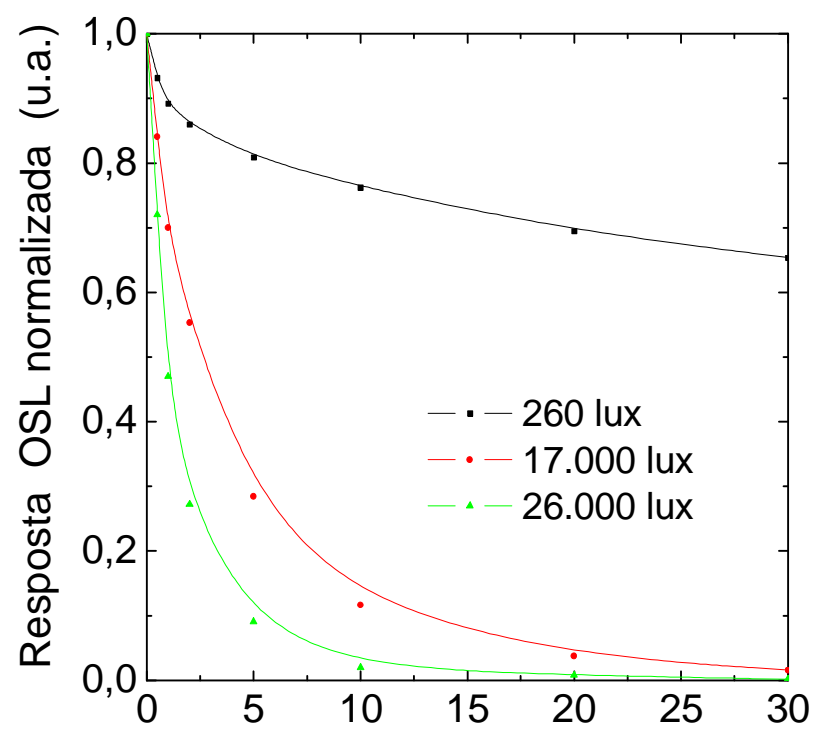

Tempo de exposição à luz fluorescente (min)

FIGURA 4.8 - Decaimento do sinal OSL dos detectores $\mathrm{Al}_{2} \mathrm{O}_{3}: \mathrm{C}$ InLight Dot préirradiados com 15 mGy de radiação beta em função do tempo de exposição a 260 lux, 17.000 lux e 26.000 lux de luz fluorescente. A incerteza máxima das medições foi de 5,0\%. 


\subsubsection{Exposição dos detectores InLight Dot à luz solar}

A influência da luz solar no sinal OSL dos detectores $\mathrm{Al}_{2} \mathrm{O}_{3}$ : C foi estudada em amostras não irradiadas e pré-irradiadas. Um conjunto de oito detectores InLight Dot abertos não irradiados foram expostos diretamente à luz solar com tempo de exposição entre 30 e $3.600 \mathrm{~s}$.

O estudo foi realizado em um dia do verão completamente claro e sem nuvens em São Paulo (2332'51"S e 4638'10"O e 760 m acima do nível do mar). A temperatura ambiente era de $40^{\circ} \mathrm{C}$ e o nível de iluminamento médio no local onde os detectores foram posicionados era de 100.000 lux. Estas medidas foram feitas com os sensores LP 9021 PHOT e TP 870A conectados ao radiômetro Delta OHM, no momento da exposição, na mesma posição em que foram colocados os detectores no solo (granito preto).

Um conjunto de quatro detectores InLight Dot foi irradiado com $15 \mathrm{mGy}$ de radiação beta $\left({ }^{90} \mathrm{Sr}+{ }^{90} \mathrm{Y}\right)$ e os detectores abertos foram expostos ao sol nas mesmas condições ambientais com o tempo de exposição variando de 30 a $3.600 \mathrm{~s}$. Nos detectores pré-irradiados notou-se uma queda percentual do sinal OSL de $87,7 \%$ nos primeiros $30 \mathrm{~s}$ de exposição ao sol (FIG. 4.9). As medidas OSL dos detectores foram realizadas antes e após as irradiações e as exposições à luz solar.

A curva em vermelho da FIG. 4.9, que representa o grupo de detectores não irradiados expostos ao sol, mostra que houve uma ativação inicial do sinal OSL dos detectores nos primeiros 3 min de exposição ao sol e logo após houve uma queda do sinal OSL tendendo a zero. As FIG. 4.10a e 4.10b mostram detalhes desta ativação inicial da resposta OSL dos detectores não irradiados expostos ao sol.

Resultados similares foram relatados por West e col. [2006], que sugeriram a ocorrência de luminescência opticamente estimulada fototransferida (PTOSL) em dosímetros Luxel da Landauer não irradiados. 


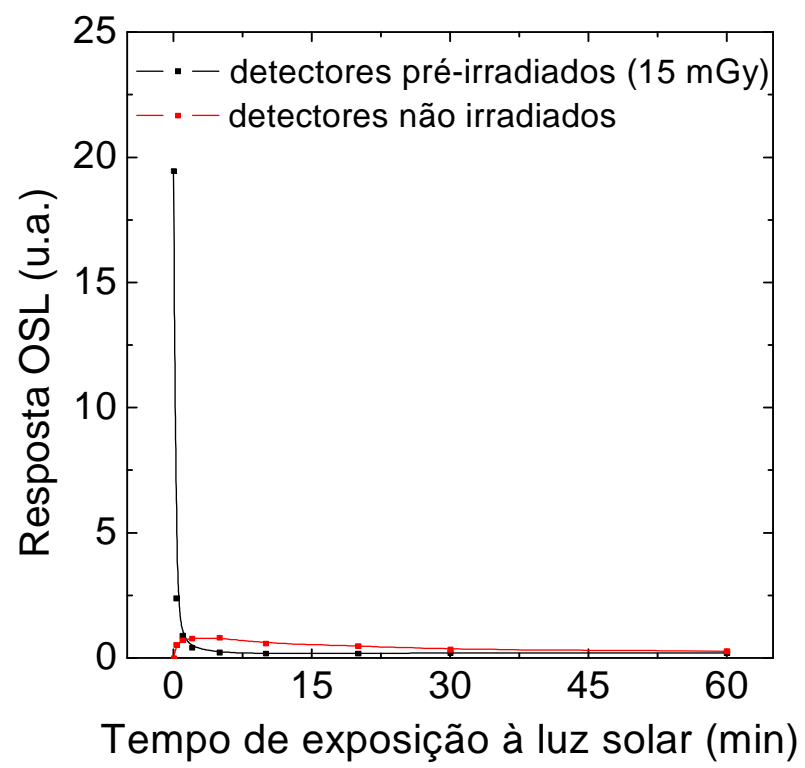

FIGURA 4.9 - Decaimento do sinal OSL dos detectores $\mathrm{Al}_{2} \mathrm{O}_{3}: \mathrm{C}$ InLight Dot não irradiados e pré-irradiados com 15 mGy em função do tempo de exposição à luz solar.
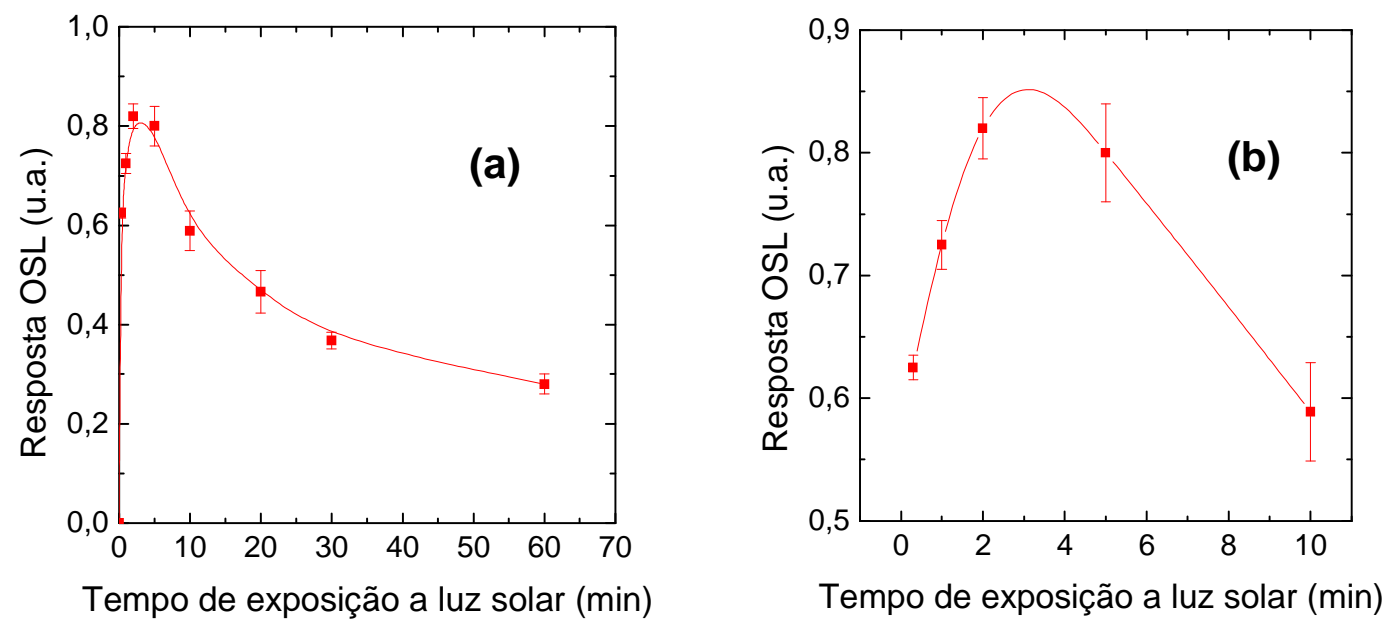

FIGURA 4.10 - Detalhes da curva de decaimento do sinal OSL entre 0 e 60 min (a) e entre 0 e $10 \mathrm{~min}$ (b), que mostram a ativação inicial da resposta OSL dos detectores InLight Dot não irradiados e expostos à luz solar. 
Este estudo mostrou que os detectores OSL, por causa da sua alta sensibilidade à luz, precisam ser manipulados em ambiente escuro para evitar o decaimento óptico do sinal OSL. Além disso, verificou-se que a exposição a 26.000 lux dentro da caixa de luz (FIG. 3.11) é uma excelente forma de tratar opticamente os detectores para reutilização. Estes procedimentos passaram a ser adotados no decorrer do desenvolvimento deste trabalho.

\subsection{Caracterização dos detectores $\mathrm{Al}_{2} \mathrm{O}_{3}: \mathrm{C}$ sem pré-condicionamentos expostos diretamente à RUV}

A caracterização dos detectores $\mathrm{Al}_{2} \mathrm{O}_{3}: \mathrm{C}$ InLight, sem précondicionamentos, ou seja, sem pré-irradiações e sem tratamentos ópticos, expostos diretamente à luz da fonte artificial do sistema de iluminação de RUV, consistiu em verificar a resposta OSL destes detectores em função dos parâmetros: comprimento de onda, irradiância, tempo de iluminação UV, exposição radiante e decaimento do sinal OSL dos detectores.

\subsubsection{Resposta OSL e o comprimento de onda}

A resposta OSL dos detectores $\mathrm{Al}_{2} \mathrm{O}_{3}: \mathrm{C}$ InLight em função do comprimento de onda da luz do sistema de RUV foi estudada no intervalo de 280 a $400 \mathrm{~nm}$. Um conjunto contendo vinte e um detectores totalmente "zerados" foi utilizado para o estudo. As medidas OSL foram realizadas a cada $5 \mathrm{~nm}$.

Os parâmetros irradiância e tempo de iluminação foram fixados em $0,5 \mathrm{~W} \cdot \mathrm{m}^{-2}$ e $10 \mathrm{~min}$ para cada comprimento de onda. A medida da irradiância foi tomada antes e depois das iluminações UV, para verificar se não houve alteração no valor fixado. Este estudo foi repetido três vezes e os resultados são as médias e os desvios padrão das respostas OSL ( $\sigma=1, k=1$ ).

A FIG. 4.11 mostra que este detector apresentou uma sensibilidade da resposta OSL maior na região do comprimento de onda de $330 \mathrm{~nm}$. 


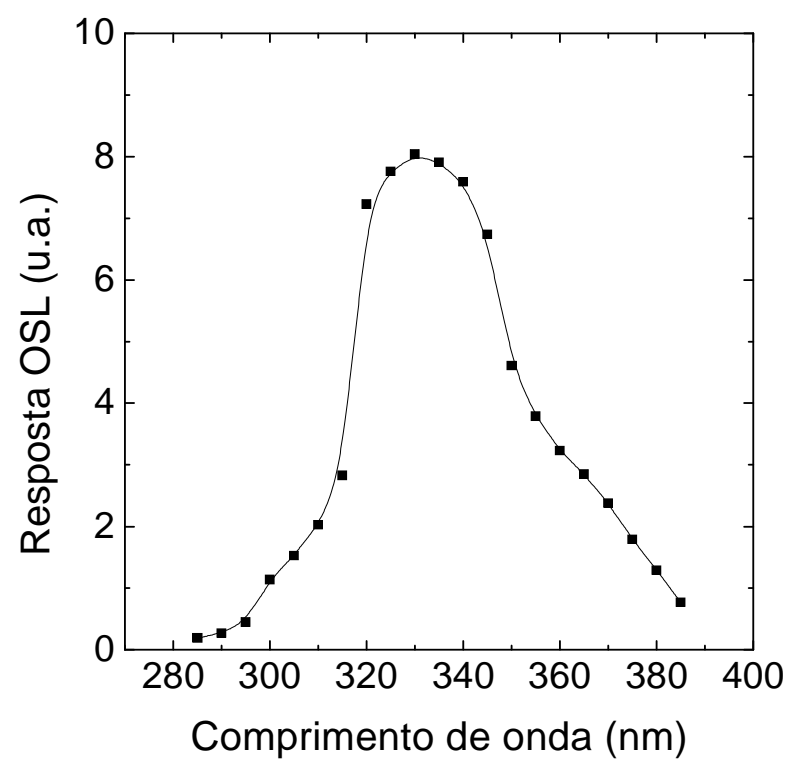

FIGURA 4.11 - Resposta OSL dos detectores $\mathrm{Al}_{2} \mathrm{O}_{3}: \mathrm{C}$ InLight em função do comprimento de onda de luz do sistema de RUV. A incerteza máxima das medições foi de $5,4 \%$.

\subsubsection{Resposta OSL e a irradiância}

A resposta OSL dos detectores $\mathrm{Al}_{2} \mathrm{O}_{3}: \mathrm{C}$ InLight em função da irradiância foi estudada em amostras iluminadas no sistema de RUV. Um grupo de sete detectores "zerados" foi exposto às irradiâncias no intervalo de $0,07 \mathrm{~W} \cdot \mathrm{m}^{-2}$ a 1,7 W.m. $\mathrm{m}^{-2}$. Os parâmetros comprimento de onda e tempo de iluminação foram mantidos fixos em $330 \mathrm{~nm}$ e $10 \mathrm{~min}$, respectivamente. As medidas das irradiâncias foram tomadas antes e depois das iluminações UV dos detectores.

Pode-se observar na FIG. 4.12 que a resposta OSL aumenta de maneira significativa até $0,5 \mathrm{~W} \cdot \mathrm{m}^{-2} \mathrm{e}$, para irradiâncias acima de $1,7 \mathrm{~W} \cdot \mathrm{m}^{-2}$ a resposta OSL mostra uma tendência à saturação. Verifica-se que a irradiância de $0,5 \mathrm{~W} \cdot \mathrm{m}^{-2}$ escolhida para o estudo encontra-se dentro do intervalo de estimulação do sinal OSL destes detectores. 


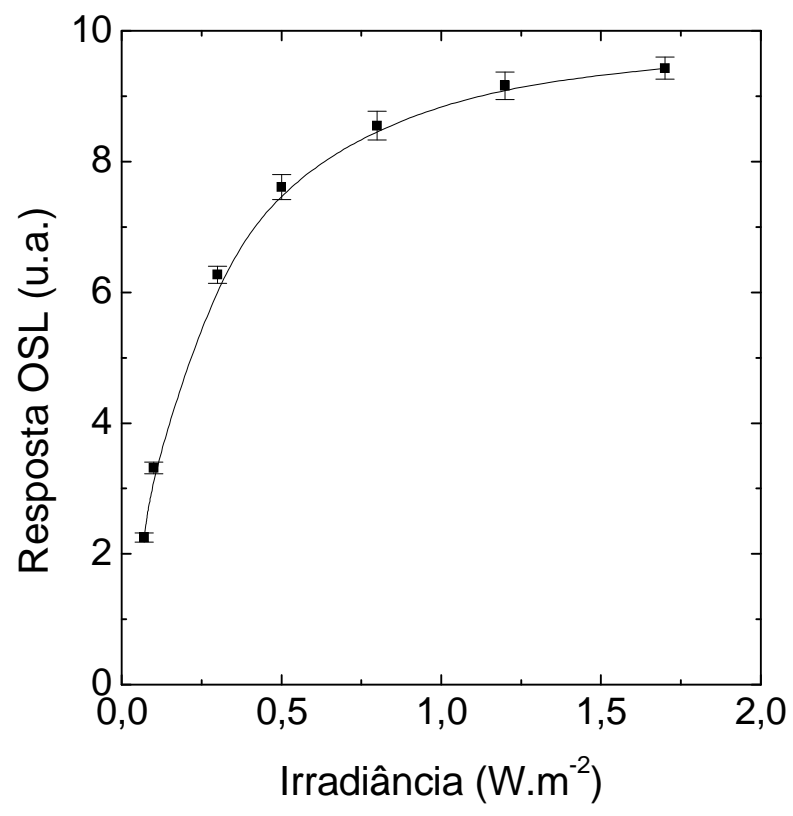

FIGURA 4.12 - Resposta OSL dos detectores $\mathrm{Al}_{2} \mathrm{O}_{3}: \mathrm{C}$ InLight em função da irradiância da fonte de luz do sistema de RUV.

\subsubsection{Resposta OSL e o tempo de iluminação}

Os detectores $\mathrm{Al}_{2} \mathrm{O}_{3}: \mathrm{C}$ InLight foram caracterizados em relação ao tempo de iluminação de UV. Um conjunto de sete detectores "zerados" foi utilizado neste estudo. Os parâmetros comprimento de onda e irradiância foram fixados em $330 \mathrm{~nm}$ em 0,5 W. $\mathrm{m}^{-2}$, respectivamente, variando o tempo de iluminação UV entre 1 e 60 min.

Observa-se na FIG. 4.13 que ocorreu um aumento significativo do sinal até 30 min de iluminação UV e a seguir uma tendência à saturação. Verifica-se também que o tempo de iluminação UV de $10 \mathrm{~min}$ escolhido para o estudo foi suficiente para sensibilizar o sinal OSL da amostra e otimizar o estudo, uma vez que entre 10 e 30 min de iluminação UV o aumento do sinal OSL seria apenas de $15,4 \%$. 


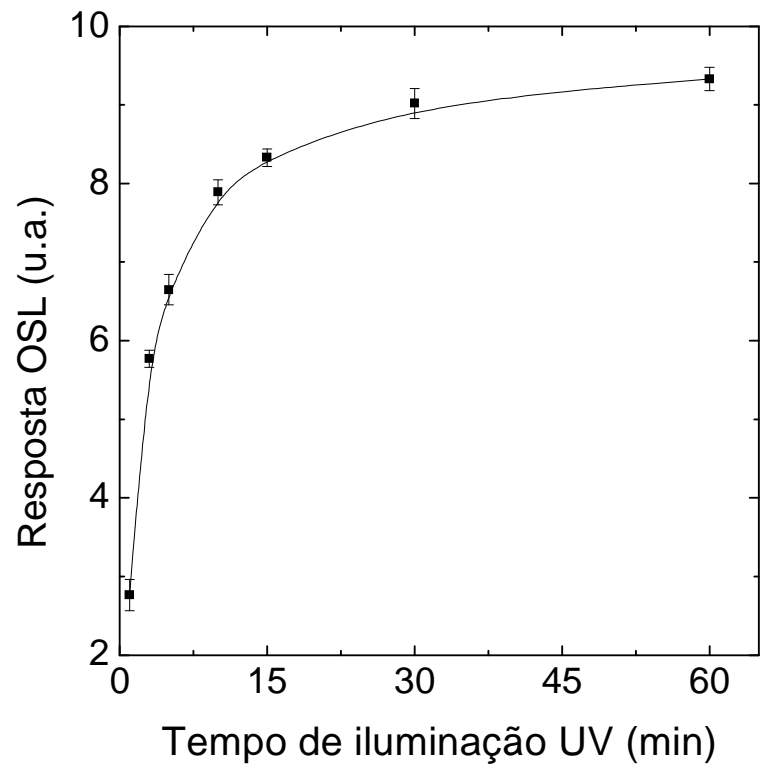

FIGURA 4.13 - Resposta OSL dos detectores $\mathrm{Al}_{2} \mathrm{O}_{3}: \mathrm{C}$ InLight em função do tempo de iluminação UV.

\subsubsection{Resposta OSL e a exposição radiante}

A caracterização dos detectores $\mathrm{Al}_{2} \mathrm{O}_{3}: \mathrm{C}$ InLight em relação à exposição radiante foi realizada para os comprimentos de onda $330 \mathrm{~nm}$ e $340 \mathrm{~nm}$.

Um conjunto de seis detectores foi utilizado para a realização deste estudo. $O$ intervalo de exposição radiante foi entre $15 \mathrm{~J} . \mathrm{m}^{-2}$ e $1.350 \mathrm{~J} . \mathrm{m}^{-2}$. O comprimento de onda de $330 \mathrm{~nm}$ e a irradiância foram fixados em $330 \mathrm{~nm}$ e $0,5 \mathrm{~W} \cdot \mathrm{m}^{-2}$, respectivamente. Este procedimento foi repetido com outro conjunto de seis detectores para o mesmo intervalo de exposição radiante e mesma irradiância, fixando o comprimento de onda em $340 \mathrm{~nm}$.

Somente uma leitura por detector foi realizada por causa da rápida queda do sinal OSL. O estudo foi realizado três vezes para cada comprimento de onda e os resultados mostrados nas FIG. 4.14 e 4.15 são os valores médios e desvios padrões das respostas OSL $(\sigma=1, k=1)$ em função da exposição radiante para os comprimentos de ondas fixados em $330 \mathrm{~nm}$ e $340 \mathrm{~nm}$, respectivamente. 


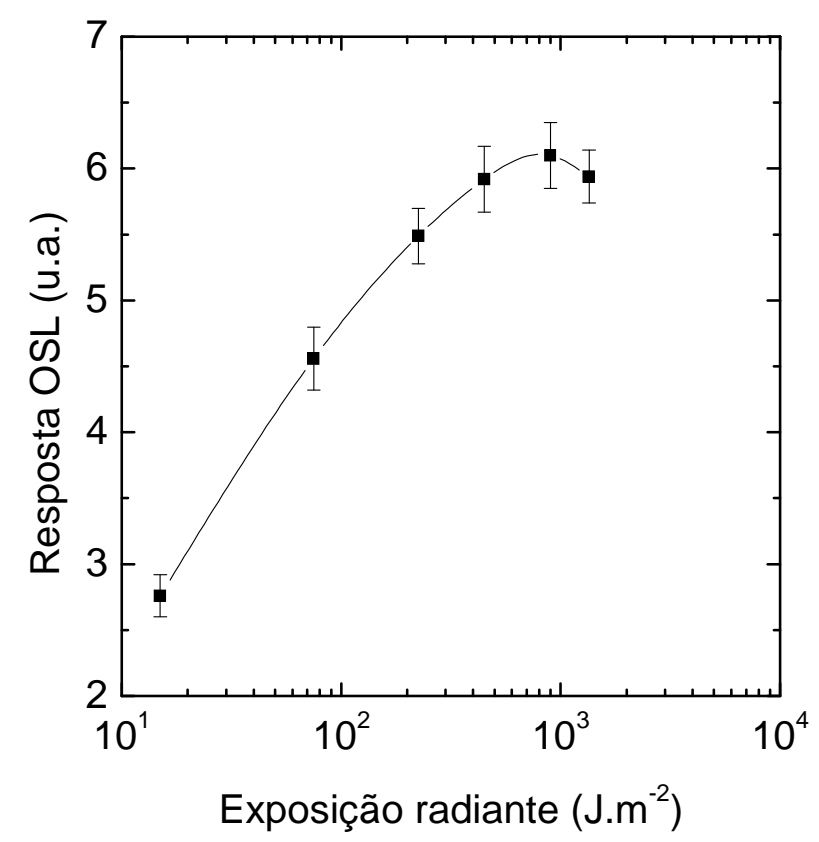

FIGURA 4.14 - Resposta OSL dos detectores $\mathrm{Al}_{2} \mathrm{O}_{3}: \mathrm{C}$ InLight para $\mathrm{O}$ comprimento de onda de $330 \mathrm{~nm}$ em função da exposição radiante.

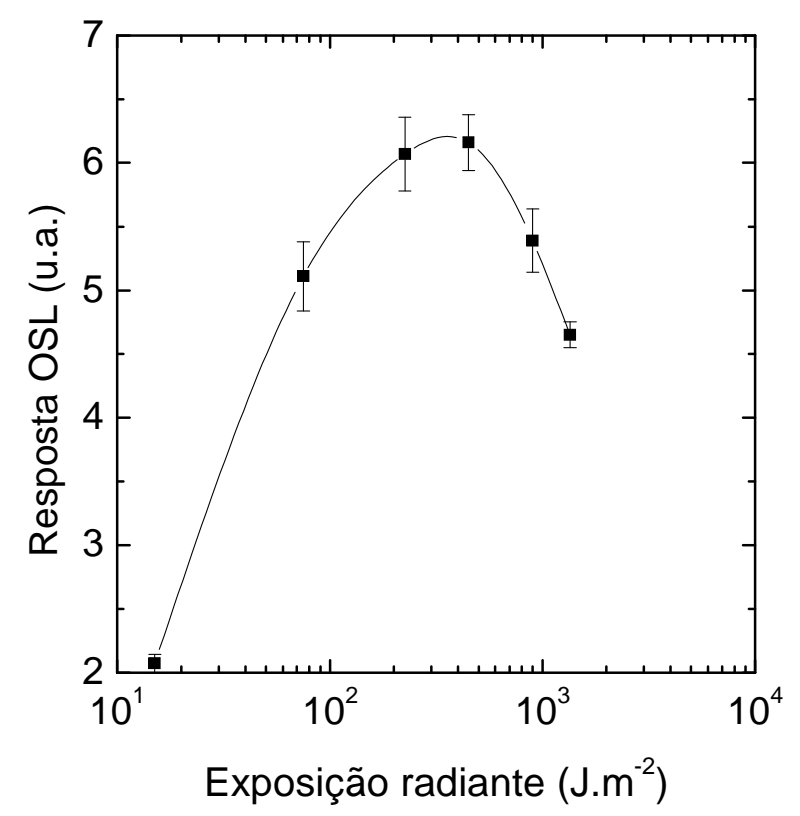

FIGURA 4.15 - Resposta OSL dos detectores $\mathrm{Al}_{2} \mathrm{O}_{3}: \mathrm{C}$ InLight para 0 comprimento de onda de $340 \mathrm{~nm}$ em função da exposição radiante. 
Pode-se observar nas FIG. 4.14 e 4.15 que as respostas OSL têm um aumento significativo para os intervalos de exposições radiantes entre $15 \mathrm{~J}^{-2} \mathrm{e}$ $450 \mathrm{~J} . \mathrm{m}^{-2}$ e entre $15 \mathrm{~J} . \mathrm{m}^{-2}$ e $225 \mathrm{~J} . \mathrm{m}^{-2}$, respectivamente.

Verifica-se que as energias radiantes incidentes nos detectores em função do tempo, provenientes da fonte artificial do sistema de UV, não foram suficientes para liberar as cargas armadilhadas e produzir um estímulo maior do sinal OSL, apresentando queda do sinal OSL para as exposições radiantes acima de $900 \mathrm{~J} . \mathrm{m}^{-2}$ e $450 \mathrm{~J} . \mathrm{m}^{-2}$ para os comprimentos de ondas de $330 \mathrm{~nm}$ e $340 \mathrm{~nm}$, respectivamente.

\subsubsection{Decaimento do sinal OSL}

$\mathrm{O}$ decaimento do sinal OSL dos detectores $\mathrm{Al}_{2} \mathrm{O}_{3}: \mathrm{C}$ InLight sem précondicionamentos foi verificado após iluminação UV. Primeiramente, foi realizado um estudo do decaimento do sinal OSL de quatro detectores expostos às irradiâncias entre $0,07 \mathrm{~W} \cdot \mathrm{m}^{-2}$ e $1,70 \mathrm{~W} . \mathrm{m}^{-2}$, com o comprimento de onda fixo em $330 \mathrm{~nm}$ e $10 \mathrm{~min}$ de tempo de iluminação UV.

A primeira leitura OSL foi feita imediatamente após cada iluminação UV; a partir daí foram tomadas as medidas OSL de cada detector a cada hora, num total de $5 \mathrm{~h}$.

A FIG. 4.16 mostra o decaimento do sinal OSL em função do tempo pós-iluminação UV da resposta OSL.

Na FIG. 4.17 observa-se que após uma hora houve um percentual de perda do sinal OSL acentuado de $75 \%$ a $85 \%$ e após 5 horas da exposição à RUV o percentual de perda do sinal OSL foi de $90 \%$ a $95 \%$, para o intervalo de irradiância estudada. 


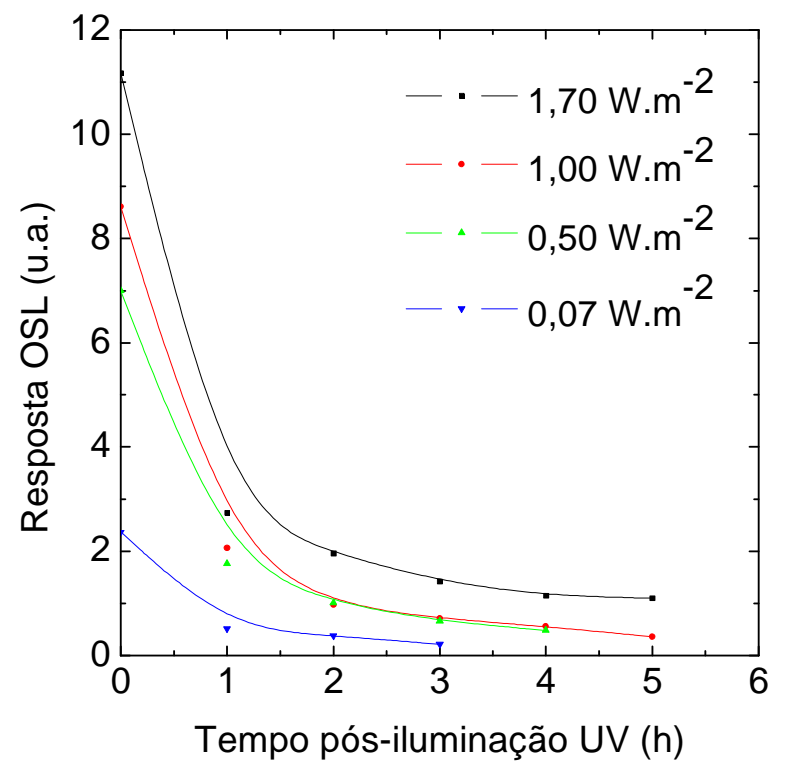

FIGURA 4.16 - Decaimento do sinal OSL dos detectores $\mathrm{Al}_{2} \mathrm{O}_{3}: \mathrm{C}$ InLight, expostos a diferentes irradiâncias (RUV), em função do tempo pós-iluminação UV.

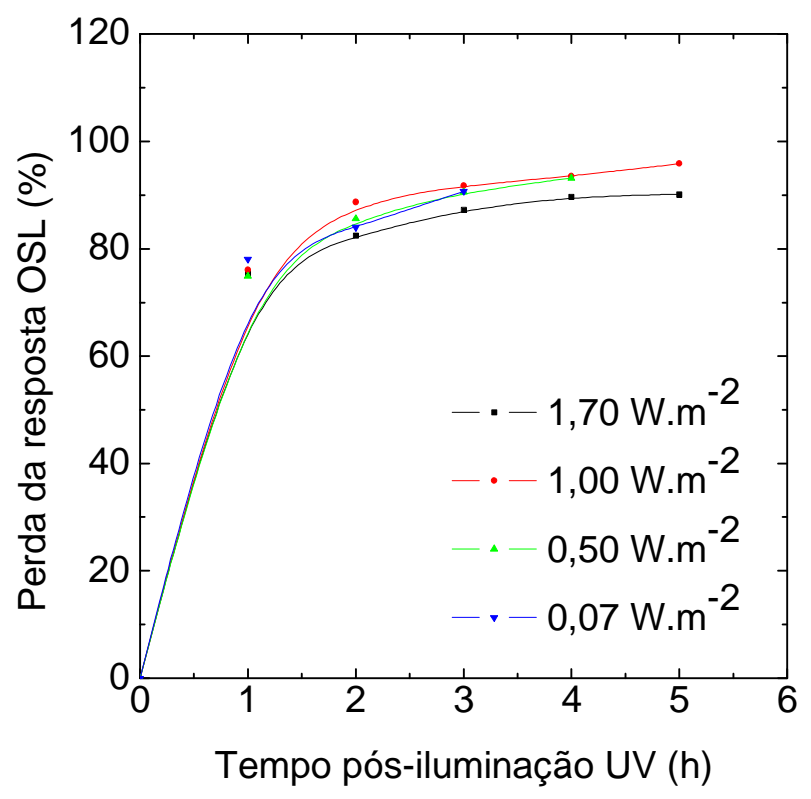

FIGURA 4.17 - Perda percentual do sinal OSL em função do tempo pósiluminação UV dos detectores $\mathrm{Al}_{2} \mathrm{O}_{3}: \mathrm{C}$ InLight, expostos a diferentes irradiâncias (RUV). 
Em seguida, foram fixados os parâmetros de comprimento de onda em $330 \mathrm{~nm}$ e irradiância em $0,50 \mathrm{~W} \cdot \mathrm{m}^{-2}$ e variou-se o tempo de iluminação UV, com a finalidade de verificar se um detector iluminado por mais tempo armazenaria o sinal OSL durante um intervalo de tempo mais longo.

Então, quatro lâminas foram iluminadas com RUV em tempos diferentes entre 10 e 60 min e as medidas OSL foram tomadas imediatamente após cada iluminação.

O decaimento do sinal OSL de cada detector foi monitorado em tempos subsequentes de 1 a 60 min.

As FIG. 4.18 e 4.19 mostram o decaimento do sinal OSL destes detectores em função do tempo pós-iluminação UV e o percentual de perda do sinal OSL, respectivamente. Nota-se que após $1 \mathrm{~min}$, a perda do sinal OSL variou de $16 \%$ a $28 \%$, e após 60 min a perda do sinal OSL variou de $80 \%$ a $88 \%$, para o intervalo de tempo de iluminação RUV estudado.

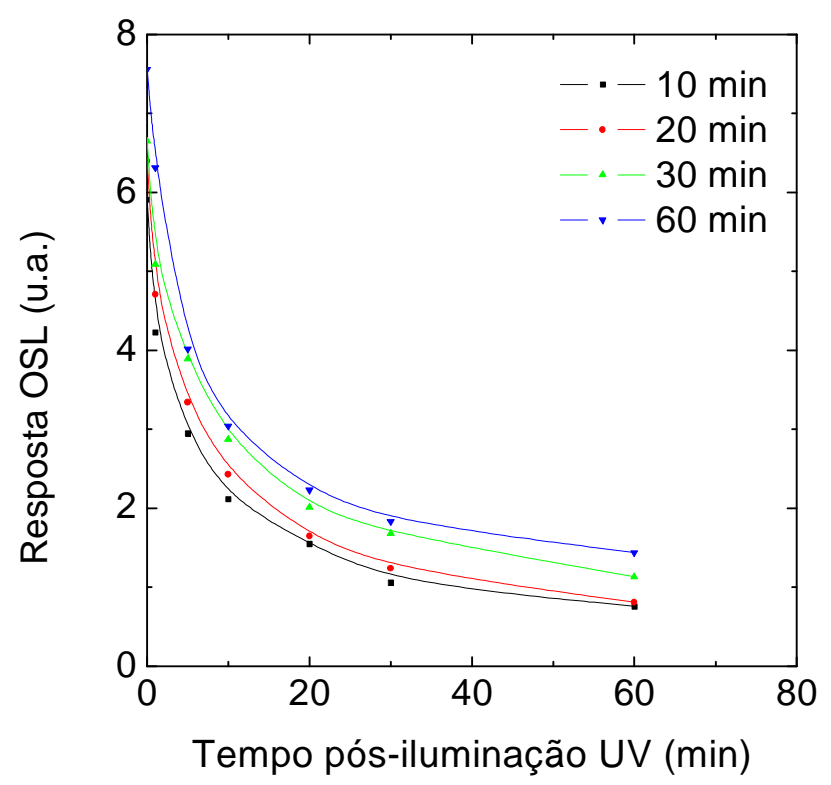

FIGURA 4.18 - Decaimento do sinal OSL em função do tempo pós-iluminação UV dos detectores $\mathrm{Al}_{2} \mathrm{O}_{3}: \mathrm{C}$ InLight, expostos a diferentes intervalos de tempo de iluminação UV. 


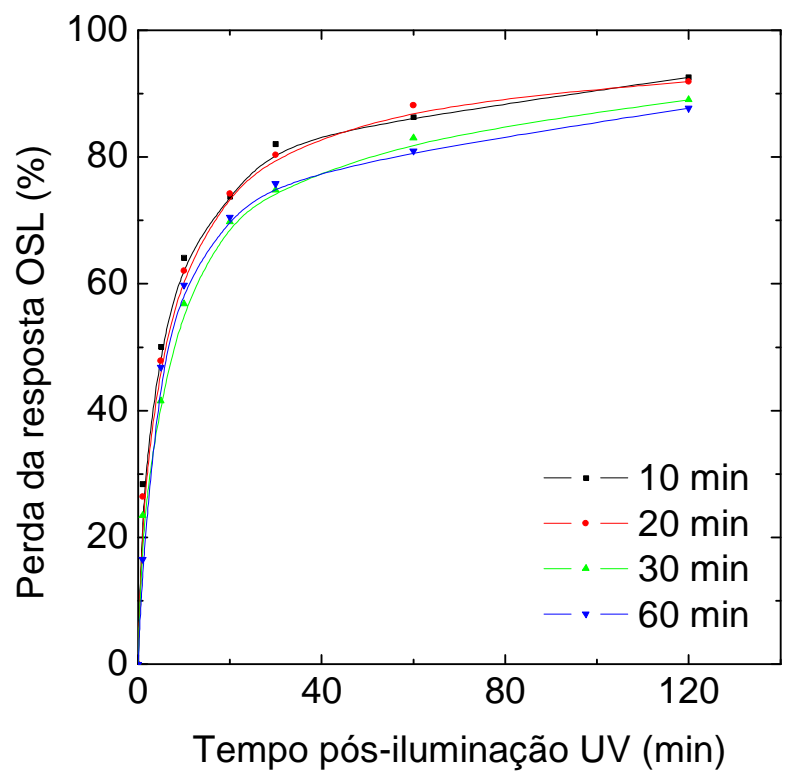

FIGURA 4.19 - Perda percentual do sinal OSL em função do tempo pósiluminação UV dos detectores $\mathrm{Al}_{2} \mathrm{O}_{3}: \mathrm{C}$ InLight, expostos a diferentes intervalos de tempo de iluminação UV.

Os detectores $\mathrm{Al}_{2} \mathrm{O}_{3}: \mathrm{C}$ InLight sem pré-condicionamentos expostos diretamente à fonte artificial de luz UV não conservaram o sinal OSL por muito tempo, apresentando um decaimento acentuado na primeira hora após a iluminação UV, independente dos intervalos de tempo de iluminação UV e dos valores de irradiância.

Os resultados indicam que dentro das condições e dos parâmetros estudados, os detectores $\mathrm{Al}_{2} \mathrm{O}_{3}: \mathrm{C}$ InLight em conjunto com o leitor OSL microStar System da Landauer, que é portátil e possui peso e dimensões que permitem o seu uso no local a ser avaliado, tornam-se uma boa opção para detectar emissões luminescentes estimuladas pela presença de RUV produzida por uma fonte artificial no local de trabalho ou em regiões próximas. 


\subsection{Caracterização dos detectores $\mathrm{Al}_{2} \mathrm{O}_{3}: \mathrm{C}$ utilizando a técnica PTOSL}

Os dados do item 4.5 mostraram que os detectores $\mathrm{Al}_{2} \mathrm{O}_{3}: \mathrm{C}$ InLight sem pré-condicionamentos e expostos diretamente à RUV não armazenam a resposta OSL por muito tempo. Então, passou-se a realizar o estudo com estes detectores utilizando a técnica PTOSL.

Os detectores $\mathrm{Al}_{2} \mathrm{O}_{3}: \mathrm{C}$ InLight Dot e InLight da Landauer não podem ser tratados termicamente por causa das camadas de poliéster que cobrem estes materiais.

Portanto, para a prática da PTOSL, ao invés de exposição a altas temperaturas, os detectores foram tratados opticamente com luz fluorescente na caixa de luz descrita no item 3.6, com o intuito de esvaziar as armadilhas rasas após a pré-irradiação.

Os valores apresentados nas figuras deste item representam os valores médios e os desvios padrões de 10 leituras OSL consecutivas em cada detector, realizadas imediatamente após as irradiações com fonte de ${ }^{60} \mathrm{Co}$, os tratamentos ópticos e as iluminações com fonte de RUV (k=1, $\sigma=1)$.

A manipulação dos invólucros e das lâminas foi realizada em ambiente escuro para evitar interferência da luz visível.

Os parâmetros pré-dose (para sensibilização destes detectores), tempo de tratamento óptico e tempo de iluminação UV foram, então, determinados para o estímulo da PTOSL.

\subsubsection{Sensibilização dos detectores $\mathrm{Al}_{2} \mathrm{O}_{3}: \mathrm{C}$}

A sensibilização dos detectores $\mathrm{Al}_{2} \mathrm{O}_{3}: \mathrm{C}$ InLight foi feita com pré-doses de $1,3,5$ e 10 Gy de fonte de ${ }^{60} \mathrm{Co}$. As irradiações sempre foram realizadas com 
os detectores localizados entre duas placas de Lucite, para garantir as condições de equilíbrio eletrônico.

As lâminas destes detectores foram iluminadas na caixa de luz a 26.000 lux no intervalo de 1 a 150 min para verificar a curva de decaimento óptico das doses em função do tempo de exposição à luz.

As FIG. 4.20 e 4.21 mostram as curvas de decaimento do sinal OSL dos detectores irradiados com diferentes doses absorvidas em função do tempo de iluminação a 26.000 lux e a perda percentual do sinal OSL em função do tempo de iluminação a 26.000 lux, respectivamente.

A perda percentual do sinal OSL em 30 min de iluminação a 26.000 lux foi de aproximadamente $99 \%$ para todas as doses estudadas.

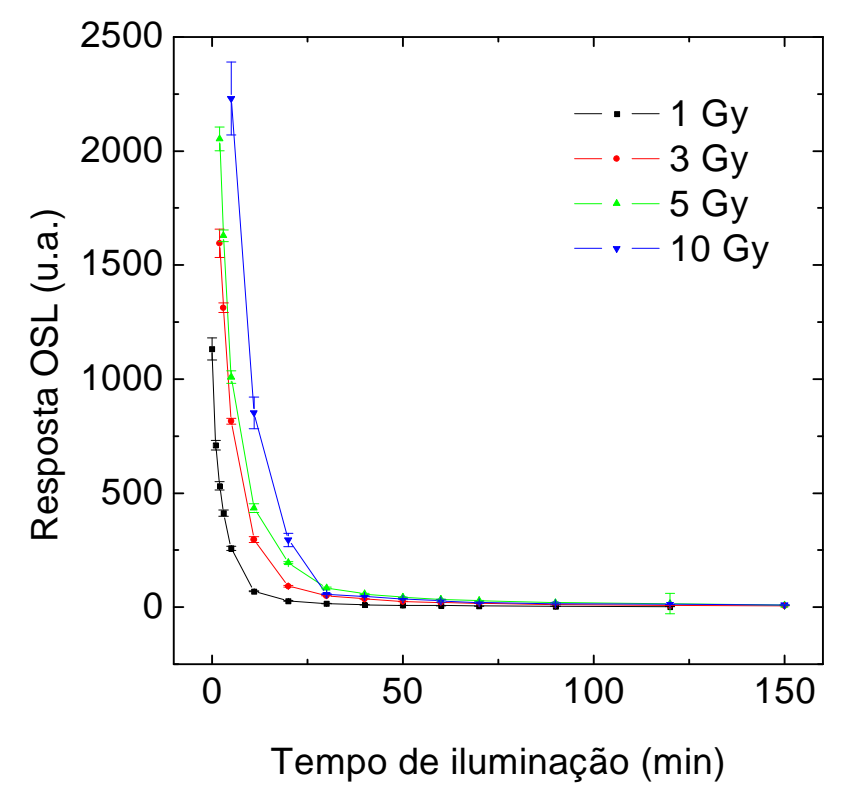

FIGURA 4.20 - Curva de decaimento óptico dos detectores $\mathrm{Al}_{2} \mathrm{O}_{3}: \mathrm{C}$ InLight em função do tempo de iluminação a 26.000 lux, para diferentes doses absorvidas de pré-irradiação $\left({ }^{60} \mathrm{Co}\right)$. 


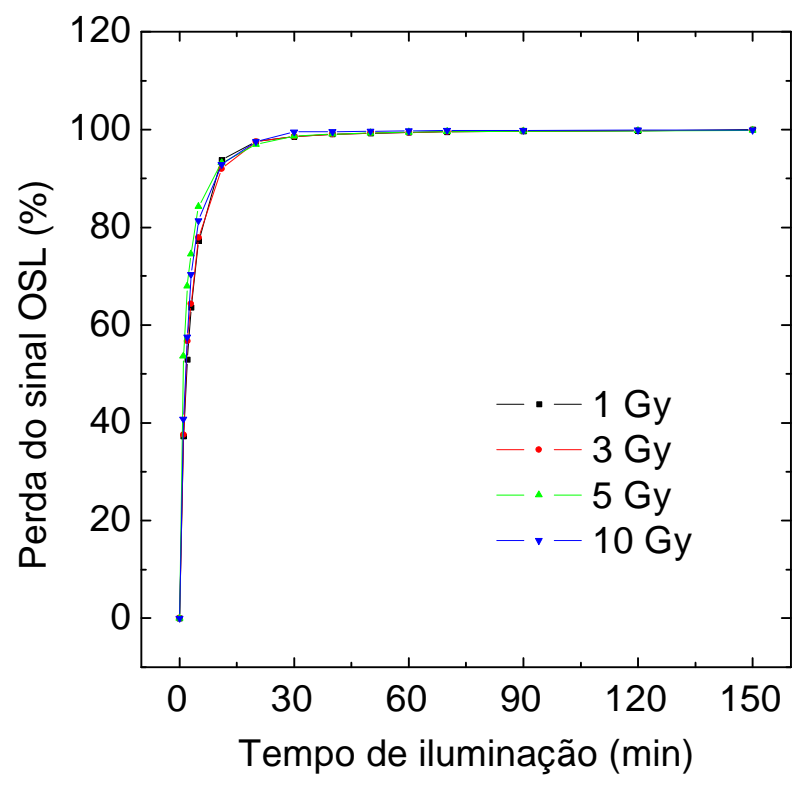

FIGURA 4.21 - Perda percentual do sinal OSL dos detectores $\mathrm{Al}_{2} \mathrm{O}_{3}: \mathrm{C}$ InLigth em função das doses de iluminação a 26.000 lux, para diferentes doses absorvidas de pré-irradiação $\left({ }^{60} \mathrm{Co}\right)$.

A dose de 1 Gy foi escolhida para sensibilizar as amostras e otimizar o estudo da PTOSL, uma vez que para as doses mais altas a perda do sinal OSL é mais lenta a partir de 30 min e exigem tempos de exposição à luz (26.000 lux) mais prolongados para "zerar" totalmente os detectores. O detector irradiado com dose de 10 Gy após 24 horas de iluminação a 26.000 lux ainda apresentava valor residual sendo necessário mais de $72 \mathrm{~h}$ de iluminação na caixa de luz para "zerá-lo" totalmente.

\subsubsection{Tratamento óptico e o tempo de iluminação UV}

Nesta seção será apresentado um estudo sobre o intervalo de tempo mais adequado para o tratamento óptico e o tempo de iluminação UV dos detectores $\mathrm{Al}_{2} \mathrm{O}_{3}: \mathrm{C}$ InLight pré-irradiados com dose de $1 \mathrm{~Gy}\left({ }^{60} \mathrm{Co}\right)$.

A caixa de luz descrita no item 3.6 foi usada para estabelecer qual o melhor intervalo de tempo de tratamento óptico a 26.000 lux. 
Primeiramente, um conjunto de seis detectores $\mathrm{Al}_{2} \mathrm{O}_{3}: \mathrm{C}$ InLight foi irradiado com dose de 1 Gy de ${ }^{60} \mathrm{Co}$. A seguir, as lâminas foram tratadas opticamente com 26.000 lux durante intervalos de tempo que variaram de $10 \mathrm{a}$ 120 min. Em seguida, dentro do sistema de radiação UV as lâminas foram iluminadas em tempos subsequentes no intervalo de 5 a $60 \mathrm{~min}$. $O$ comprimento de onda foi fixado em $307 \mathrm{~nm}$ e a irradiância foi mantida constante em $0,25 \mathrm{~W} \cdot \mathrm{m}^{-2}$. Esses parâmetros foram baseados no estudo de Colyott e col. [1999], sendo que o valor da irradiância aqui adotado foi maior, uma vez que o sistema de iluminação UV do laboratório não permitiu alcançar valores mais baixos.

As FIG. 4.22 e 4.23 mostram a resposta PTOSL dos detectores em função do tempo de tratamento óptico a 26.000 lux de 10 e $20 \mathrm{~min}$, respectivamente, e do tempo de iluminação UV. Observa-se que os detectores tratados opticamente durante $10 \mathrm{~min}$ apresentaram uma ativação do sinal OSL nos primeiros 5 min de iluminação UV e depois ocorreu o decaimento do sinal (FIG. 4.22). Na FIG. 4.23 nota-se o mesmo comportamento aos $5 \mathrm{~min}$ de iluminação UV para o detector tratado opticamente durante $20 \mathrm{~min}$, mas a partir de $30 \mathrm{~min}$ ocorreu uma elevação do sinal OSL. Os resultados dos tratamentos ópticos de 10 min e 20 min não demonstraram ser boas opções de escolha em razão das oscilações do sinal OSL e por apresentaram desvios padrões das medições muito elevados.

As FIG. 4.24, 4.25, 4.26 e 4.27 mostram a resposta OSL dos detectores tratados opticamente a 26.000 lux durante os intervalos de tempo de 30, 60, 90 e $120 \mathrm{~min}$, respectivamente, e iluminados com RUV durante 5 a $60 \mathrm{~min}$. Nota-se um comportamento similar nas respostas OSL para todos estes intervalos de tempo de tratamento óptico e uma tendência à saturação da resposta OSL das amostras a partir de 60 min de iluminação UV, independente do tempo de tratamento óptico prévio. 


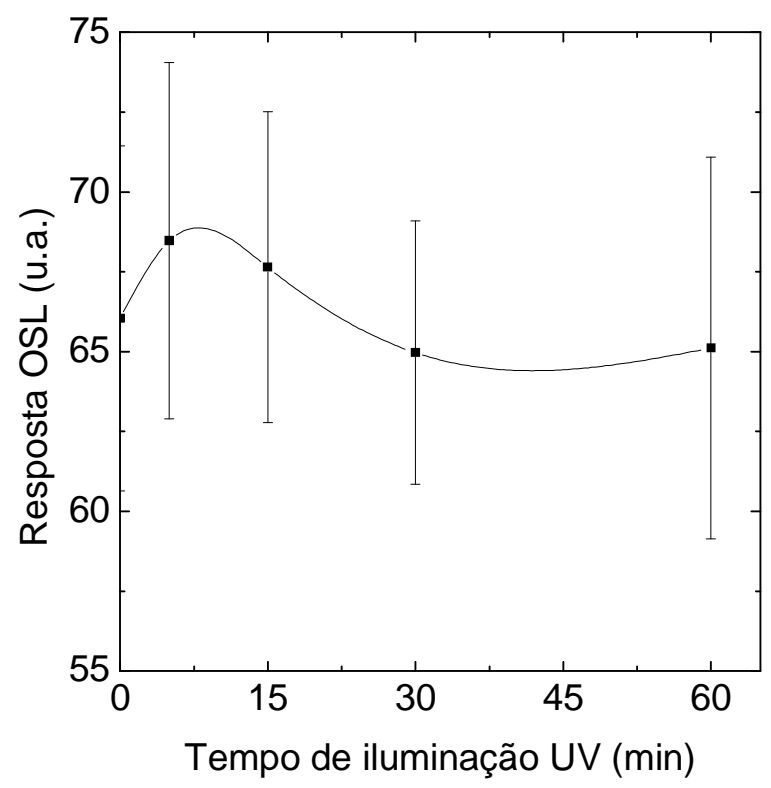

FIGURA 4.22 - Resposta OSL dos detectores $\mathrm{Al}_{2} \mathrm{O}_{3}: \mathrm{C}$ InLight tratados opticamente durante 10 min em função do tempo de iluminação UV (26.000 lux).

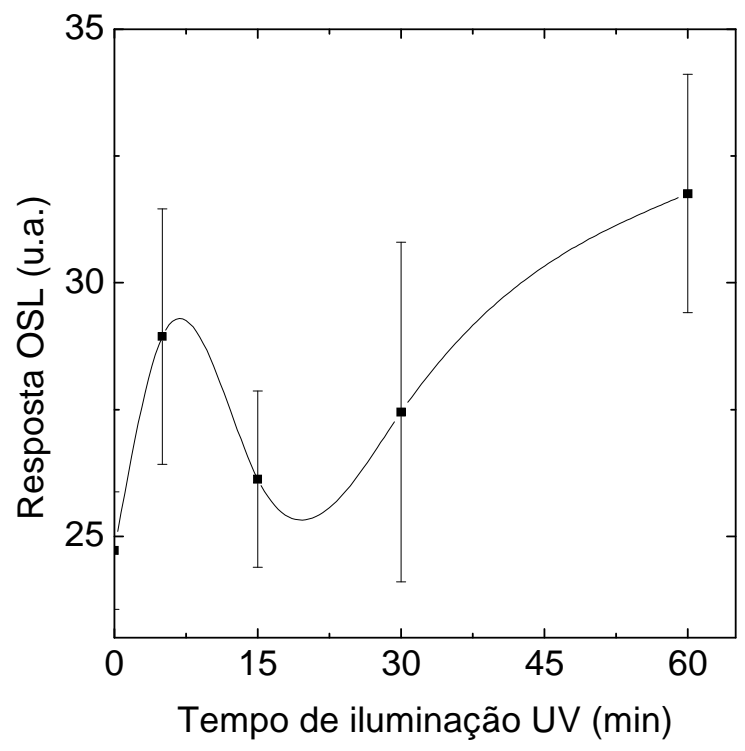

FIGURA 4.23 - Resposta OSL dos detectores $\mathrm{Al}_{2} \mathrm{O}_{3}: \mathrm{C}$ InLight tratados opticamente durante $20 \mathrm{~min}$ em função do tempo de iluminação UV (26.000 lux). 


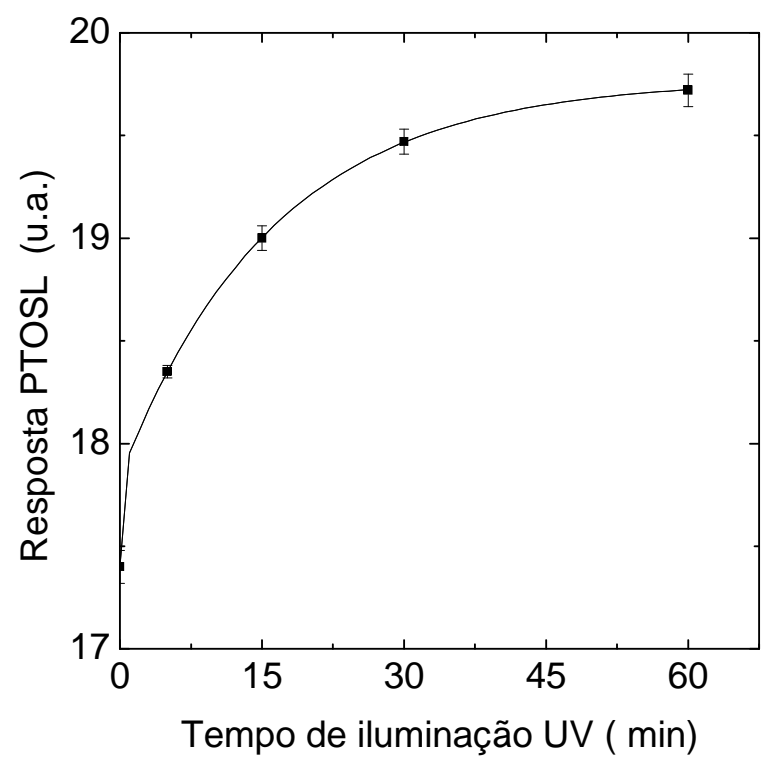

FIGURA 4.24 - Resposta PTOSL dos detectores $\mathrm{Al}_{2} \mathrm{O}_{3}: \mathrm{C}$ InLight tratados opticamente durante $30 \mathrm{~min}$ em função do tempo de iluminação UV (26.000 lux).

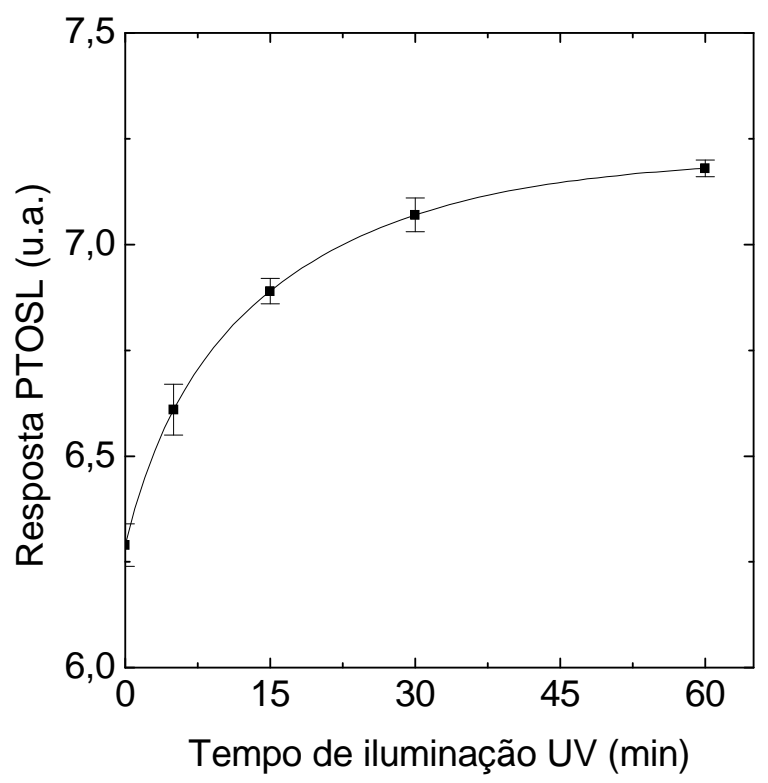

FIGURA 4.25 - Resposta PTOSL dos detectores $\mathrm{Al}_{2} \mathrm{O}_{3}: \mathrm{C}$ InLight tratados opticamente durante $60 \mathrm{~min}$ em função do tempo de iluminação UV (26.000 lux). 


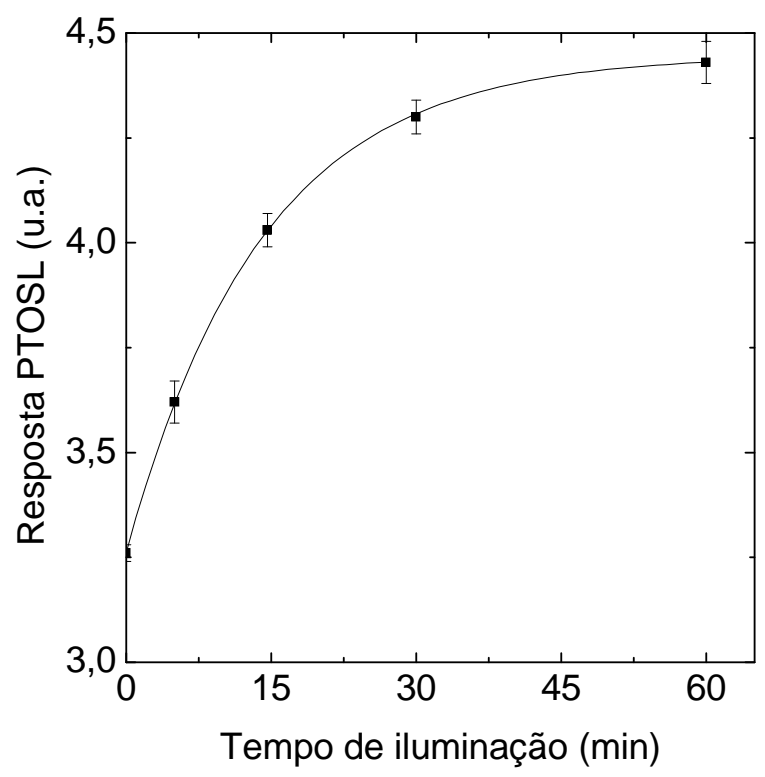

FIGURA 4.26 - Resposta PTOSL dos detectores $\mathrm{Al}_{2} \mathrm{O}_{3}: \mathrm{C}$ InLight tratados opticamente durante $90 \mathrm{~min}$ em função do tempo de iluminação UV (26.000 lux).

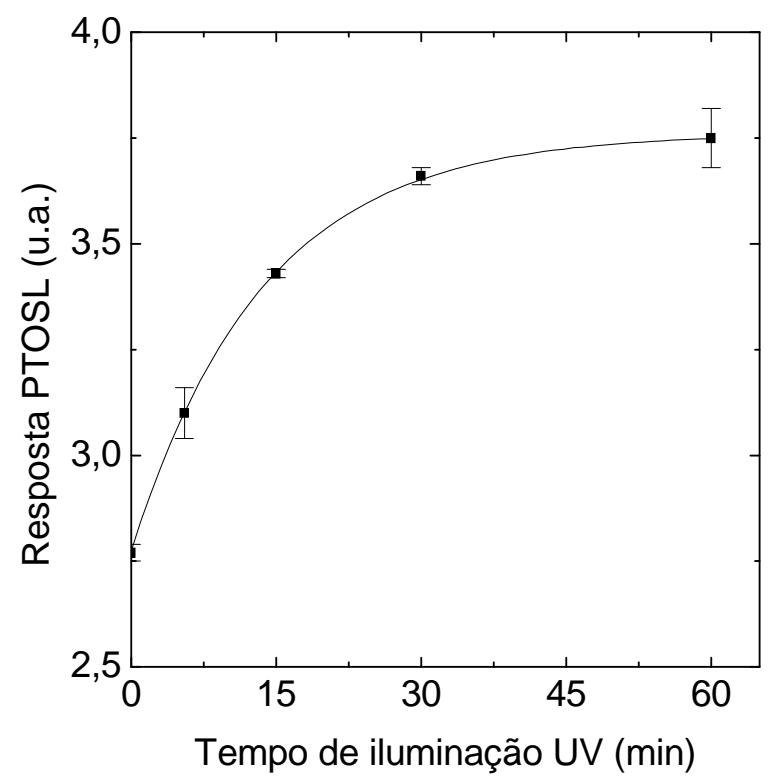

FIGURA 4.27 - Resposta PTOSL dos detectores $\mathrm{Al}_{2} \mathrm{O}_{3}: \mathrm{C}$ InLight tratados opticamente durante $120 \mathrm{~min}$ em função do tempo de iluminação UV (26.000 lux). 
A TAB 4.2 mostra a resposta PTOSL dos detectores após 30 e $60 \mathrm{~min}$ de iluminação UV para os intervalos de tempo de tratamento óptico de 30, 60, 90 e $120 \mathrm{~min}$.

TABELA 4.2 - Resposta OSL e PTOSL dos detectores $\mathrm{Al}_{2} \mathrm{O}_{3}: \mathrm{C}$ InLight em função do tempo de tratamento óptico e do tempo de iluminação UV.

\begin{tabular}{ccc}
\hline $\begin{array}{c}\text { Tratamento óptico } \\
\text { a 26.000 lux } \\
\text { (min) }\end{array}$ & $\begin{array}{c}\text { Resposta PTOSL } \\
\text { após 30 min } \\
\text { de iluminação UV } \\
\text { (u.a) }\end{array}$ & $\begin{array}{c}\text { Resposta PTOSL } \\
\text { após 60 min } \\
\text { de iluminação UV } \\
\text { (u.a) }\end{array}$ \\
\hline $\mathbf{3 0}$ & $19,47 \pm 0,06$ & $19,72 \pm 0,08$ \\
\hline $\mathbf{6 0}$ & $7,07 \pm 0,04$ & $7,18 \pm 0,02$ \\
\hline $\mathbf{9 0}$ & $4,34 \pm 0,04$ & $4,43 \pm 0,05$ \\
\hline $\mathbf{1 2 0}$ & $3,66 \pm 0,02$ & $3,75 \pm 0,07$ \\
\hline
\end{tabular}

Tendo em vista que o ganho de resposta PTOSL de $30 \mathrm{~min}$ para 60 min de iluminação UV, para todos os tempos de tratamentos ópticos estudados, foi de apenas 1,5\%, estabeleceu-se o tempo de tratamento óptico de 30 min para esvaziamento das armadilhas rasas e o tempo de $30 \mathrm{~min}$ de iluminação UV para o estímulo da PTOSL, visando otimizar o procedimento de utilização destes detectores neste trabalho.

Fixados os parâmetros para o pré-condicionamento dos detectores $\mathrm{Al}_{2} \mathrm{O}_{3}: \mathrm{C}$ InLight, pré-dose de 1Gy, tratamento óptico a 26.000 lux durante $30 \mathrm{~min}$ e tempo de iluminação UV de $30 \mathrm{~min}$, estudou-se a resposta PTOSL destes detectores em função do comprimento de onda, do tempo de iluminação UV, da irradiância, da exposição radiante e da dependência angular em relação ao feixe de incidência da RUV.

Para minimizar as incertezas medidas foram determinados fatores de correção da resposta OSL para cada detector $\mathrm{Al}_{2} \mathrm{O}_{3}: \mathrm{C}$ InLight após os 
tratamentos ópticos. Estes fatores foram aplicados na correção das respostas OSL dos detectores após exposição à RUV.

A determinação dos fatores de correção $\left(f_{c}\right)$ consistiu, primeiramente, em calcular a média das respostas OSL de cada detector $\left(M_{d}\right)$ após o tratamento óptico (30 min a 26.000 lux), e, em seguida, calcular a média total dos valores médios das respostas OSL $\left(M_{t}\right)$ dos detectores tratados opticamente $(\mathrm{k}=1, \sigma=1)$, sendo:

$$
\mathrm{f}_{\mathrm{C}}=M_{t} / M_{d}
$$

O fator de correção para cada detector foi recalculado sempre que um lote "zerado" passava novamente pelo pré-condicionamento inicial (dose de 1 Gy e tratamento óptico a 26.000 lux durante $30 \mathrm{~min}$ ).

\subsubsection{Reprodutibilidade da resposta PTOSL}

A reprodutibilidade da resposta PTOSL dos detectores $\mathrm{Al}_{2} \mathrm{O}_{3}: \mathrm{C}$ InLight foi determinada em um conjunto de dez amostras irradiadas com dose de 1 Gy de fonte de radiação gama $\left({ }^{60} \mathrm{Co}\right)$, tratadas opticamente durante 30 min a 26.000 lux e iluminadas durante 30 min com RUV. O comprimento de onda foi fixado de $330 \mathrm{~nm}$ e irradiância mantida constante em $0,25 \mathrm{~W} \cdot \mathrm{m}^{-2}$. Esse procedimento foi repetido cinco vezes consecutivas $(k=1, \sigma=1)$. $O$ desvio padrão percentual foi de $5,4 \%$, demonstrando uma boa reprodutibilidade da resposta PTOSL destes detectores.

\subsubsection{PTOSL e o comprimento de onda}

A resposta PTOSL dos detectores $\mathrm{Al}_{2} \mathrm{O}_{3}: \mathrm{C}$ InLight foi estudada em função do comprimento de onda na faixa de $280 \mathrm{~nm}$ a $400 \mathrm{~nm}$. Primeiramente, onze detectores foram "zerados", depois irradiados com dose de 1 Gy de fonte de radiação gama $\left({ }^{60} \mathrm{Co}\right)$ e tratados opticamente a 26.000 lux durante $30 \mathrm{~min}$. Em seguida, cada detector foi exposto a um comprimento de onda entre $290 \mathrm{~nm}$ e $390 \mathrm{~nm}$, durante $30 \mathrm{~min}$ de iluminação UV e irradiância constante de $0,25 \mathrm{~W} / \mathrm{m}^{2}$. 
As medidas foram tomadas a cada $10 \mathrm{~nm}$. Os resultados são as médias e os desvios padrões de 10 leituras OSL de cada detector $(\sigma=1, k=1)$.

Os detectores apresentaram uma sensibilidade alta para 0 comprimento de onda de $330 \mathrm{~m}$ (FIG. 4.28). Este mesmo resultado foi obtido para os detectores sem pré-condicionamentos iluminados diretamente com UV (item 4.5.1).

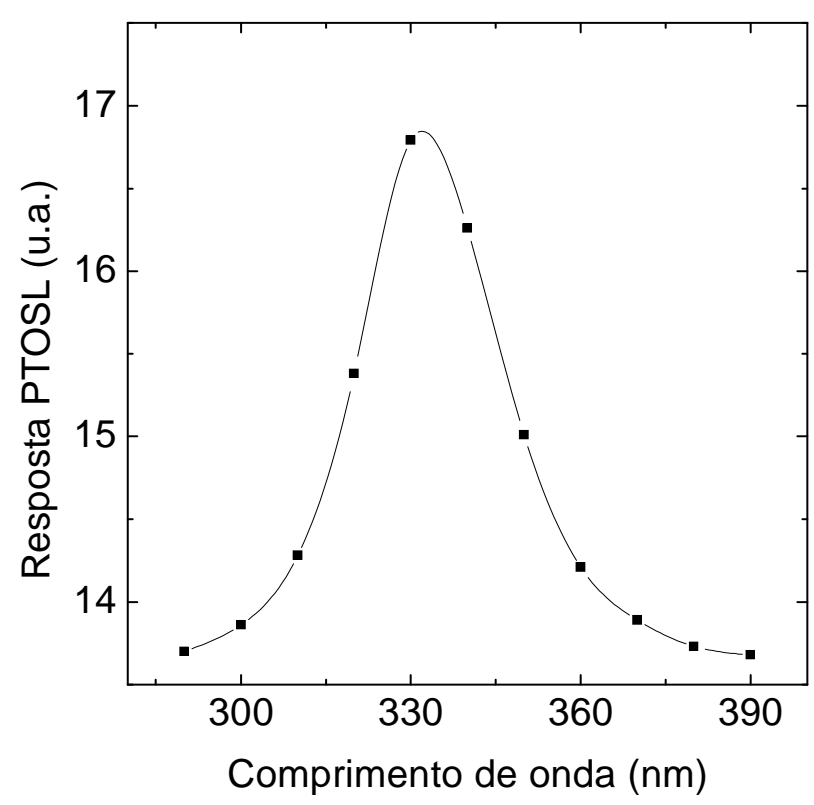

FIGURA 4.28 - Resposta PTOSL dos detectores $\mathrm{Al}_{2} \mathrm{O}_{3}: \mathrm{C}$ InLight em função do comprimento de onda da RUV. A incerteza máxima das medições foi de $5,2 \%$.

\subsubsection{PTOSL e o tempo de iluminação UV}

Um conjunto de quatro detectores $\mathrm{Al}_{2} \mathrm{O}_{3}: \mathrm{C}$ InLight foi utilizado para 0 estudo da resposta PTOSL em função do tempo de iluminação UV.

Primeiramente, os detectores foram irradiados com $1 \mathrm{~Gy}$ de ${ }^{60} \mathrm{Co}$ e as lâminas foram tratadas opticamente com 26.000 lux durante 30 min. As lâminas destes detectores foram iluminadas com UV, em tempos pré-determinados para 
cada uma, que variaram de 5 a 60 min. Os parâmetros comprimento de onda e irradiância foram fixados em $330 \mathrm{~nm}$ e $0,25 \mathrm{~W} . \mathrm{m}^{-2}$, respectivamente. Ao final de cada tempo de iluminação UV, foram tomadas as medidas OSL.

Observa-se na FIG. 4.29 que houve um aumento significativo da resposta PTOSL até 30 min de iluminação UV e uma tendência à saturação a partir de 60 min de iluminação UV.

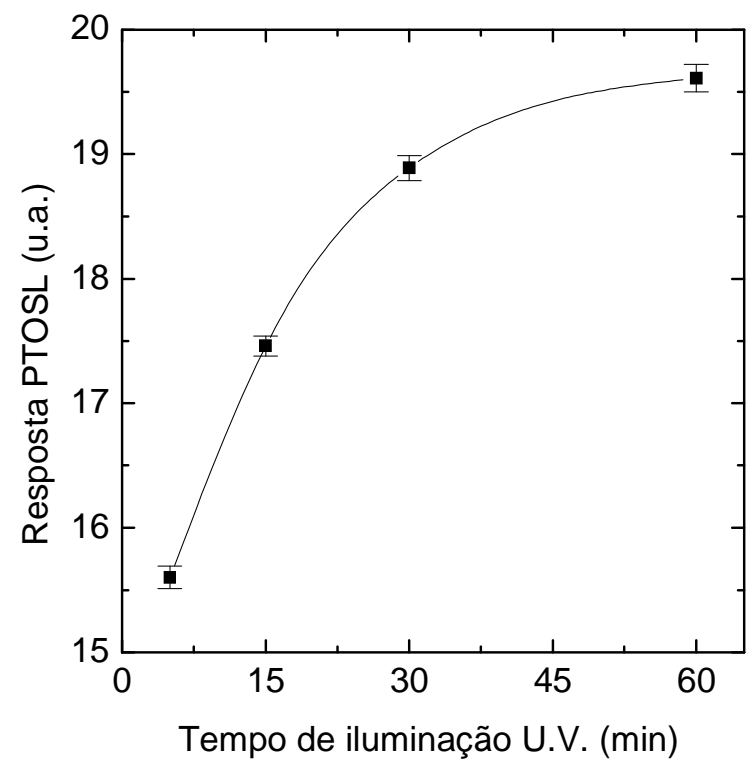

FIGURA 4.29 - Resposta PTOSL dos detectores $\mathrm{Al}_{2} \mathrm{O}_{3}: \mathrm{C}$ InLight em função do tempo de iluminação UV, para o comprimento de onda de $330 \mathrm{~nm}$.

\subsubsection{PTOSL e a irradiância}

Um conjunto de seis detectores $\mathrm{Al}_{2} \mathrm{O}_{3}: \mathrm{C}$ InLight foi estudado em função da irradiância da fonte artificial de UV. Depois de "zerados", irradiados com 1 Gy de ${ }^{60} \mathrm{Co}$ e tratados opticamente a 26.000 lux durante $30 \mathrm{~min}$, as lâminas foram iluminadas com RUV.

O comprimento de onda e o tempo de iluminação UV foram fixados em $330 \mathrm{~nm}$ e $30 \mathrm{~min}$, respectivamente. O intervalo de irradiância variou de $0,09 \mathrm{~W} \cdot \mathrm{m}^{-2}$ a 1,36 W. $\mathrm{m}^{-2}$. As medidas PTOSL foram tomadas ao final de cada iluminação UV. 
Nota-se na FIG. 4.30 que ocorreu um aumento linear da resposta PTOSL até $0,37 \mathrm{~W} \cdot \mathrm{m}^{-2}$ e uma tendência à saturação para irradiâncias acima de 0,80 W.m. ${ }^{-2}$.

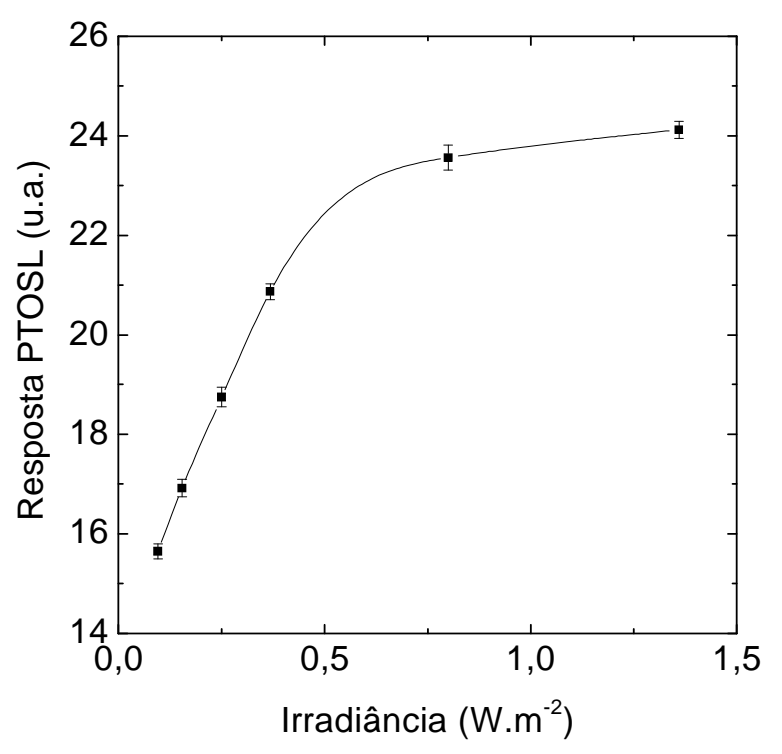

FIGURA 4.30 - Resposta PTOSL dos detectores $\mathrm{Al}_{2} \mathrm{O}_{3}: \mathrm{C}$ InLight em função da irradiância da fonte do sistema de RUV.

\subsubsection{PTOSL e a exposição radiante}

Uma outra característica estudada foi a resposta PTOSL dos detectores $\mathrm{Al}_{2} \mathrm{O}_{3}: \mathrm{C}$ InLight em função da exposição radiante da fonte artificial de RUV para os comprimentos de onda de $330 \mathrm{~nm}$ e $340 \mathrm{~nm}$.

As lâminas de sete detectores que passaram pelo pré-condicionamento inicial (dose de 1 Gy de ${ }^{60} \mathrm{Co}$ e tratamento óptico a 26.000 lux durante $30 \mathrm{~min}$ ) foram submetidas à exposição radiante da fonte de iluminação UV no intervalo de $7,5 \mathrm{~J} . \mathrm{m}^{-2}$ a $1350 \mathrm{~J} . \mathrm{m}^{-2}$. O comprimento de onda foi fixado em $330 \mathrm{~nm} \mathrm{e}$ manteve-se a irradiância constante em $0,25 \mathrm{~W} \cdot \mathrm{m}^{-2}$.

A FIG. 4.31 mostra a curva de calibração dos detectores $\mathrm{Al}_{2} \mathrm{O}_{3}: \mathrm{C}$ InLight pré-condicionados para o comprimento de onda de $330 \mathrm{~nm}$ em função da exposição radiante. Verifica-se que há um aumento significativo do sinal 
OSL para o intervalo de exposição radiante estudada e a curva apresenta uma sub-linearidade a partir de $75 \mathrm{~J} . \mathrm{m}^{-2}$.

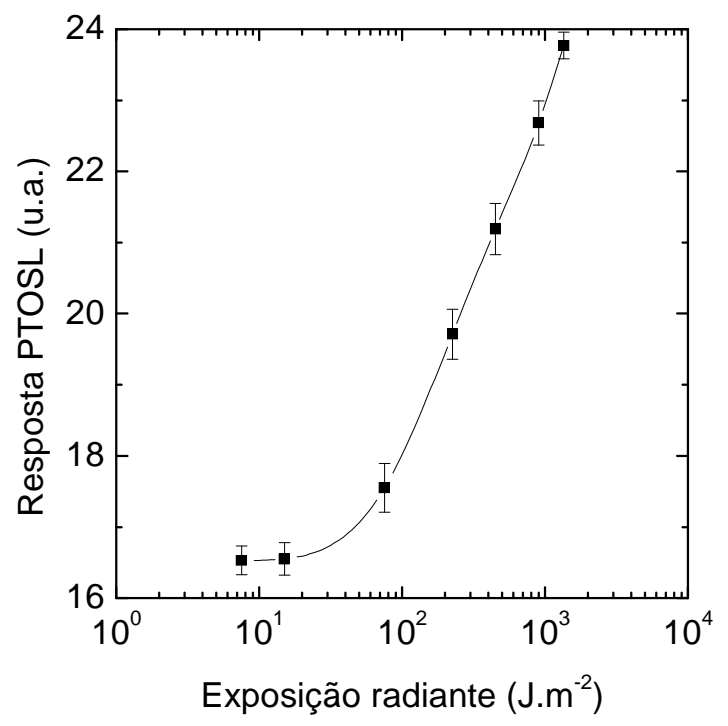

FIGURA 4.31 - Curva de calibração dos detectores $\mathrm{Al}_{2} \mathrm{O}_{3}: \mathrm{C}$ InLight, précondicionados, para o comprimento de onda de $330 \mathrm{~nm}$ em função da exposição radiante.

Um outro conjunto de lâminas de oito detectores pré-condicionados foram submetidas à exposição radiante no intervalo de $7,5 \mathrm{~J} \cdot \mathrm{m}^{-2}$ a $1.800 \mathrm{~J} \cdot \mathrm{m}^{-2} .0$ comprimento de onda foi fixado em $340 \mathrm{~nm}$ e manteve-se a irradiância constante em $0,25 \mathrm{~W} \cdot \mathrm{m}^{-2}$.

Na FIG. 4.32 tem-se a curva de calibração dos detectores $\mathrm{Al}_{2} \mathrm{O}_{3}: \mathrm{C}$ InLight pré-condicionados para o comprimento de onda de $340 \mathrm{~nm}$ em função da exposição radiante. Verifica-se que neste caso ocorreu um aumento significativo do sinal OSL até $900 \mathrm{~J} . \mathrm{m}^{-2}$ e depois uma queda da resposta PTOSL.

As respostas PTOSL dos detectores $\mathrm{Al}_{2} \mathrm{O}_{3}: \mathrm{C}$ InLight, précondicionados, mostram um intervalo de sub-linearidade mais amplo de exposição radiante entre $75 \mathrm{~J} . \mathrm{m}^{-2}$ e $1.350 \mathrm{~J} \cdot \mathrm{m}^{-2}$ para o comprimento de onda de 
$330 \mathrm{~nm}$, e para o comprimento de onda de $340 \mathrm{~nm}$ mostra uma resposta PTOSL sub-linear num intervalo de exposição radiante menor, entre $75 \mathrm{~J} . \mathrm{m}^{-2}$ e $450 \mathrm{~J} . \mathrm{m}^{-2}$.

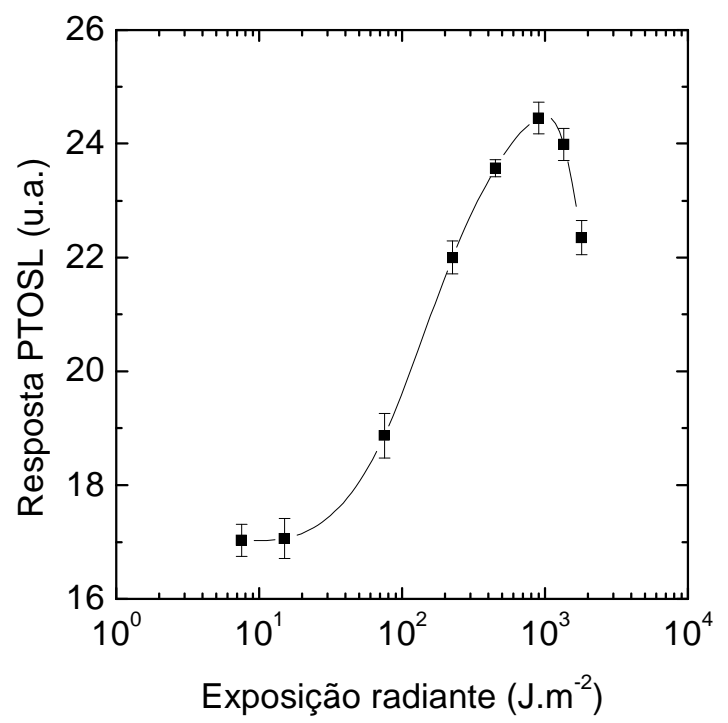

FIGURA 4.32 - Curva de calibração dos detectores $\mathrm{Al}_{2} \mathrm{O}_{3}: \mathrm{C}$ InLight, précondicionados, para o comprimento de onda de $340 \mathrm{~nm}$ em função da exposição radiante.

Comparando os resultados das FIG. 4.31 e 4.32 com os resultados das FIG. 4.14 e 4.15 do item 4.5.4, observa-se que as curvas de calibração dos detectores $\mathrm{Al}_{2} \mathrm{O}_{3}: \mathrm{C}$ InLight pré-condicionados em relação à exposição radiante, apresentaram resultados mais satisfatórios para a dosimetria UV em função dos intervalos de sub-linearidade das respostas PTOSL. Este fato não ocorreu com as respostas OSL em relação à exposição radiante dos detectores $\mathrm{Al}_{2} \mathrm{O}_{3}: \mathrm{C}$ InLight sem pré-condicionamento.

Tendo em vista estes resultados, as curvas das FIG. 4.31 e 4.32 foram usadas na relação com as respostas PTOSL dos detectores $\mathrm{Al}_{2} \mathrm{O}_{3}: \mathrm{C}$ InLight pré-condicionados expostos à RUV artificial nas aplicações práticas descritas nos itens 4.7.2.2 e 4.7.2.3. 


\subsubsection{PTOSL e a dependência angular}

Um lote de vinte detectores $\mathrm{Al}_{2} \mathrm{O}_{3}: \mathrm{C}$ InLight foi utilizado para estudo da resposta PTOSL em função do ângulo de incidência do feixe de iluminação UV.

Primeiramente, os detectores "zerados" passaram pelo précondicionamento inicial e em seguida, as lâminas foram iluminadas com UV, em função do ângulo de incidência do feixe de RUV. Para a determinação do ângulo de incidência, a base com o suporte de amostra foi posicionada sobre um transferidor e rotacionado em torno do seu eixo central. Os ângulos variaram de $-90^{\circ}$ a $90^{\circ}$.

O ângulo de incidência do feixe de iluminação UV de 0ำ refere-se à posição de incidência máxima de RUV, isto é, a amostra fica posicionada de frente para a fonte de iluminação do sistema de RUV.

As medidas PTOSL foram realizadas a cada $10^{\circ}$ e as lâminas foram submetidos a 30 min de iluminação UV. O comprimento de onda foi fixado em $330 \mathrm{~nm}$ e manteve-se a irradiância constante em $0,25 \mathrm{~W} \cdot \mathrm{m}^{-2}$.

A FIG. 4.33 mostra a resposta PTOSL em função do ângulo de incidência da iluminação UV. Observa-se que para os intervalos de $0^{\circ}$ a $60^{\circ} \mathrm{e}$ de $0^{\circ}$ a $-60^{\circ}$ a resposta PTOSL apresenta uma perda percentual de apenas $18,1 \%$.

Estes intervalos de resposta PTOSL em função do ângulo incidência do feixe de UV encontram-se próximos aos resultados do estudo realizado por Colyott e col.[1999], no qual apresentaram resposta angular para intervalo entre 0 a 75 de um dosímetro de $\mathrm{Al}_{2} \mathrm{O}_{3}: \mathrm{C}$ com resposta centrada para o comprimento de onda de $307 \mathrm{~nm}$. 


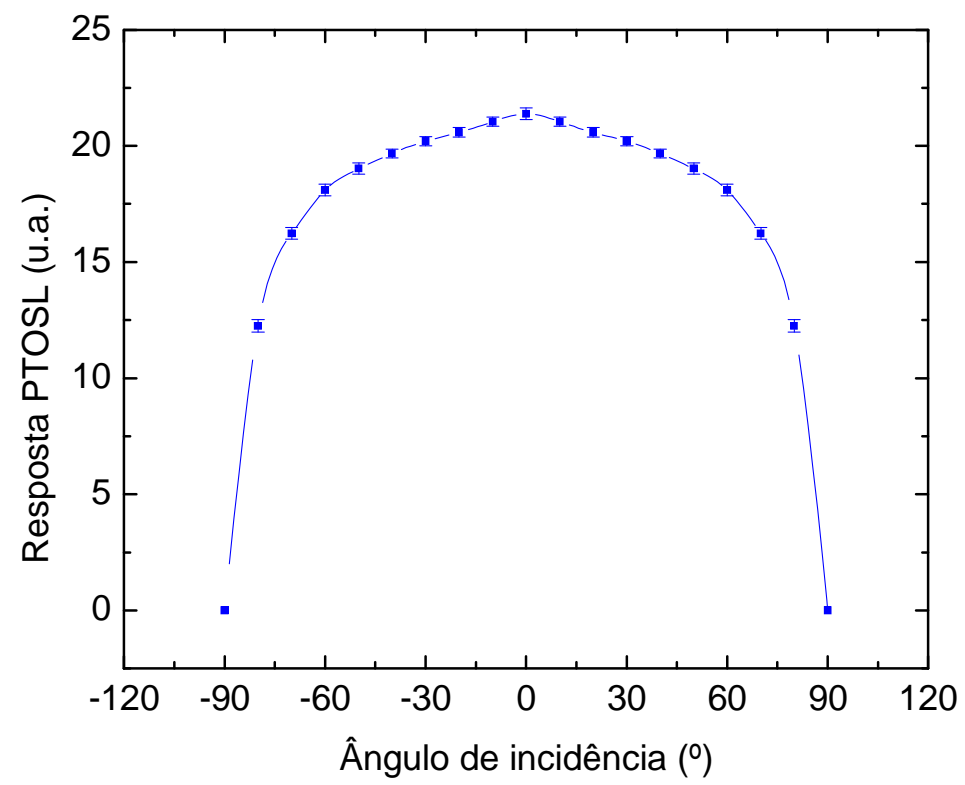

FIGURA 4.33 - Resposta PTOSL dos detectores $\mathrm{Al}_{2} \mathrm{O}_{3}: \mathrm{C}$ InLight em função do ângulo de incidência do feixe de iluminação UV.

\subsubsection{Decaimento do sinal PTOSL}

O decaimento do sinal PTOSL foi verificado em um conjunto de quatro detectores $\mathrm{Al}_{2} \mathrm{O}_{3}: \mathrm{C}$ InLight no intervalo de $720 \mathrm{~h}$ após iluminação UV.

Inicialmente, os detectores foram irradiados com uma dose de $1 \mathrm{~Gy}\left({ }^{60} \mathrm{Co}\right)$; em seguida, as lâminas foram tratadas opticamente a 26.000 lux durante $30 \mathrm{~min}$ e iluminadas com fonte UV durante $30 \mathrm{~min}$. O comprimento de onda e a irradiância foram mantidas constantes em $330 \mathrm{~nm}$ e $0,25 \mathrm{~W} \cdot \mathrm{m}^{-2}$, respectivamente.

A primeira medida PTOSL foi realizada imediatamente após a iluminação UV. Em seguida, os detectores foram armazenados em um recipiente fechado e em ambiente escuro. Após $720 \mathrm{~h}$ foram feitas medidas do sinal PTOSL.

A TAB 4.3 mostra a resposta PTOSL dos detectores logo após a iluminação UV e as respostas PTOSL medidas $720 \mathrm{~h}$ após a iluminação UV. 
TABELA 3.3 Respostas PTOSL dos detectores $\mathrm{Al}_{2} \mathrm{O}_{3}: \mathrm{C}$ InLight imediatamente após a iluminação UV e após $720 \mathrm{~h}$.

\begin{tabular}{ccc}
\hline Detector & $\begin{array}{c}\text { Resposta PTOSL } \\
\text { imediatamente após } \\
\text { iluminação UV }\end{array}$ & $\begin{array}{c}\text { Resposta PTOSL } \\
\text { após 720 } \mathbf{h} \\
\text { da iluminação UV }\end{array}$ \\
\hline$\# 1$ & $22,23 \pm 0,07$ & $19,23 \pm 0,10$ \\
\hline$\# 2$ & $22,53 \pm 0,11$ & $19,41 \pm 0,12$ \\
\hline$\# 3$ & $22,68 \pm 0,10$ & $19,72 \pm 0,12$ \\
\hline$\# 4$ & $22,74 \pm 0,11$ & $19,92 \pm 0,13$ \\
\hline
\end{tabular}

Observa-se que após $720 \mathrm{~h}$ da iluminação UV, os detectores apresentaram sinal PTOSL com perda percentual variando de $12,4 \%$ a $13,8 \%$ em relação às leituras realizadas logo após a exposição à RUV.

Comparando os resultados deste item com os resultados apresentados no item 4.5.5, verifica-se que os detectores que receberam pré-condicionamento (pré-dose e tratamento óptico) antes da exposição à RUV, armazenaram por um tempo mais longo o sinal PTOSL do que os detectores sem pré-condicionamento.

\subsubsection{Limite mínimo detectável dos detectores $\mathrm{Al}_{2} \mathrm{O}_{3}: \mathrm{C}$ de $\mathrm{RUV}$}

O limite mínimo detectável da resposta dos detectores é uma característica muito importante na dosimetria das radiações. $O$ valor do limite mínimo detectável de UV dos detectores $\mathrm{Al}_{2} \mathrm{O}_{3}: \mathrm{C}$ InLight pré-condicionados foi de $15 \mathrm{~J}^{-2}$ de exposição radiante, conforme se pode observar nas FIG. 4.31 e 4.32 (item 4.6.7).

O limite obtido neste trabalho encontra-se abaixo do limite de detecção mínimo de UV de $20 \mathrm{~J} . \mathrm{m}^{-2}$ apresentado por Smetana e col. [2008] num estudo realizado em pastilhas de $\mathrm{Al}_{2} \mathrm{O}_{3}: \mathrm{C}$ de $10 \mathrm{~mm}$ de diâmetro, com e sem filtros UG1 
absorvedores de UV, expostos a uma lâmpada de arco curto de xenônio (Xe) de $300 \mathrm{~W}$.

\subsection{Aplicações práticas dos detectores $\mathrm{Al}_{2} \mathrm{O}_{3}: \mathrm{C}$ InLight}

As aplicações práticas foram realizadas com o objetivo de verificar se os detectores, sem pré-condicionamento e pré-condicionados, apresentariam respostas OSL e PTOSL quando expostos à RUV solar e à RUV proveniente dos processos de solda elétrica e TIG (Tungsten Inert Gas).

A exposição dos detectores à RUV solar foi realizada numa área externa do prédio da GMR/IPEN e a exposição dos detectores à RUV proveniente dos processos de soldas foi realizada na Divisão de Projetos e Planejamento (DPF/IPEN).

Tendo com base os resultados apresentados no item 4.4, foram utilizados filtros HOYAU 330 e U 340 sobre os detectores para impedir a interferência da luz visível no estímulo do sinal OSL e PTOSL quando expostos à RUV.

Os dois tipos de filtros têm transmitâncias para as faixas de comprimento de onda UVA, UVB e UVC. O filtro HOYA U 330 tem transmitância máxima (89,6 \%) para o comprimento de onda de $330 \mathrm{~nm}$, abrangendo a região espectral entre $220 \mathrm{~nm}$ e $400 \mathrm{~nm}$ (Anexo II). O filtro HOYA U 340 tem transmitância máxima $(79,9 \%)$ para o comprimento de onda de $340 \mathrm{~nm}$ e abrange uma região espectral menor, entre $250 \mathrm{~nm}$ e $390 \mathrm{~nm}$ (Anexo III).

Nas aplicações práticas realizadas durante os processos de soldagens, os resultados obtidos com os detectores $\mathrm{Al}_{2} \mathrm{O}_{3}: \mathrm{C}$ InLight pré-condicionados foram analisados em função das curvas de calibração para o comprimento de onda de $330 \mathrm{~nm}$ (FIG. 4.31) e 340 nm (FIG. 4.32). 


\subsubsection{Aplicações práticas dos detectores $\mathrm{Al}_{2} \mathrm{O}_{3}: \mathrm{C}$ InLight (sem pré- condicionamentos) expostos diretamente à RUV.}

A seguir são apresentadas três aplicações práticas dos detectores $\mathrm{Al}_{2} \mathrm{O}_{3}: \mathrm{C}$, sem pré-condicionamentos, expostos à $\mathrm{RUV}$ solar e à $\mathrm{RUV}$ proveniente dos processos de solda elétrica e de solda TIG.

\subsubsection{Exposição dos detectores $\mathrm{Al}_{2} \mathrm{O}_{3}: \mathrm{C}$ InLight (sem pré- condicionamentos) à RUV solar.}

A primeira aplicação dos detectores $\mathrm{Al}_{2} \mathrm{O}_{3}: \mathrm{C}$ InLight com filtros HOYA foi realizada para verificar se ocorreria o estímulo do sinal OSL destes detectores expostos à RUV solar. O filtro HOYA U 330 (Anexo II) foi escolhido por ter uma transmitância maior para $330 \mathrm{~nm}$, que corresponde ao mesmo comprimento de onda no qual se obteve a resposta OSL máxima (FIG. 4.11). Além disso, a radiação solar emite RUV em seu amplo espectro e este filtro absorve uma faixa espectral de UV maior do que o filtro HOYA U 340.

Um grupo de quatro detectores InLight, sem pré-condicionamentos, foi usado para a realização deste estudo. Cada lâmina, após "zerada", foi fixada em papel cartão preto $(5,0 \mathrm{~cm} \times 7,0 \mathrm{~cm})$ e identificada com o número do detector, e sobre a primeira pastilha da lâmina foi fixado o filtro HOYA U 330. A FIG. 4.34 mostra o conjunto formado (cartão+lâmina+filtro). Os conjuntos foram expostos diretamente à RUV solar num intervalo de tempo entre 5 e 60 min. As medidas OSL foram tomadas imediatamente após as exposições.

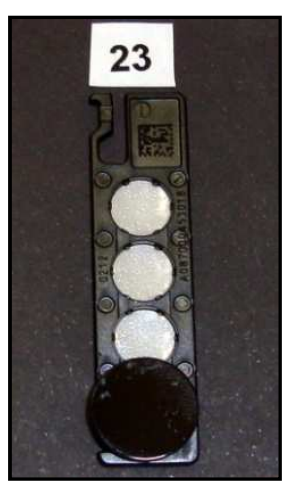

FIGURA 4.34 - Conjunto (cartão+lâmina+filtro) para uso nas aplicações práticas. 
O estudo foi realizado em dois dias de outono, completamente claros e sem nuvens, em São Paulo (2332'51'S e 46³'10"O e 760 m acima do nível do mar). A temperatura ambiente média era de $26^{\circ} \mathrm{C}$ e o nível de iluminamento médio no local onde os detectores foram posicionados era de 85.000 lux. Estas medidas foram feitas com os sensores LP 9021 PHOT e TP 870A conectados ao radiômetro Delta $\mathrm{OHM}$, no momento da exposição, na mesma posição em que foram colocados os detectores no solo (granito preto).

Em função da rápida queda do sinal OSL, este tipo de dosimetria só foi possível ser realizada no próprio local da exposição em conjunto com o sistema leitor OSL. O estudo foi repetido três vezes e os resultados apresentados são as médias e os desvios padrões das respostas OSL obtidas pelos detectores. A FIG. 4.35 mostra que ocorreu um aumento linear do sinal OSL em função do tempo de exposição à RUV solar.

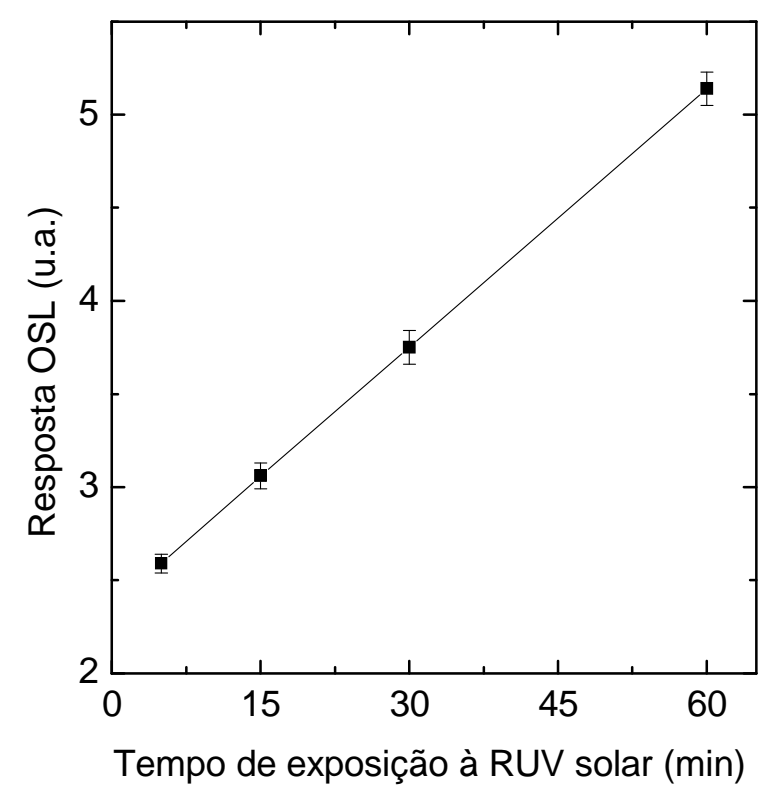

FIGURA 4.35 - Resposta OSL dos detectores $\mathrm{Al}_{2} \mathrm{O}_{3}: \mathrm{C}$ InLight sem précondicionamentos, com filtro HOYA U330, em função do tempo de exposição à RUV solar.

Comparando a FIG. 4.10b, que mostra o estímulo do sinal OSL do detector, sem pré-irradiação e sem filtro, exposto diretamente à luz solar, nos 
primeiros 3 min e posterior queda do sinal OSL, com a FIG. 4.35, que mostra um aumento linear da resposta OSL dos detectores sem pré-condicionamento, com filtro HOYA U 330, expostos à RUV solar, conclui-se que o uso do filtro absorvedor de UV é um fator determinante para o estímulo do sinal OSL destes detectores expostos ao sol.

Consequentemente, o conjunto formado pelo detector e filtro absorvedor de UV é uma boa opção para a realização de estudos da exposição à UVA solar.

\subsubsection{Exposição dos detectores $\mathrm{Al}_{2} \mathrm{O}_{3}: \mathrm{C}$ InLight (sem pré- condicionamentos) à RUV proveniente do processo de solda elétrica.}

A segunda aplicação prática dos detectores $\mathrm{Al}_{2} \mathrm{O}_{3}: \mathrm{C}$ InLight em conjunto com o leitor OSL microStar System da Landauer foi realizada para verificar se ocorre o estímulo do sinal OSL à RUV proveniente de uma fonte artificial. Esta aplicação foi realizada no setor de solda elétrica da Divisão de Projetos e Planejamento (DPF/IPEN). Neste tipo de soldagem, um arco elétrico é formado durante o contato do eletrodo consumível com a peça a ser soldada.

Um conjunto contendo quatro detectores $\mathrm{Al}_{2} \mathrm{O}_{3}: \mathrm{C}$ InLight totalmente "zerados" foram expostos à RUV proveniente do processo de solda elétrica para verificar o estímulo da resposta OSL. Cada lâmina foi fixada em um papel cartão preto $(5,0 \mathrm{~cm} \times 7,0 \mathrm{~cm})$ e identificada com o número do detector e o tipo de filtro. Sobre a primeira pastilha da lâmina foi fixado cada filtro.

Nesta aplicação foram utilizados os filtros HOYA U 330 e U 340, ambos com transmitâncias variáveis nas faixas UVA, UVB e UVC, conforme Anexos II e III, tendo em vista que os processos de soldagens a arco geram RUV em seu amplo espectro [DIXON e DIXON, 2004]. 
Os conjuntos (cartão + lâmina + filtro), mostrados na FIG. 4.34, foram fixados em tripés na altura em que a soldagem foi realizada, conforme dados apresentados na TAB. 4.4 e ilustrados nas FIG. 4.36 e 4.37. A aplicação prática foi realizada durante o processo de soldagem elétrica de uma peça de aço carbono com tempo de duração de 2 min.

O filtro HOYA U 330 foi escolhido para ser posicionado com o detector no protetor facial do soldador em virtude de sua máxima transmitância em $330 \mathrm{~nm}$, que é o mesmo comprimento de onda de maior resposta OSL para estes detectores (item 4.5.1; FIG. 4.11).

TABELA 4.4 - Posição e distância dos conjuntos (cartão+lâmina+filtro) durante 2 min de soldagem elétrica.

\begin{tabular}{|c|c|c|}
\hline $\begin{array}{c}\text { Conjunto } \\
\text { (cartão + lâmina + filtro) }\end{array}$ & $\begin{array}{c}\text { Posição durante a } \\
\text { operação de solda } \\
\text { elétrica }\end{array}$ & $\begin{array}{c}\text { Distância da solda } \\
\text { elétrica } \\
\text { (cm) }\end{array}$ \\
\hline$\# 10+U 330$ & Protetor facial & 20 \\
\hline$\# 11+\cup 330$ & Tripé 1 & 100 \\
\hline$\# 12+U 340$ & Tripé 2 & 100 \\
\hline$\# 13+$ U 340 & Tripé 2 & 100 \\
\hline
\end{tabular}




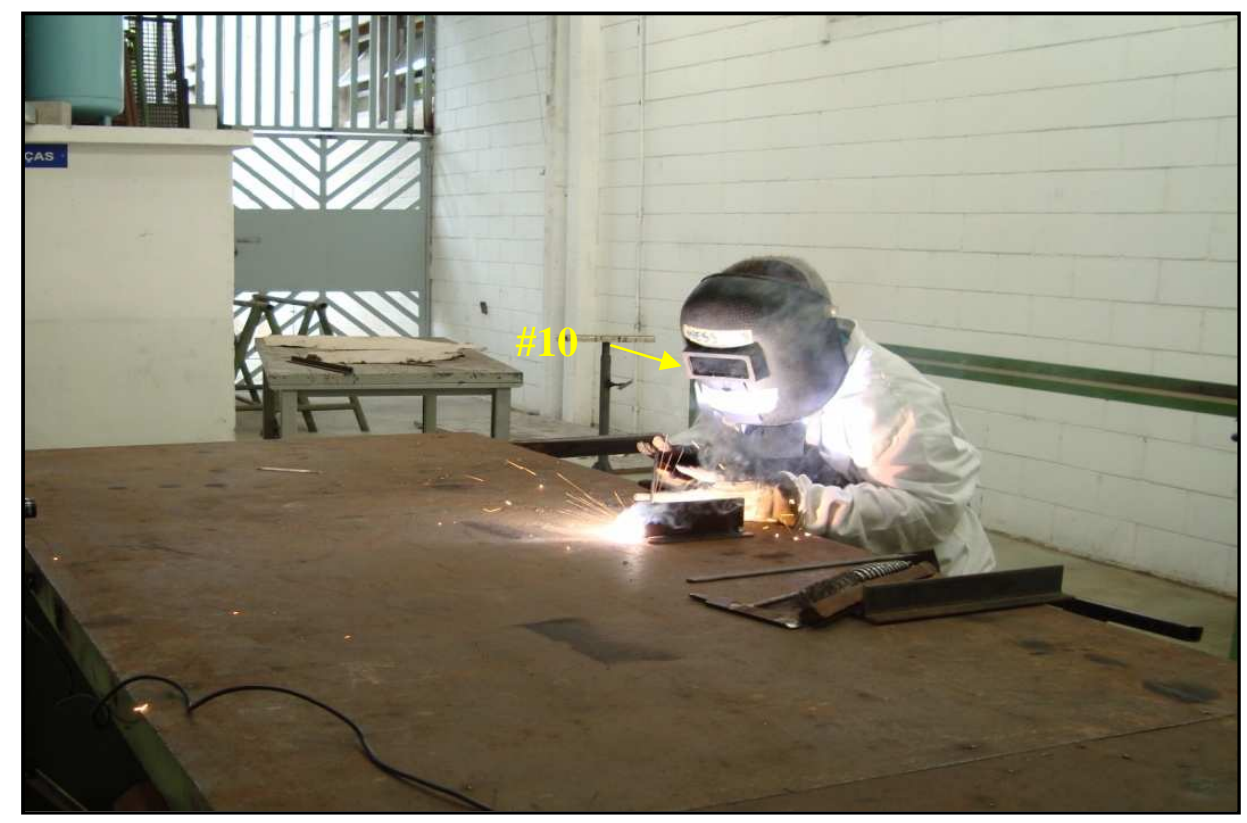

FIGURA 4.36 - Posição do conjunto (cartão+lâmina+filtro) na máscara de proteção do soldador durante 2 min de soldagem elétrica.

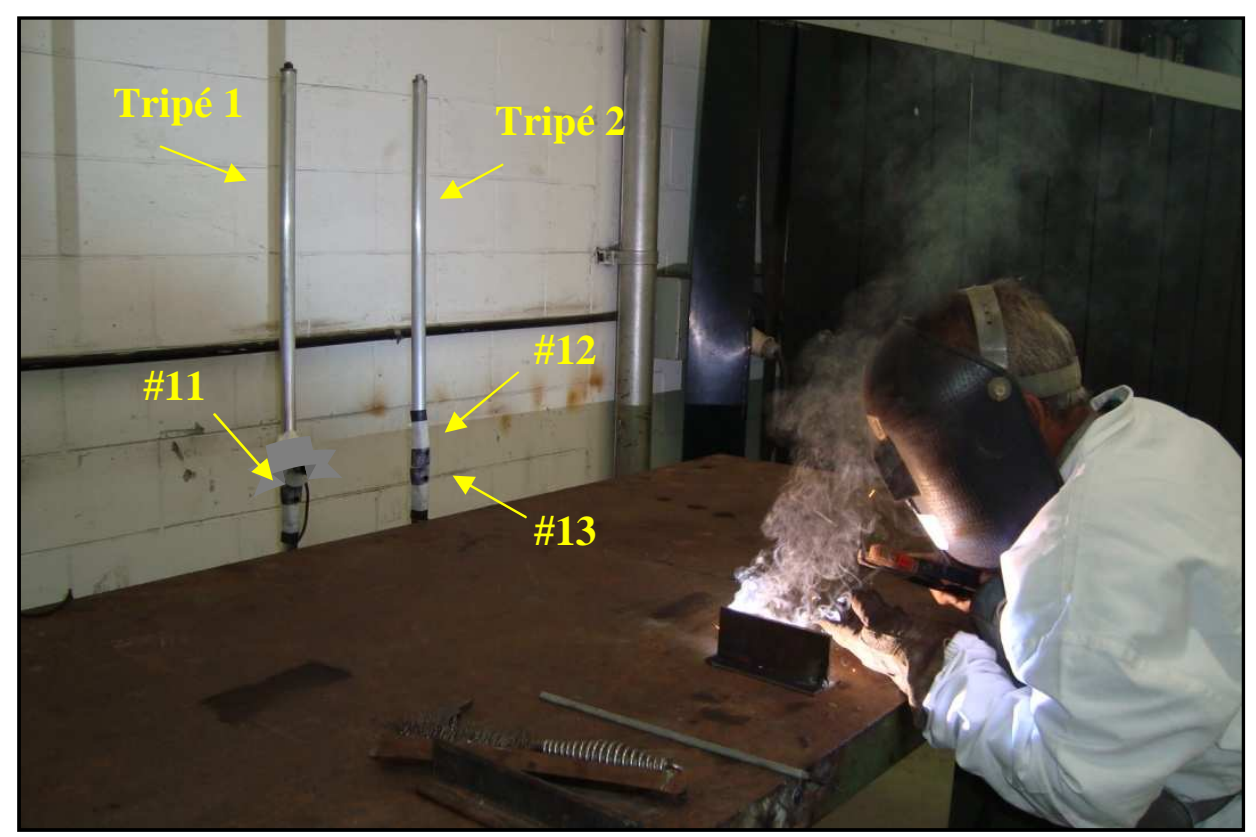

FIGURA 4.37 - Posição dos conjuntos (cartão+lâmina+filtro), nos tripés, expostos à RUV durante 2 min de soldagem elétrica.

Como os detectores sem pré-condicionamentos apresentam uma rápida queda do sinal OSL, conforme discutido no item 4.5 .5 deste trabalho, 
realizou-se somente uma medida OSL para cada detector. As leituras foram feitas no local da soldagem, logo após a exposição à RUV.

A FIG. 4.38 mostra a resposta OSL dos detectores $\mathrm{Al}_{2} \mathrm{O}_{3}: \mathrm{C}$ InLight após exposição à RUV proveniente do processo de solda elétrica. Pode-se observar que houve o estímulo do sinal OSL em todos os detectores expostos à RUV durante 2 min de soldagem elétrica.

Os detectores \#11, \#12 e \#13, posicionados a $100 \mathrm{~cm}$ de distância do processo de solda elétrica, apresentaram respostas OSL mais baixas do que a resposta OSL do detector \#10, posicionado a $20 \mathrm{~cm}$ da fonte de RUV, conforme mostra a FIG. 4.38. Os fatores distância e posição dos detectores em relação à fonte de RUV podem ter influenciado nos resultados.

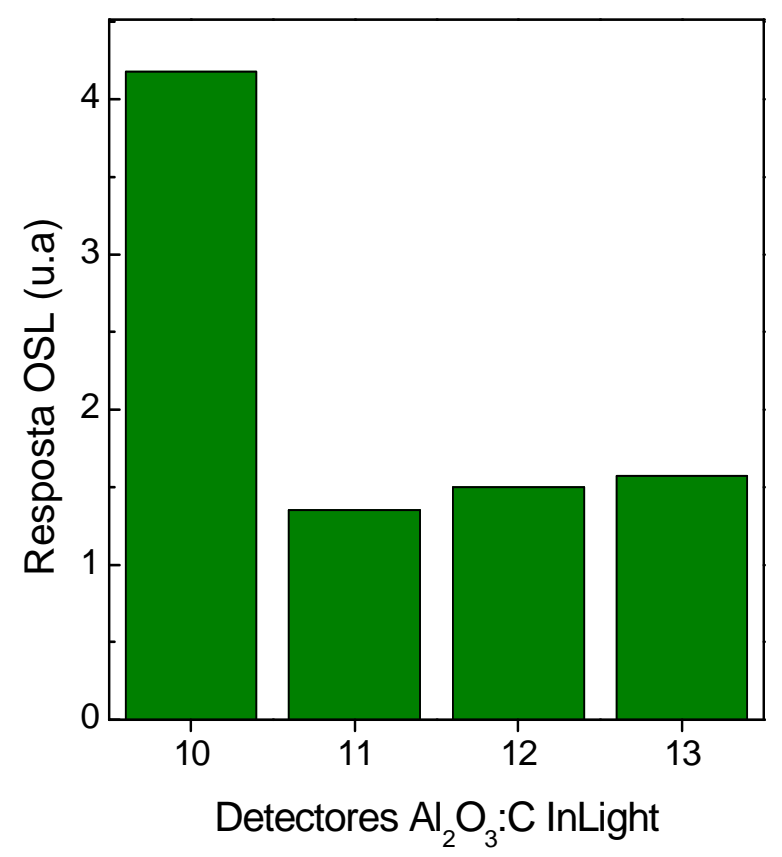

FIGURA 4.38 - Resposta OSL dos detectores $\mathrm{Al}_{2} \mathrm{O}_{3}: \mathrm{C}$ InLight, sem précondicionamentos, após exposição à RUV, durante 2 min de soldagem elétrica. 


\subsubsection{Exposição dos detectores $\mathrm{Al}_{2} \mathrm{O}_{3}: \mathrm{C}$ InLight (sem pré- condicionamentos) à RUV proveniente do processo de solda TIG.}

A terceira aplicação prática dos detectores $\mathrm{Al}_{2} \mathrm{O}_{3}: \mathrm{C}$ InLight, sem précondicionamento, em conjunto com o leitor OSL microStar System da Landauer, no local de trabalho, foi também realizada para verificar a resposta OSL estimulada pela RUV proveniente de uma fonte artificial. Esta aplicação foi realizada no setor de solda TIG (Tungsten Inert Gas) da Divisão de Projetos e Fabricação do IPEN. A solda TIG é um processo de soldagem a arco elétrico que utiliza um arco entre um eletrodo não consumível de tungstênio e a poça de soldagem.

Foi utilizado um conjunto contendo quatro detectores $\mathrm{Al}_{2} \mathrm{O}_{3}: \mathrm{C}$ InLight, sem pré-condicionamento, totalmente "zerados". Cada lâmina foi fixada em papel cartão preto $(5,0 \mathrm{~cm} \times 7,0 \mathrm{~cm})$ e identificada com o número do detector e o tipo de filtro. Sobre a primeira pastilha da lâmina foi fixado o filtro.

Nesta aplicação também se optou por utilizar os mesmos filtros absorvedores de UV, e o filtro HOYA U 330 também foi escolhido para ser posicionado com o detector no protetor facial do soldador, pelas mesmas razões apresentadas no item anterior.

A aplicação foi realizada durante o processo de soldagem TIG de uma peça de alumínio com um tempo de duração de 5 min. Os conjuntos (cartão + lâmina + filtro), ilustrado na FIG. 4.34, foram fixados em tripés na altura em que a soldagem foi realizada, conforme dados apresentados na TAB. 4.5 e ilustrados na FIG. 4.39.

As medições OSL foram feitas no local da soldagem, logo após a exposição à RUV. Foi realizada apenas uma medição OSL para cada detector, tendo em vista que os detectores sem pré-condicionamentos apresentam uma rápida queda do sinal OSL, conforme discutido no item 4.5.5 deste trabalho. 
TABELA 4.5 - Posição e distância dos conjuntos (cartão+lâmina+filtro) durante 5 min de soldagem TIG.

\begin{tabular}{ccc}
\hline $\begin{array}{c}\text { Conjunto } \\
\text { (cartão + lâmina + filtro) }\end{array}$ & $\begin{array}{c}\text { Posição durante a } \\
\text { operação de solda TIG }\end{array}$ & $\begin{array}{c}\text { Distância da } \\
\text { soldagem } \\
(\mathbf{c m})\end{array}$ \\
\hline$\# 14+$ U 330 & Protetor facial & 20 \\
\hline $15+$ U 330 & Tripé 1 & 100 \\
\hline$\# 16+$ U 340 & Tripé 2 & 100 \\
\hline $17+\mathrm{U} 340$ & Tripé 2 & 100 \\
\hline
\end{tabular}

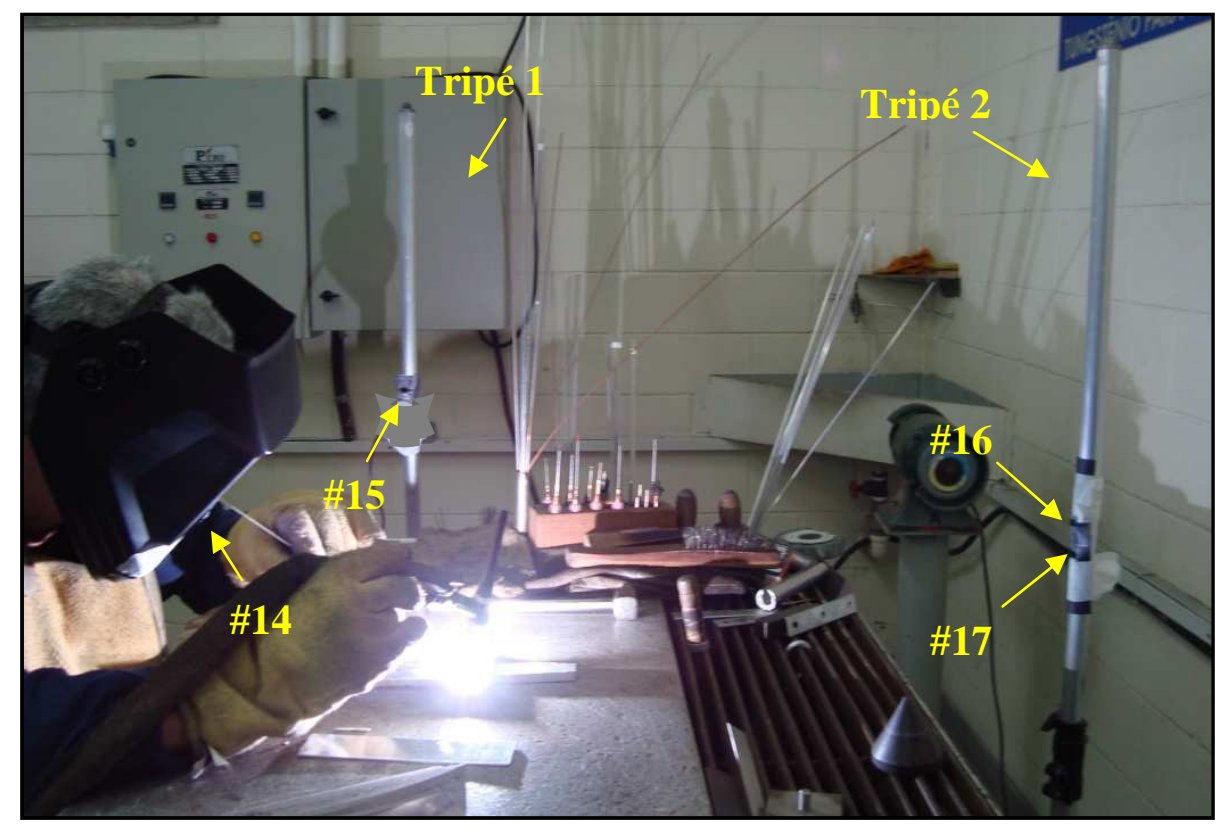

FIGURA 4.39 - Posição dos conjuntos (cartão+lâmina+filtro), nos tripés, expostos à RUV durante 5 min de soldagem TIG. 
A FIG. 4.40 mostra a resposta OSL dos detectores $\mathrm{Al}_{2} \mathrm{O}_{3}: \mathrm{C}$ InLight após exposição direta à RUV proveniente do processo de solda TIG. Pode-se observar que, para 5 min de duração do processo de soldagem, houve o estímulo do sinal OSL em todos os detectores.

Observa-se também que, em função da distância, as respostas OSL dos detectores \#15, \#16 e \#17 foram mais baixas do que a resposta OSL do detector \#14, conforme mostra a FIG. 4.40.

Apesar do tempo curto de exposição dos conjuntos (cartão+lâmina+filtro) à RUV, verifica-se que houve o estímulo do sinal OSL de todos os detectores, sem pré-condicionamento, expostos à RUV, em ambos os processos de soldagem.

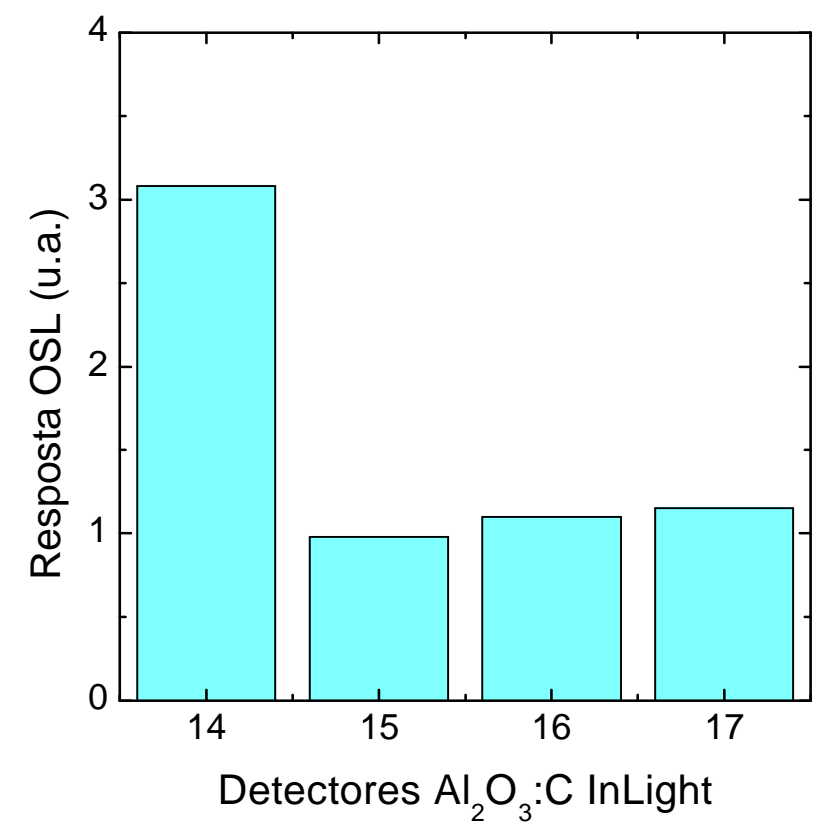

FIGURA 4.40 - Resposta OSL dos detectores $\mathrm{Al}_{2} \mathrm{O}_{3}: \mathrm{C}$ InLight, sem précondicionamentos, após exposição direta à RUV durante 5 min de soldagem TIG. 
Uma análise dos dados obtidos nos dois processos de soldagem (FIG. 4.38 e 4.40) permitiu verificar que, apesar do tempo de exposição à RUV do processo de solda elétrica ter sido menor, o estímulo do sinal OSL do detector posicionado no protetor facial do soldador foi $26,3 \%$ maior que a resposta do detector posicionado no protetor facial do trabalhador da solda TIG.

Os parâmetros como voltagem, amperagem, tipo de peça usada na soldagem e tipo de eletrodo, dentre outros, podem ter influenciado esses resultados.

Os dados obtidos nas duas últimas aplicações confirmam o exposto no item 4.5.5, no qual consta o uso dos detectores $\mathrm{Al}_{2} \mathrm{O}_{3}: \mathrm{C}$ InLight em conjunto com o leitor OSL portátil para a detecção do estímulo das emissões luminescentes em função da exposição à RUV em locais de trabalho.

\subsubsection{Aplicações práticas dos detectores $\mathrm{Al}_{2} \mathrm{O}_{3}: \mathrm{C}$ InLight, pré-condicionados, utilizando a técnica PTOSL.}

A seguir são apresentadas mais quatro aplicações práticas dos detectores $\mathrm{Al}_{2} \mathrm{O}_{3}: \mathrm{C}$ InLight, desta vez pré-condicionados, expostos à RUV solar e à RUV proveniente dos processos de solda elétrica e de solda TIG para o estímulo da PTOSL.

\subsubsection{Exposição dos detectores $\mathrm{Al}_{2} \mathrm{O}_{3}: \mathrm{C}$ InLight (pré-condicionados) à RUV solar}

A primeira aplicação dos detectores $\mathrm{Al}_{2} \mathrm{O}_{3}: \mathrm{C}$ InLight, précondicionados, com filtros HOYA, utilizando a técnica PTOSL, foi realizada com o propósito de verificar a possibilidade de empregá-los em dosimetria da RUV solar.

A resposta PTOSL em relação à exposição à RUV solar foi feita com um conjunto de quatro detectores irradiados com $1 \mathrm{~Gy}\left({ }^{60} \mathrm{Co}\right)$. As lâminas foram 
tratadas opticamente a 26.000 lux durante 30 min na caixa de luz. A seguir, cada lâmina foi fixada em papel cartão preto $(5,0 \mathrm{~cm} \times 7,0 \mathrm{~cm})$ e identificada com 0 número do detector, e sobre a primeira pastilha da lâmina foi fixado o filtro HOYA U 330 formando o conjunto (cartão+lâmina+filtro), conforme ilustrado na FIG. 4.34.

O filtro HOYA U 330 (Anexo II) foi escolhido por ter uma transmitância maior para $330 \mathrm{~nm}$, que corresponde ao mesmo comprimento de onda onde se obteve a máxima resposta PTOSL (item 4.6.4, FIG.4.28).

Os conjuntos (cartão + lâmina + filtro) foram expostos ao sol em um dia de verão completamente claro e sem nuvens no IPEN em São Paulo (23932'51'S e 4638'10"O e $760 \mathrm{~m}$ acima do nível do mar). Os co njuntos foram posicionados no nível do solo, sobre o cimento.

A temperatura ambiental era de $30^{\circ} \mathrm{C}$ e o nível de iluminamento médio no local onde os detectores foram posicionados era de 100.000 lux. Estas medidas foram feitas com os sensores LP 9021 PHOT e TP 870A conectados ao radiômetro Delta OHM, no momento da exposição, na mesma posição em que foram colocados os detectores.

O tempo de exposição para cada conjunto variou de 5 a 60 min. Foram realizadas 10 leituras OSL para cada detector exposto à $\mathrm{RUV}$ solar $(\mathrm{k}=1, \sigma=1)$.

A TAB. 4.6 e a FIG. 4.41 apresentam, respectivamente, os resultados das medidas OSL após o tratamento óptico e as medidas OSL após exposição à RUV solar. Observa-se que a exposição à RUV solar causou uma queda do sinal OSL destes detectores em relação ao tempo de exposição, não ocorrendo o estímulo da PTOSL. 
TABELA 4.6 - Respostas OSL dos detectores $\mathrm{Al}_{2} \mathrm{O}_{3}: \mathrm{C}$ InLight da Landauer com filtros HOYA U 330 após o tratamento térmico e após exposição ao sol.

\begin{tabular}{cccc}
\hline Detectores & $\begin{array}{c}\text { Resposta OSL } \\
\text { após o } \\
\text { tratamento óptico } \\
\text { (u.a) }\end{array}$ & $\begin{array}{c}\text { Tempo de } \\
\text { exposição à } \\
\text { RUV solar } \\
\text { (min) }\end{array}$ & $\begin{array}{c}\text { Resposta OSL } \\
\text { após exposição à } \\
\text { RUV solar } \\
\text { (u.a) }\end{array}$ \\
\hline$\# 14$ & $14,86 \pm 0,16$ & 5 & $13,58 \pm 0,19$ \\
$\# 15$ & $14,74 \pm 0,14$ & 15 & $10,89 \pm 0,24$ \\
$\# 17$ & $14,53 \pm 0,17$ & 30 & $8,01 \pm 0,27$ \\
\hline 18 & $14,69 \pm 0,19$ & 60 & $3,38 \pm 0,17$ \\
\hline
\end{tabular}

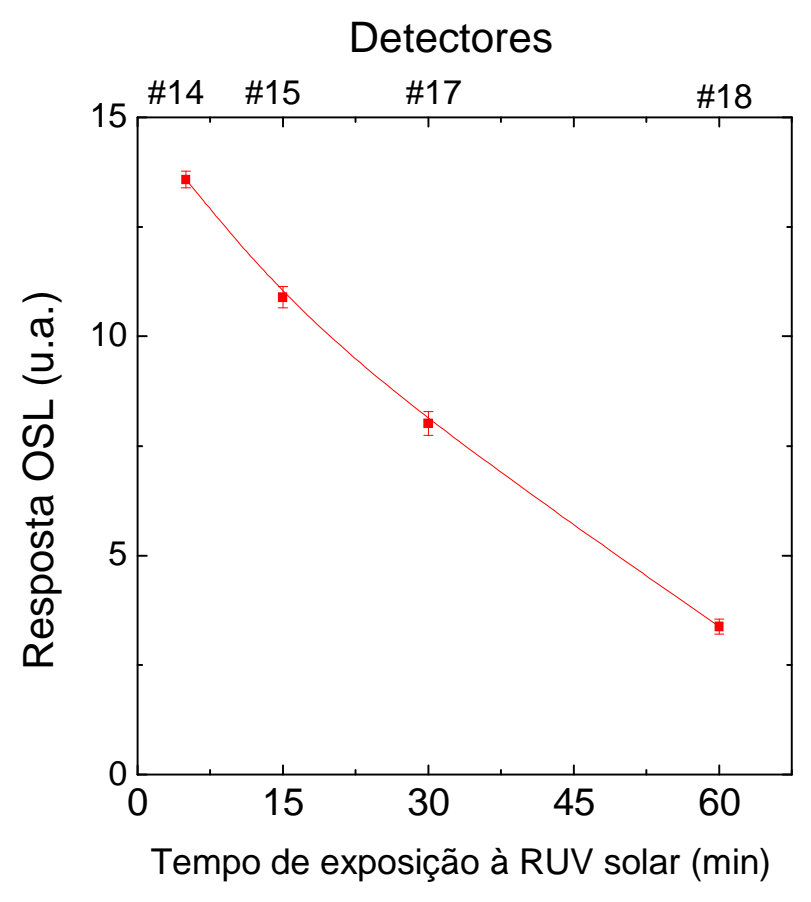

FIGURA 4.41 - Resposta OSL dos detectores $\mathrm{Al}_{2} \mathrm{O}_{3}: \mathrm{C}$ InLight, pré-condicionados, com filtro HOYA U 330, em função do tempo de exposição à RUV solar. 
A comparação entre as FIG. 4.35 e 4.41 permitiu observar que a primeira mostrou o estímulo do sinal OSL dos detectores com filtro HOYA U 330, sem pré-condicionamentos, para o intervalo de tempo estudado, e a segunda mostrou que os detectores, pré-condicionados, com filtro HOYA U 330 não apresentaram o estímulo PTOSL quando expostos à RUV solar; houve neste caso uma queda do sinal OSL.

Este fato, a princípio, mostrou que a aplicação destes detectores précondicionados com filtro HOYA U 330 não foi favorável para o estímulo da PTOSL em práticas de dosimetria da RUV solar.

\subsubsection{Exposição dos detectores $\mathrm{Al}_{2} \mathrm{O}_{3}: \mathrm{C}$ InLight, pré-condicionados, à RUV proveniente do processo de solda elétrica.}

A segunda aplicação prática para verificar a possibilidade do uso dos detectores $\mathrm{Al}_{2} \mathrm{O}_{3}: \mathrm{C}$, pré-condicionados, utilizando a técnica PTOSL na dosimetria da RUV, foi realizada no setor de solda elétrica da DPF/IPEN.

Um conjunto de quatro detectores $\mathrm{Al}_{2} \mathrm{O}_{3}: \mathrm{C}$ InLight foram irradiados com dose uma de $1 \mathrm{~Gy}\left({ }^{60} \mathrm{Co}\right)$ e as lâminas foram tratadas opticamente a 26.000 lux, durante 30 min na caixa de luz, para o estímulo da resposta PTOSL durante a exposição à RUV proveniente do processo de solda elétrica.

Foi repetido o mesmo procedimento de fixar cada lâmina em papel cartão preto $(5,0 \mathrm{~cm} \times 7,0 \mathrm{~cm})$ e identificar com o número do detector e tipo de filtro. $O$ filtro foi fixado sobre a primeira pastilha da lâmina.

Nesta aplicação foram utilizados os filtros HOYA U 330 e U 340 (com transmitâncias nas faixas UVA, UVB e UVC), tendo em vista que os processos de solda a arco geram RUV em seu amplo espectro [DIXON e DIXON, 2004]. O filtro HOYA U 330 também foi escolhido para ser posicionado com o detector no protetor facial do soldador. Ele foi escolhido por ter uma transmitância maior para $330 \mathrm{~nm}$, que corresponde ao mesmo comprimento de onda onde se obteve a máxima resposta PTOSL (item 4.6.4, FIG.4.28). 
Os conjuntos (cartão + lâmina + filtro) foram fixados em tripés na altura da soldagem e conforme apresentado na TAB. 4.7 e mostrados nas FIG. 4.42 e 4.43. O tempo de duração da soldagem elétrica de uma peça de aço carbono foi de 2 min. Foram realizadas 10 leituras OSL com cada detector exposto à RUV proveniente do processo de solda elétrica $(\sigma=1, k=1)$.

TABELA 4.7 - Posição e distância dos conjuntos (cartão+lâmina+filtro) durante o processo de solda elétrica.

\begin{tabular}{ccc}
\hline $\begin{array}{c}\text { Conjunto } \\
\text { (cartão + lâmina + filtro) }\end{array}$ & $\begin{array}{c}\text { Posição durante a } \\
\text { operação de solda } \\
\text { elétrica }\end{array}$ & $\begin{array}{c}\text { Distância da soldagem } \\
\text { (cm) }\end{array}$ \\
\hline$\# 18+$ U 330 & Protetor facial & 20 \\
\hline$\# 19+$ U 330 & Tripé 1 & 100 \\
\hline$\# 20+$ U 340 & Tripé 2 & 100 \\
\hline$\# 21+$ U 340 & Tripé 2 \\
\hline
\end{tabular}

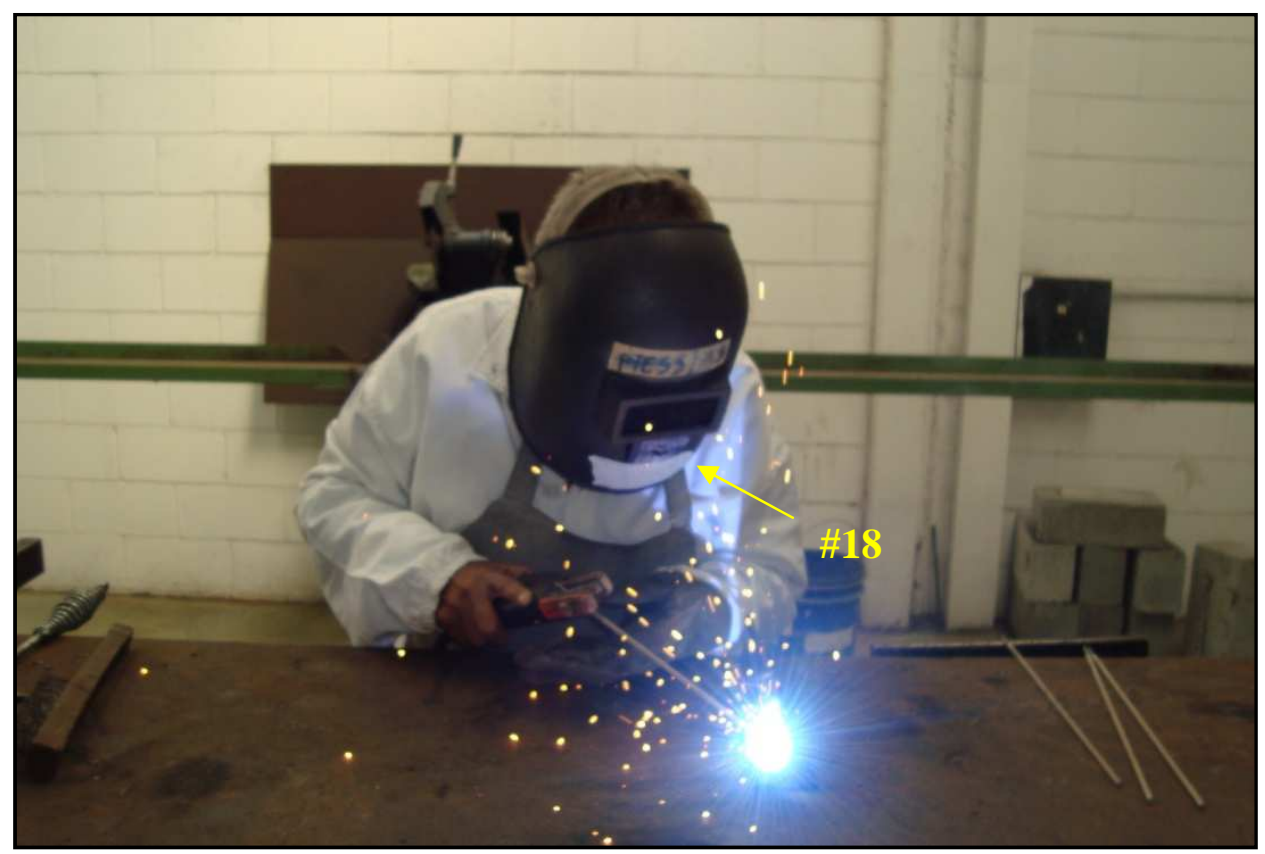

FIGURA 4.42 - Posição do conjunto (cartão + lâmina + filtro) no protetor facial do soldador, durante 2 min de soldagem elétrica. 


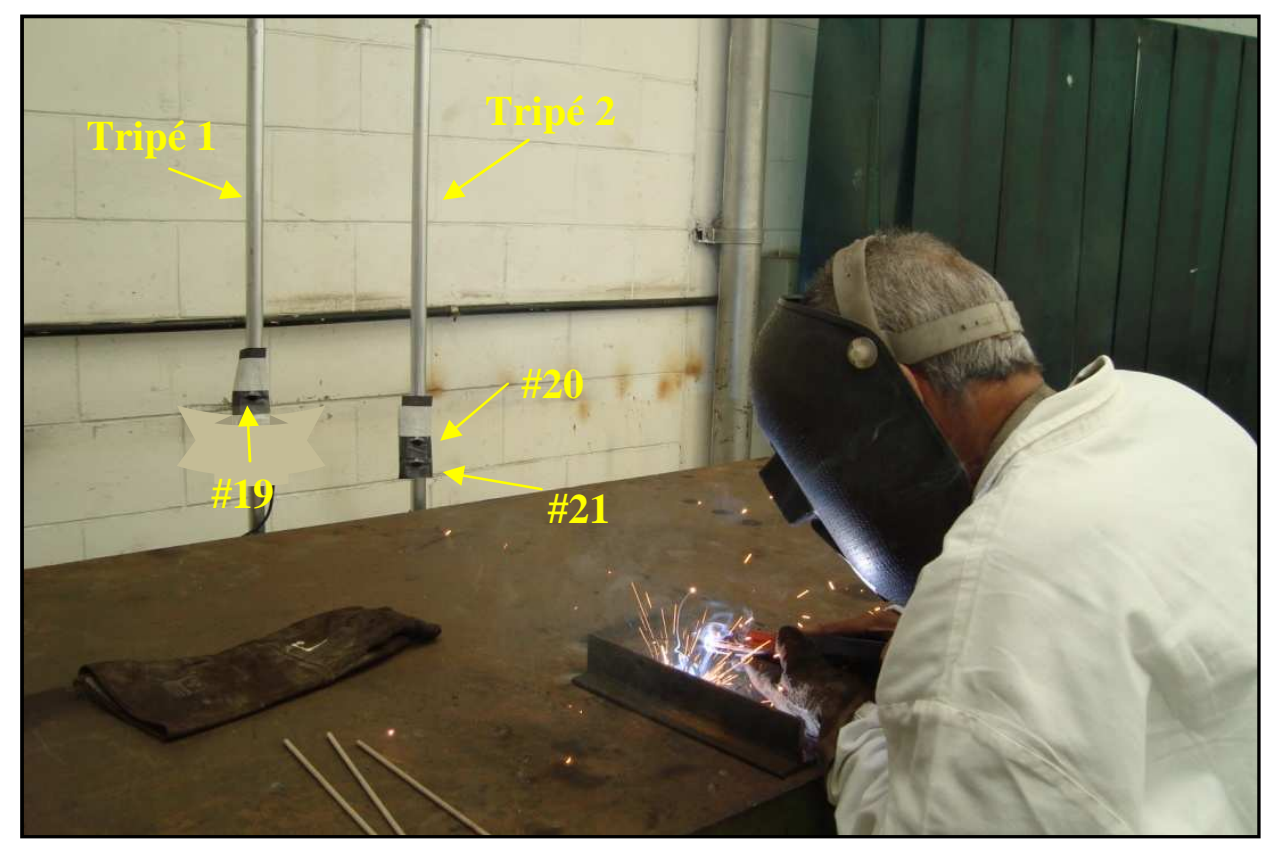

FIGURA 4.43 - Posição dos conjuntos (cartão + lâmina + filtro) nos tripés, durante 2 min de soldagem elétrica.

A TAB. 4.8 e a FIG. 4.44 apresentam, respectivamente, as respostas OSL após o tratamento óptico e as respostas PTOSL dos detectores $\mathrm{Al}_{2} \mathrm{O}_{3}: \mathrm{C}$ InLight, após exposição à RUV proveniente do processo de solda elétrica.

A FIG. 4.45 mostra o ganho percentual da resposta PTOSL após exposição à RUV proveniente do processo de solda elétrica. Pode-se observar que para o intervalo de tempo de 2 min de duração do processo de soldagem elétrica houve o estímulo da PTOSL em todos os detectores.

Nota-se que os detectores \#18 e \#19 foram os que apresentaram maior ganho do sinal PTOSL. Os fatores distância e posição dos detectores em relação à fonte de RUV, dentre outros, podem ter influenciado esses resultados. 
TABELA 4.8 - Resposta OSL e PTSOL dos detectores $\mathrm{Al}_{2} \mathrm{O}_{3}: \mathrm{C}$ InLight, précondicionados, após o tratamento óptico e exposição à RUV durante 2 min de soldagem elétrica.

\begin{tabular}{ccc}
\hline $\begin{array}{c}\text { Conjunto } \\
\text { (cartão + lâmina + filtro) }\end{array}$ & $\begin{array}{c}\text { Resposta OSL após } \\
\text { o tratamento óptico } \\
\text { (u.a.) }\end{array}$ & $\begin{array}{c}\text { Resposta } \\
\text { PTOSL } \\
\text { (u.a) }\end{array}$ \\
\hline$\# 18+$ U330 & $16,48 \pm 0,14$ & $21,55 \pm 0,18$ \\
$\# 19+$ U330 & $16,05 \pm 0,15$ & $19,58 \pm 0,19$ \\
\hline$\# 20+$ U340 & $16,73 \pm 0,10$ & $17,21 \pm 0,14$ \\
\hline \#21+ U340 & $16,44 \pm 0,08$ & $16,70 \pm 0,10$ \\
\hline
\end{tabular}

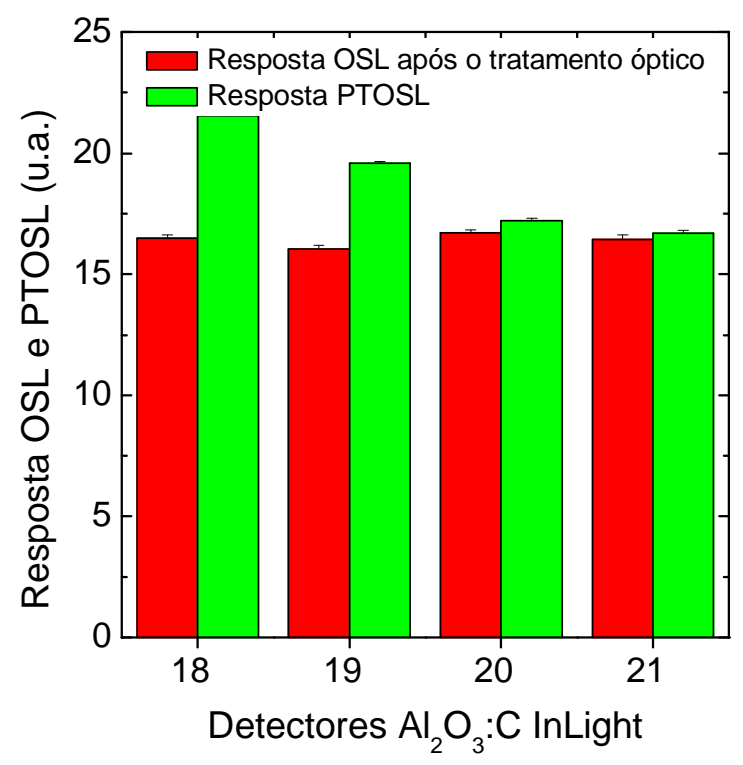

FIGURA 4.44 - Resposta OSL dos detectores $\mathrm{Al}_{2} \mathrm{O}_{3}: \mathrm{C}$ InLight após o tratamento óptico e resposta PTOSL após exposição à RUV durante 2 min de soldagem elétrica. 


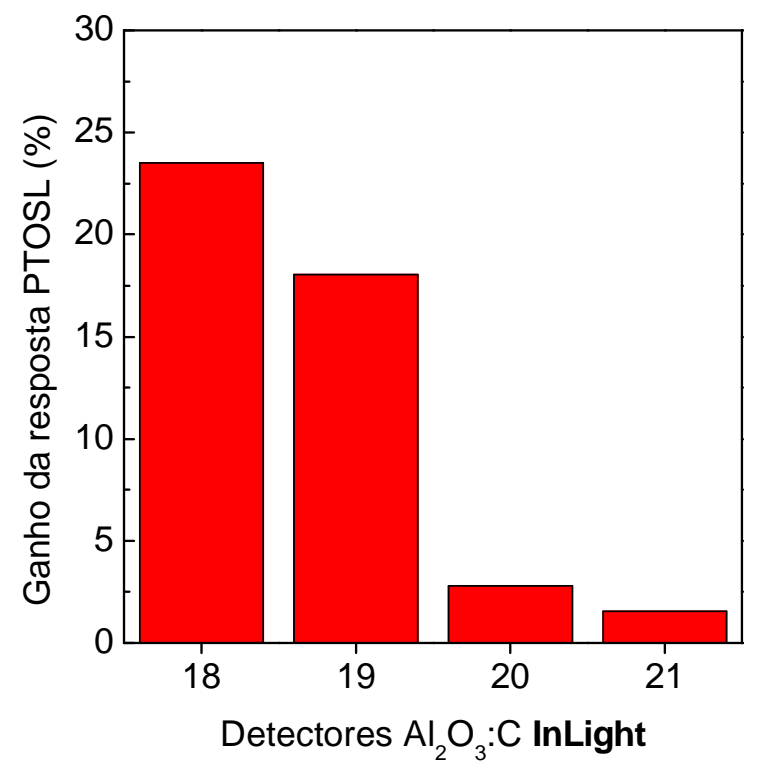

FIGURA 4.45 - Ganho percentual da resposta PTOSL dos detectores $\mathrm{Al}_{2} \mathrm{O}_{3}: \mathrm{C}$ InLight expostos à RUV da soldagem elétrica durante 2 min.

Os valores das exposições radiantes, apresentados na TAB. 4.9, foram obtidos pela relação das respostas PTOSL dos detectores \#18 e \#19 da TAB. 4.8 com a curva de calibração dos detectores $\mathrm{Al}_{2} \mathrm{O}_{3}: \mathrm{C}$ InLight para o comprimento de onda de $330 \mathrm{~nm}$ da FIG. 4.31.

O valor da exposição radiante do detector \# 20 foi obtido pela relação da resposta PTOSL com a curva de calibração dos detectores $\mathrm{Al}_{2} \mathrm{O}_{3}: \mathrm{C}$ InLight para o comprimento de onda de $340 \mathrm{~nm}$ da FIG. 4.32. Este valor também consta na TAB. 4.9.

Apesar do detector \#21 ter apresentado estímulo PTOSL, verifica-se que sua resposta a PTOSL em relação à curva de calibração dos detectores $\mathrm{Al}_{2} \mathrm{O}_{3}: \mathrm{C}$ InLight para o comprimento de onda de $340 \mathrm{~nm}$, da FIG. 4.32, está abaixo do limite inferior de detecção que é de $15 \mathrm{~J}^{-2}$, de acordo com o item 4.6.10. 
TABELA 4.9 - Valores das exposições radiantes obtidas nas posições dos detectores \#18, \#19 e \# 20

\begin{tabular}{cc}
\hline Detector & $\begin{array}{c}\text { Exposição radiante } \\
\left(\mathbf{J} . \mathbf{m}^{-2}\right)\end{array}$ \\
\hline$\# 18$ & $522,2 \pm 0,1$ \\
\hline$\# 19$ & $214,7 \pm 0,1$ \\
\hline$\# 20$ & $22,1 \pm 0,1$ \\
\hline
\end{tabular}

O detector posicionado no protetor facial do soldador foi o que apresentou o maior valor de exposição radiante.

\subsubsection{Exposição dos detectores $\mathrm{Al}_{2} \mathrm{O}_{3}: \mathrm{C}$ InLight, pré-condicionados, à RUV proveniente do processo de solda TIG.}

Dando continuidade ao estudo para verificar a possibilidade do uso dos detectores $\mathrm{Al}_{2} \mathrm{O}_{3}: \mathrm{C}$, pré-condicionados, em dosimetria da $\mathrm{RUV}$ em locais de trabalho, a terceira e quarta aplicações práticas foram realizadas no setor de solda TIG da DPF/IPEN.

Cada aplicação prática foi realizada com um conjunto contendo quatro detectores $\mathrm{Al}_{2} \mathrm{O}_{3}: \mathrm{C}$ InLight. Os detectores foram irradiados com $1 \mathrm{~Gy}$ $\left({ }^{60} \mathrm{Co}\right)$ e as lâminas foram tratadas opticamente a 26.000 lux, durante 30 min na caixa de luz, para o estímulo da resposta PTOSL durante a exposição à RUV proveniente do processo de solda TIG. As lâminas também foram fixadas em papel cartão preto $(5,0 \mathrm{~cm} \times 7,0 \mathrm{~cm})$ e identificadas com o número do detector e o tipo de filtro. $O$ filtro também foi fixado sobre a primeira pastilha da lâmina.

Nestas aplicações também foram utilizados os dois tipos de filtros absorvedores de UV e o filtro HOYA U 330 foi posicionado com o detector nos protetores faciais dos soldadores em virtude das mesmas razões descritas nos itens 4.7.2.1 e 4.7.2.2. 
4.7.2.3.1 Exposição dos detectores $\mathrm{Al}_{2} \mathrm{O}_{3}: \mathrm{C}$ InLight, pré-condicionados, à RUV proveniente do processo de solda TIG durante $5 \mathrm{~min}$.

A terceira aplicação foi realizada num processo de solda TIG de uma peça de alumínio com duração de 5 min.

Um grupo de quatro detectores passou pelo pré-condicionamento inicial antes da exposição à RUV proveniente da soldagem TIG. Os conjuntos (cartão + lâmina + filtro) foram fixados em tripés à altura das soldagens, conforme dados apresentados na TAB. 4.10 e ilustrados nas FIG. 4.46 e 4.47. Foram realizadas dez leituras OSL com cada detector exposto à RUV proveniente do processo de solda TIG $(\sigma=1, \mathrm{k}=1)$.

TABELA 4.10 - Posição e distância dos conjuntos (cartão+lâmina+filtro) durante 5 min de soldagem TIG.

\begin{tabular}{ccc}
\hline $\begin{array}{c}\text { Conjunto } \\
\text { (cartão + lâmina + filtro) }\end{array}$ & $\begin{array}{c}\text { Posição durante a } \\
\text { operação de solda TIG }\end{array}$ & $\begin{array}{c}\text { Distância da soldagem } \\
\text { (cm) }\end{array}$ \\
\hline$\# 22+$ U 330 & Protetor facial & 20 \\
\hline$\# 23+$ U 330 & Tripé 1 & 100 \\
\hline \#24+ U 340 & Tripé 2 & 100 \\
\hline \#25 + U 340 & & 100 \\
\hline
\end{tabular}




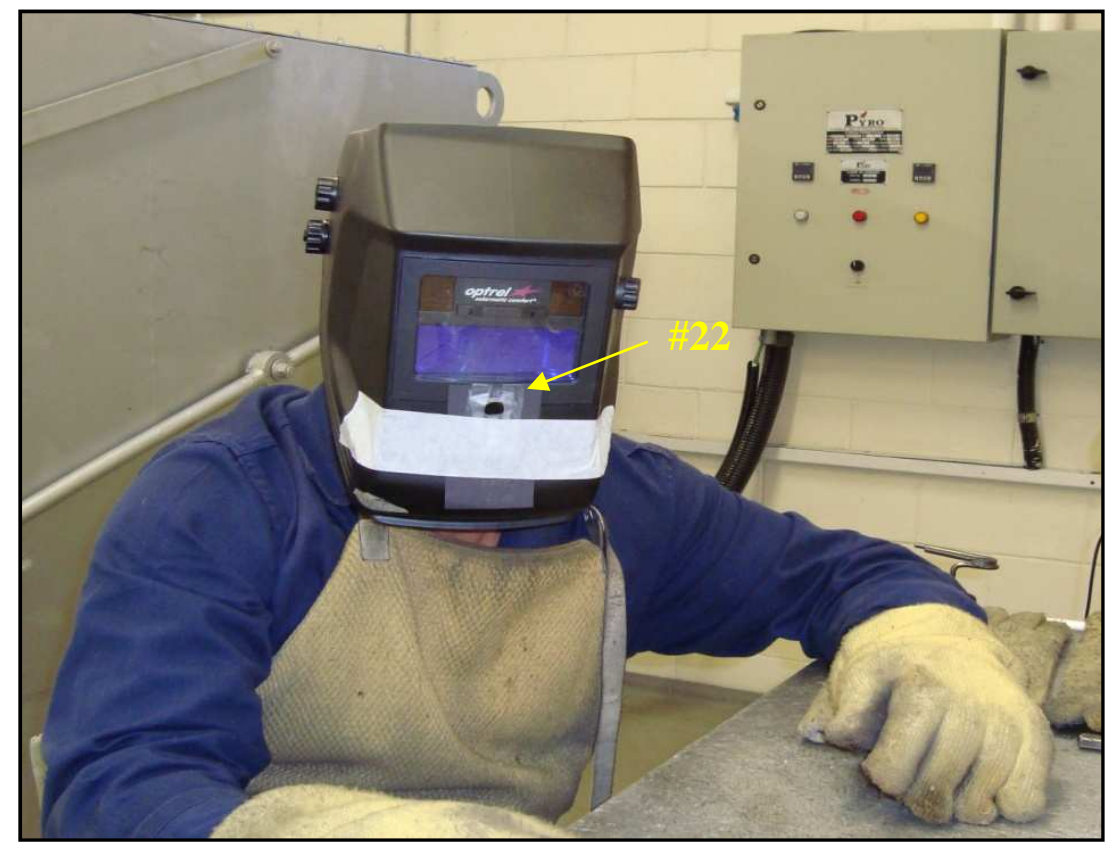

FIGURA 4.46 - Posição do conjunto (cartão + lâmina + filtro) no protetor facial do soldador, durante 5 min de soldagem TIG.

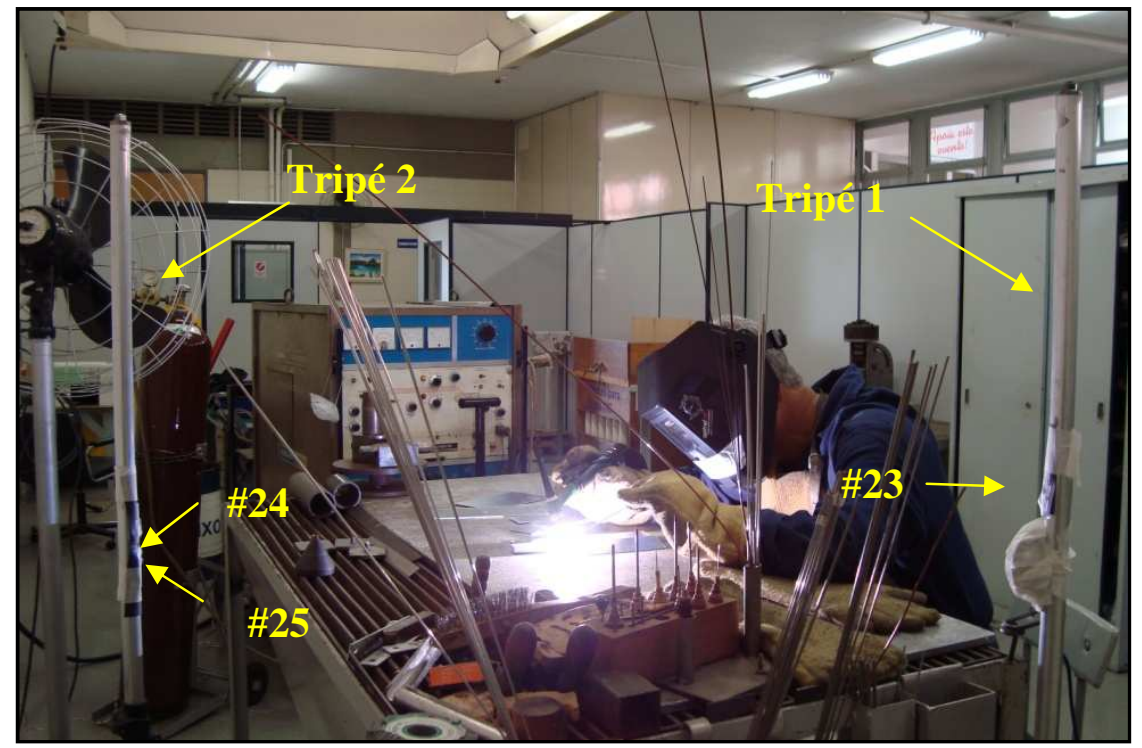

FIGURA 4.47 - Posição dos conjuntos (cartão + lâmina + filtro) nos tripés, durante 5 min de soldagem TIG.

A TAB. 4.11 e a FIG. 4.48 apresentam, respectivamente, as respostas PTOSL dos detectores $\mathrm{Al}_{2} \mathrm{O}_{3}: \mathrm{C}$ InLight, pré-condicionados, após o tratamento óptico e as respostas PTOSL após exposição à RUV proveniente do processo de 
solda TIG. Pode-se observar que para o tempo de 5 min de duração do processo de soldagem TIG, houve o estímulo do sinal PTOSL em todos os detectores.

TABELA 4.11 - Resposta OSL e PTSOL dos detectores $\mathrm{Al}_{2} \mathrm{O}_{3}: \mathrm{C}$ InLight após o tratamento óptico e exposição à RUV proveniente da solda TIG realizada durante 5 min.

\begin{tabular}{ccc}
\hline $\begin{array}{c}\text { Conjunto } \\
\text { (cartão + lâmina + filtro) }\end{array}$ & $\begin{array}{c}\text { Resposta OSL após } \\
\text { o tratamento óptico } \\
\text { (u.a.) }\end{array}$ & $\begin{array}{c}\text { Resposta } \\
\text { PTOSL } \\
\text { (u.a) }\end{array}$ \\
\hline$\# 22+\mathrm{U} 330$ & $15,64 \pm 0,16$ & $21,32 \pm 0,18$ \\
\hline$\# 23+\mathrm{U330}$ & $15,56 \pm 0,11$ & $18,20 \pm 0,22$ \\
\hline$\# 24+\mathrm{U} 340$ & $16,43 \pm 0,09$ & $16,88 \pm 0,14$ \\
\hline$\# 25+\mathrm{U} 340$ & $16,40 \pm 0,12$ & $17,82 \pm 0,14$ \\
\hline
\end{tabular}

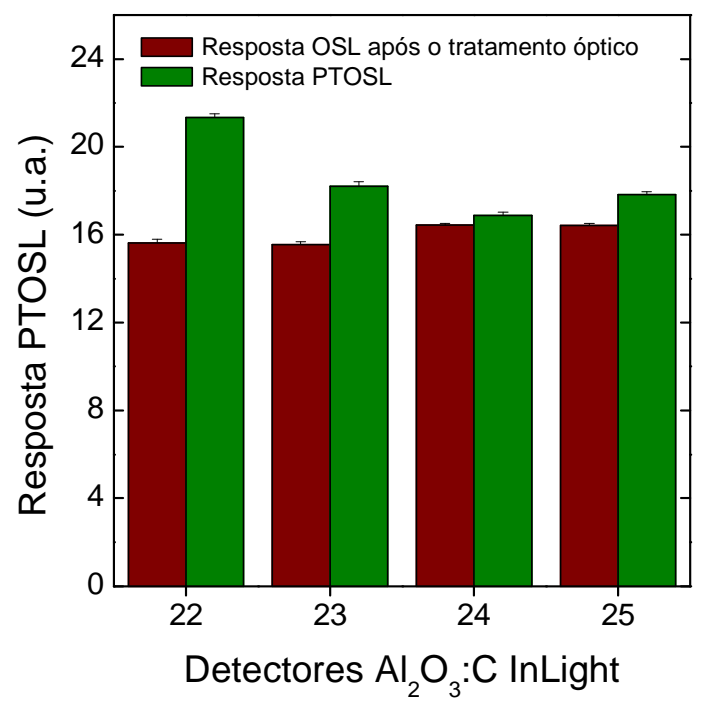

FIGURA 4.48 - Respostas OSL e PTOSL dos detectores $\mathrm{Al}_{2} \mathrm{O}_{3}: \mathrm{C}$ InLight após o tratamento óptico e exposição à RUV durante $5 \mathrm{~min}$ de soldagem TIG, respectivamente. 
A FIG. 4.49 mostra o ganho percentual da resposta PTOSL após exposição à RUV proveniente do processo de solda TIG. Observa-se que os dosímetros \#22 e \#23 apresentaram um ganho de sinal maior que os demais detectores. A distância e a posição dos detectores em relação à fonte de RUV, dentre outros fatores, podem ter interferido nestes resultados.

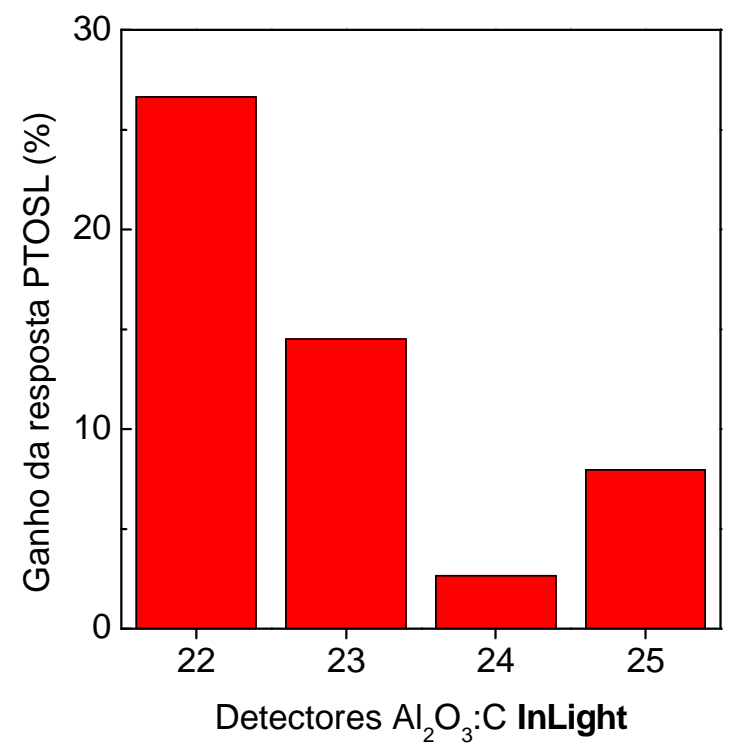

FIGURA 4.49 - Ganho percentual da resposta PTOSL dos detectores $\mathrm{Al}_{2} \mathrm{O}_{3}: \mathrm{C}$ InLight expostos à RUV do processo de solda TIG durante $5 \mathrm{~min}$.

As exposições radiantes apresentadas na TAB. 4.12 foram obtidas pela relação das respostas PTOSL dos detectores \#22 e \#23 da TAB. 4.11, com a curva de calibração dos detectores $\mathrm{Al}_{2} \mathrm{O}_{3}: \mathrm{C}$ InLight para o comprimento de onda de 330 nm da FIG. 4.31.

A resposta PTOSL do detector \#24 da TAB. 4.11 em relação à curva de calibração dos detectores $\mathrm{Al}_{2} \mathrm{O}_{3}: \mathrm{C}$ InLight para o comprimento de onda de $340 \mathrm{~nm}$, da FIG. 4.32, está abaixo do limite inferior de detecção que é de $15 \mathrm{~J} \cdot \mathrm{m}^{-2}$, de acordo com o item 4.6.10. 
A relação da resposta PTOSL do detector \#25 com a curva de calibração dos detectores $\mathrm{Al}_{2} \mathrm{O}_{3}: \mathrm{C}$ InLight para o comprimento de onda de $340 \mathrm{~nm}$ da FIG. 4.32 demonstrou uma exposição radiante de $42,0 \mathrm{~J} . \mathrm{m}^{-2}$, conforme apresentado na TAB. 4.12 .

TABELA 4.12 - Valores de exposições radiantes obtidas nas posições dos detectores \#22, \#23 e \#25

Detector

\# 22
Exposição radiante $\left(J \cdot m^{-2}\right)$

\# 23

$110,4 \pm 0,1$

\# 25

$42,0 \pm 0,1$

\subsection{Exposição dos detectores $\mathrm{Al}_{2} \mathrm{O}_{3}: \mathrm{C}$ InLight, pré-condicionados, à RUV proveniente do processo de solda TIG durante $20 \mathrm{~min}$.}

A quarta aplicação prática foi realizada durante um processo de 15 min de soldagem TIG de uma peça de aço inox.

Um grupo de quatro detectores passou pelo pré-condicionamento inicial antes da exposição à RUV. Os conjuntos (cartão + lâmina + filtro) foram fixados em tripés na altura da realização das soldagens, conforme dados apresentados na TAB. 4.13 e mostrados nas FIG. 4.50 e 4.51 . 
TABELA 4.13 - Posição e distância dos conjuntos (cartão + lâmina + filtro) durante o processo de soldagem TIG.

\begin{tabular}{ccc}
\hline $\begin{array}{c}\text { Conjunto } \\
\text { (cartão + lâmina + filtro) }\end{array}$ & $\begin{array}{c}\text { Posição durante a } \\
\text { operaça de solda à } \\
\text { arco }\end{array}$ & $\begin{array}{c}\text { Distância da soldagem } \\
\text { (cm) }\end{array}$ \\
\hline$\# 26+$ U330 & Protetor facial & 20 \\
\hline \#27 + U330 & Tripé 1 & 100 \\
\hline$\# 28+$ U340 & Tripé 2 & 100 \\
\hline$\# 29+$ U340 & Tripé 1 & 100 \\
\hline
\end{tabular}

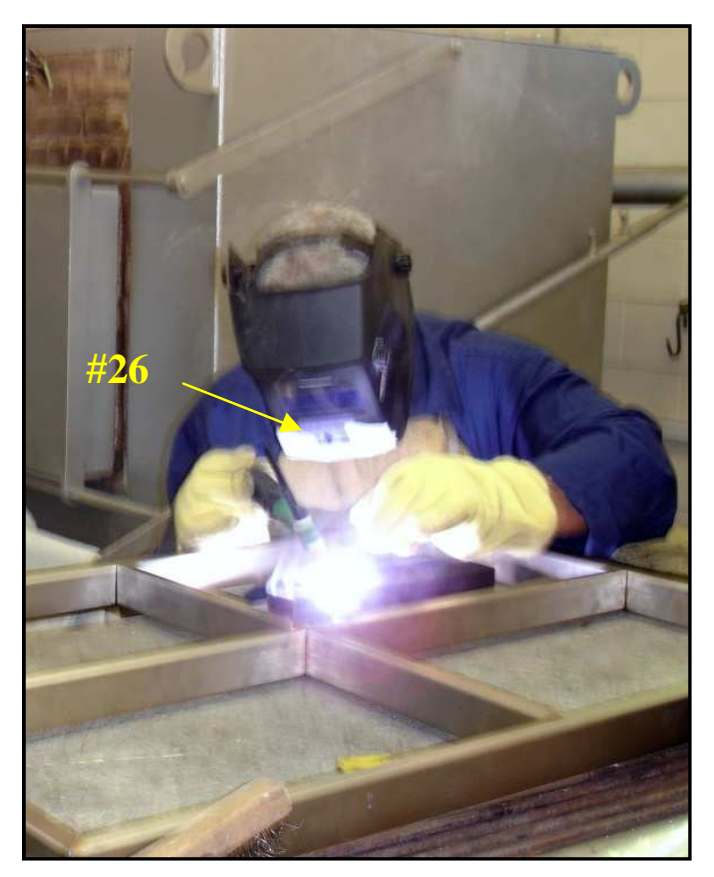

FIGURA 4.50 - Posição do conjunto (cartão + lâmina + filtro) no protetor facial durante o processo de solda TIG de $20 \mathrm{~min}$. 


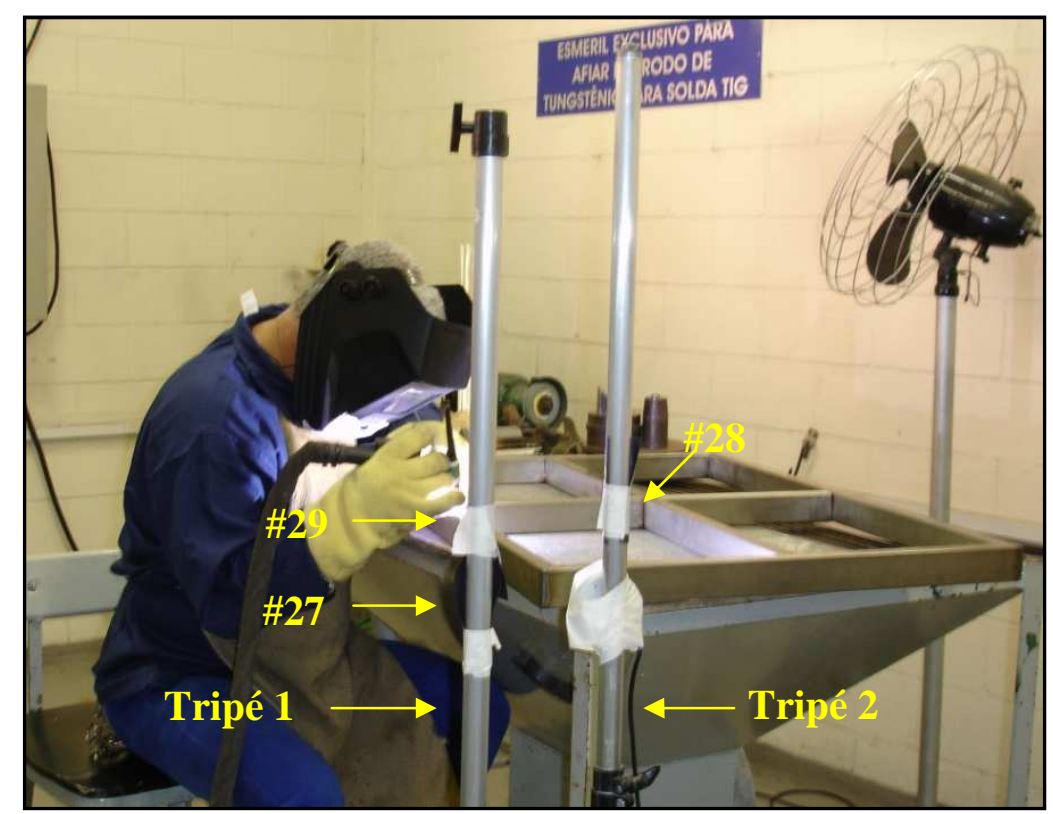

FIGURA 4.51 - Posição dos conjuntos (cartão + lâmina + filtro) nos tripés durante o processo de solda TIG de $20 \mathrm{~min}$.

Todos os detectores expostos à RUV do processo de solda TIG apresentaram resposta PTOSL, conforme valores apresentados na TAB. 4.14 e nas FIG. 4.52 e 4.53. Foram realizadas dez leituras OSL de cada detector exposto à RUV proveniente do processo de solda TIG $(\sigma=1, \mathrm{k}=1)$.

TABELA 4.14 - Resposta OSL e PTOSL dos detectores $\mathrm{Al}_{2} \mathrm{O}_{3}: \mathrm{C}$ InLight, précondicionados, após o tratamento óptico e exposição à RUV proveniente do processo de solda TIG realizado em 20 min.

\begin{tabular}{ccc}
\hline $\begin{array}{c}\text { Conjunto } \\
\text { (cartão + lâmina + filtro) }\end{array}$ & $\begin{array}{c}\text { Resposta OSL após } \\
\text { o tratamento óptico } \\
\text { (u.a.) }\end{array}$ & $\begin{array}{c}\text { Resposta } \\
\text { PTOSL } \\
\text { (u.a) }\end{array}$ \\
\hline$\# 26+$ U330 & $15,34 \pm 0,15$ & $19,70 \pm 0,19$ \\
\hline$\# 27+$ U330 & $15,37 \pm 0,18$ & $17,28 \pm 0,21$ \\
\hline \#28 + U340 & $16,45 \pm 0,21$ & $17,92 \pm 0,12$ \\
\hline$\# 29+$ U340 & $16,44 \pm 0,23$ & $19,67 \pm 0,29$ \\
\hline
\end{tabular}




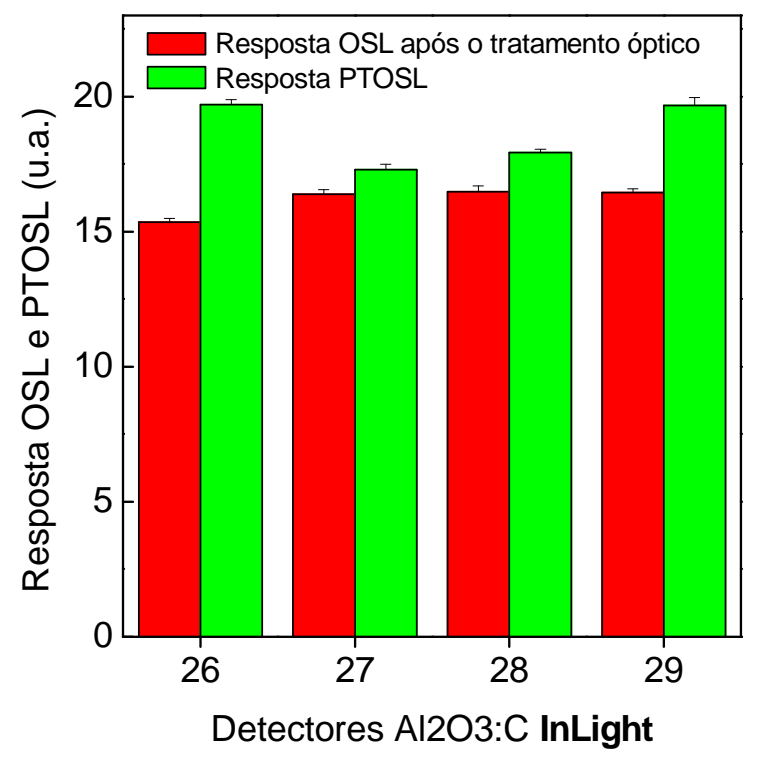

FIGURA 4.52 - Resposta OSL dos detectores $\mathrm{Al}_{2} \mathrm{O}_{3}: \mathrm{C}$ InLight após o tratamento óptico e resposta PTOSL após exposição à RUV do processo de soldagem TIG realizado em $20 \mathrm{~min}$.

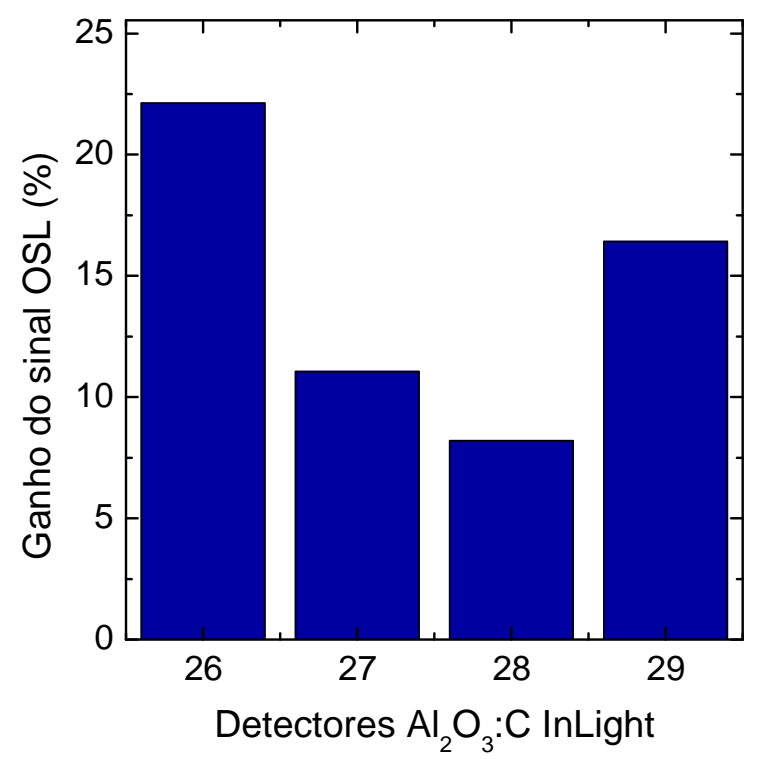

FIGURA 4.53 - Ganho percentual da resposta PTOSL dos detectores $\mathrm{Al}_{2} \mathrm{O}_{3}: \mathrm{C}$ InLight expostos à RUV do processo de solda TIG realizado em $20 \mathrm{~min}$. 
A FIG. 4.53 mostra o ganho percentual da resposta PTOSL após exposição à RUV proveniente do processo de solda elétrica. Observa-se que os dosímetros \#26 e \#29 apresentaram ganhos de sinal PTOSL maiores que os demais detectores. A distância e a posição dos detectores em relação à fonte de RUV podem também ter afetado estes resultados.

As relações das respostas PTOSL dos detectores \#26 e \#27 com a curva de calibração dos detectores $\mathrm{Al}_{2} \mathrm{O}_{3}: \mathrm{C}$ InLight para o comprimento de onda de $330 \mathrm{~nm}$ (FIG. 4.31) e da resposta PTOSL dos detectores \#28 e \#29 com a curva de calibração dos detectores $\mathrm{Al}_{2} \mathrm{O}_{3}: \mathrm{C}$ InLight para o comprimento de onda de $340 \mathrm{~nm}$ (FIG. 4.32), permitiram obter as exposições radiantes que constam da TAB. 4.15.

TABELA 4.15 - Valores de exposições radiantes obtidas nas posições dos detectores \#26, \#27 e \#28 e \#29.

\begin{tabular}{cc}
\hline Detector & $\begin{array}{c}\text { Exposição radiante } \\
\left(\mathbf{J} . \mathbf{m}^{-2}\right)\end{array}$ \\
\hline$\# 26$ & $222,6 \pm 0,1$ \\
\hline$\# 27$ & $62,0 \pm 0,1$ \\
\hline$\# 28$ & $46,1 \pm 0,1$ \\
\hline$\# 29$ & $102,1 \pm 0,1$ \\
\hline
\end{tabular}

Nas três aplicações práticas com detectores $\mathrm{Al}_{2} \mathrm{O}_{3}: \mathrm{C}$ InLight, précondicionados, expostos à RUV proveniente dos processos de soldagens elétrica e TIG, ocorreu o estímulo do sinal PTOSL.

Uma análise dos valores de exposição radiante obtidos nas aplicações práticas dos itens 4.7.2.2, 4.7.2.3.1 e 4.7.2.3.2 permitiu verificar que o detector posicionado no protetor facial do trabalhador durante a soldagem elétrica realizada em 2 min foi o que obteve um valor de exposição radiante maior num tempo menor de exposição à RUV quando comparado com os outros valores de 
exposições radiantes obtidas pelos detectores posicionados no protetor facial dos soldadores durante um intervalo de tempo maior de exposição à RUV.

Alguns fatores durante as soldagens, dentre outros, como o tipo de solda, eletrodo, tipo de peça soldada, a variação da potência e da amperagem da solda, podem ter influenciado o estímulo destas respostas PTOSL. 


\section{CONCLUSÕES}

Os resultados deste trabalho alcançaram os objetivos propostos, permitindo o estabelecimento de um método dosimétrico para avaliação da exposição à RUV, utilizando os detectores de $\mathrm{Al}_{2} \mathrm{O}_{3}: \mathrm{C}$ da Landauer e as técnicas de Luminescência Opticamente Estimulada (OSL) e Luminescência Opticamente Estimulada Fototransferida (PTOSL).

Os procedimentos e as práticas adotados nesta pesquisa mostraram-se satisfatórios, permitindo inferir que:

- o desempenho do sistema leitor OSL, durante todo o estudo, foi estável e manteve-se de acordo com os limites estabelecidos pelo fabricante;

- a caracterização inicial dos detectores $\mathrm{Al}_{2} \mathrm{O}_{3}: \mathrm{C}$ InLight Dot em relação às fontes de ${ }^{60} \mathrm{Co}$ e ${ }^{137} \mathrm{Cs}$ apresentou resultados dentro dos limites estabelecidos pelo CASMIE/CNEN;

- o estudo sobre o decaimento óptico do sinal OSL dos detectores $\mathrm{Al}_{2} \mathrm{O}_{3}: \mathrm{C}$ InLight Dot em função do nível de iluminamento de 260 lux, 26.000 lux e luz solar demonstrou a alta sensibilidade destes detectores à luz visível e a necessidade de manipular esses detectores em ambiente escuro;

- a caixa de luz com 26.000 lux demonstrou ser um sistema de tratamento óptico adequado para o esvaziamento das armadilhas dosimétricas principais dos detectores $\mathrm{Al}_{2} \mathrm{O}_{3}: \mathrm{C}$, na fase de pré-condicionamento, para 0 estimulo do sinal PTOSL após exposição à RUV, e também para o completo esvaziamento das armadilhas rasas e profundas no processo de reutilização dos detectores; 
- os detectores $\mathrm{Al}_{2} \mathrm{O}_{3}: \mathrm{C}$ InLight sem pré-condicionamento e précondicionados expostos à luz do sistema de RUV apresentaram sinais OSL e PTOSL em função do comprimento de onda, do tempo de iluminação UV, da irradiância, da exposição radiante e da dependência angular, em todos os intervalos estudados;

- os detectores pré-condicionados mostraram uma vantagem em relação aos detectores sem pré-condicionamento, que é o fato de manterem por um período mais longo o sinal PTOSL, o que possibilita a leitura em laboratório sem a necessidade de levar um leitor OSL portátil ao local da exposição dos detectores à RUV. Além disso, permite várias medições do sinal PTOSL em uma mesma amostra;

- como os detectores InLight Dot e InLight não podem passar por um tratamento térmico por causa de suas camadas de poliéster, a determinação do tempo de tratamento óptico mais adequado para a produção da PTOSL foi um fator importante no desenvolvimento deste estudo. O tempo de tratamento óptico de $30 \mathrm{~min}$, após a pré-irradiação, mostrou-se aceitável para esvaziar as armadilhas rasas dos detectores;

- o tempo de iluminação UV de 30 min também mostrou ser aceitável para o estímulo da PTOSL em relação a todos os parâmetros estudados.

A PTOSL demonstrou ser uma técnica importante no estudo da dosimetria da RUV. A determinação dos parâmetros do pré-condicionamento inicial dos detectores foi fundamental para que a RUV liberasse as cargas das armadilhas profundas para as armadilhas rasas produzindo um estímulo maior do sinal PTOSL.

As aplicações práticas dos detectores $\mathrm{Al}_{2} \mathrm{O}_{3}: \mathrm{C}$ InLight, pré-condicionados, expostos à RUV artificial proveniente de processos de soldagens elétrica e 
TIG (Tungsten Inert Gas), revelaram a possibilidade da utilização destes detectores em dosimetria da exposição à RUV.

O estudo evidenciou que é possível utilizar o leitor OSL microStar System e os detectores de $\mathrm{Al}_{2} \mathrm{O}_{3}: \mathrm{C}$ InLight, ambos da Landauer, de uso específico para dosimetria das radiações ionizantes e disponíveis comercialmente, em dosimetria da radiação ultravioleta, principalmente para a faixa UVA na região espectral centrada em $330 \mathrm{~nm}$. 


\section{APÊNDICE A}

Procedimentos básicos para utilização do leitor OSL microStar System e software da Landauer e dos detectores $\mathrm{Al}_{2} \mathrm{O}_{3}: \mathrm{C}$ InLight Dot e InLight.

\section{A.1 Objetivo}

Descrever os procedimentos básicos para utilização do leitor OSL microStar System e software da Landauer e dos detectores $\mathrm{Al}_{2} \mathrm{O}_{3}: \mathrm{C}$ InLight Dot e InLight.

\section{A.2 Campo de aplicação}

Aplica-se em dosimetria das radiações ionizantes.

\section{A.3 Procedimento geral}

A.3.1 Conectar o notebook IBM de uso exclusivo ao leitor OSL microStar System da Landauer.

A.3.2 Ligar o leitor OSL num botão localizado na parte traseira do equipamento.

A.3.3 Ligar o notebook.

A.3.4 Abrir o arquivo microStar.

A.3.5 Selecionar o tipo de detector a ser utilizado (InLight Dot ou InLight).

A.3.6 Digitar o número do detector no campo adequado da planilha do software microStar. 
A.3.7 Abrir a gaveta localizada na parte frontal do sistema leitor, colocar o detector no local adequado e fechar a gaveta. O botão mecânico do leitor deve estar selecionado na posição HP.

A.3.6 Para realizar a leitura no caso de detector tipo InLight Dot, girar o botão mecânico para a posição E1. Se estiver utilizando o detector InLight girar o botão para as posições E1, E2, E3 e E4.

A.3.7 Durante a leitura um LED amarelo acende. Ao término da leitura, o LED se apaga e o valor da medida fica registrado na planilha do software microStar.

A.3.8 Para retirar o detector de dentro do leitor OSL, posicionar o botão mecânico no modo HP e abrir a gaveta.

\section{A.4 Desempenho do sistema leitor OSL}

A.4.1 Posicionar o botão mecânico frontal do sistema leitor OSL nos padrões DARK, CAL e LED e fazer as medidas sem detector.

A.4.2 Realizar este procedimento a cada 10 leituras OSL e verificar se estão de acordo com os limites estabelecidos pelo fabricante [LANDAUER, 2006].

\section{A.5 Calibração do sistema leitor OSL}

A.5.1 Selecionar "Calibração" no programa microStar.

A.5.2 Utilizar o conjunto de 4 detectores InLight de calibração pré-irradiados pelo fabricante.

A.5.3 Realizar as medidas no sistema leitor OSL.

A.5.4 Construir a curva de calibração. 
A.5.5 Realizar esse acompanhamento a cada 2 meses ou após cada serviço de manutenção do leitor.

\section{A.6 Utilização dos detectores $\mathrm{Al}_{2} \mathrm{O}_{3}: \mathrm{C}$ InLight Dot e InLight}

A.6.1 Inicialmente deve-se "zerar" todas as lâminas dos detectores InLight Dot e InLight numa caixa de luz fluorescente com nível de iluminamento de aproximadamente 26.000 lux. O tempo necessário para "zerar" as lâminas dos detectores é de 30 min a 24 horas, dependendo da dose recebida.

A.6.2 A manipulação dos detectores $\mathrm{Al}_{2} \mathrm{O}_{3}: \mathrm{C}$ InLight Dot e InLight deve ser feita em ambiente escuro devido à alta sensibilidade desses detectores à luz visível.

A.6.3 Irradiar os detectores de acordo com o tipo de fonte e dose de radiação ionizante a ser empregada no estudo.

A.6.4 Realizar 10 medidas OSL para cada detector irradiado.

IMPORTANTE: Informações mais detalhadas e específicas do sistema leitor OSL, do software e dos detectores $\mathrm{Al}_{2} \mathrm{O}_{3}: \mathrm{C}$ InLight Dot e InLight devem ser consultadas no manual do fabricante [LANDAUER, 2008]. 


\section{APÊNDICE B}

Procedimento para utilização do sistema leitor OSL microStar e dos detectores $\mathrm{Al}_{2} \mathrm{O}_{3}: \mathrm{C}$ InLight Dot e InLight da Landauer, sem précondicionamento, expostos a uma fonte de radiação ultravioleta.

\section{B.1 Objetivo}

Descrever um procedimento para utilização do sistema leitor OSL microStar e os detectores $\mathrm{Al}_{2} \mathrm{O}_{3}: \mathrm{C}$ InLight Dot e InLight da Landauer, sem précondicionamento, expostos a uma fonte de radiação ultravioleta.

\section{B.2 Campo de aplicação}

Aplica-se na detecção de RUV centrada na região espectral de $330 \mathrm{~nm}$, em locais de trabalho.

\section{B.3 Procedimento geral}

B.3.1 Inicialmente deve-se "zerar" todas as lâminas dos detectores InLight Dot e InLight numa caixa de luz fluorescente com nível de iluminamento de aproximadamente 26.000 lux. O tempo necessário para "zerar" os detectores é de $30 \mathrm{~min}$ a 24 horas ou mais, dependendo da dose recebida.

B.3.2 A manipulação dos detectores $\mathrm{Al}_{2} \mathrm{O}_{3}: \mathrm{C}$ InLight Dot e InLight deve ser feita em ambiente escuro devido à alta sensibilidade desses detectores à luz visível.

B.4 Exposição das lâminas dos detectores $\mathrm{Al}_{2} \mathrm{O}_{3}: \mathrm{C}$ InLight Dot e InLight à luz do sistema de RUV da GMR

B.4.1 Selecionar o comprimento de onda no monocromador. 
B.4.2 Ligar a lâmpada de Hg.

B.4.3 Conectar o sensor UVA ao radiômetro Delta OHM.

B.4.4 Conectar o radiômetro a um PC compatível no qual esteja instalado o software do radiômetro Delta OHM para acompanhar e registrar o parâmetro que estiver sendo medido (irradiância).

B.4.5 Ligar o radiômetro.

B.4.6 Posicionar o sensor UV no suporte da amostra e na base sobre o trilho do sistema de radiação ultravioleta do laboratório da GMR. Posicionar a base numa distância em função da irradiância desejada.

B.4.7 Retirar o sensor da base e posicionar o suporte de amostra com a lâmina na base sobre o trilho do sistema de radiação ultravioleta do laboratório da GMR na mesma posição onde estavam a base e o sensor UVA.

B.4.8 Expor a lâmina à RUV no comprimento de onda, na irradiância e no tempo de exposição à RUV pré-determinados.

B.4.9 Retirar a lâmina do suporte da amostra e colocar no invólucro.

B.4.10 Posicionar novamente o sensor UVA na base para verificar se não houve alteração da irradiância.

B.4.11 Realizar as medidas OSL no sistema leitor OSL imediatamente após a exposição da lâmina à RUV.

B.5 Exposição das lâminas dos detectores $\mathrm{Al}_{2} \mathrm{O}_{3}: \mathrm{C}$ InLight Dot e InLight à RUV proveniente de uma fonte num local de trabalho. 
B.5.1 Usar filtro o HOYA U 330 sobre a pastilha do detector durante a exposição à fonte de RUV, para que a luz ambiente não interfira no sinal OSL do detector.

B.5.2 Identificar o detector que será utilizado no processo de dosimetria.

B.5.3 Posicionar o detector e o filtro na região dos olhos ou em regiões do corpo sem proteção no trabalhador que estiver executando procedimento que gera RUV e em trabalhadores (sem proteção adequada) que realizam suas atividades próximas a esta fonte de UV.

B.5.4 Anotar o tempo de exposição, os locais onde foram posicionados os detectores (altura e distância) e o tipo de fonte de RUV.

B.5.5 Este tipo de dosimetria exige que as medidas OSL sejam feitas imediatamente após a exposição dos detectores à RUV.

B.5.6 O sistema leitor OSL deve estar posicionado no local onde está sendo realizada a dosimetria.

B.5.7 Realizar as medidas no sistema leitor OSL. 


\section{APÊNDICE C}

Procedimento para utilização do sistema leitor OSL microStar e os detectores $\mathrm{Al}_{2} \mathrm{O}_{3}: \mathrm{C}$ InLight Dot e InLight da Landauer pré- condicionados e expostos à uma fonte de radiação ultravioleta.

\section{C.1 Objetivo}

Descrever um procedimento para utilização do sistema leitor OSL microStar e os detectores $\mathrm{Al}_{2} \mathrm{O}_{3}: \mathrm{C}$ InLight Dot e InLight da Landauer précondicionados e expostos à uma fonte de radiação ultravioleta.

\section{C.2 Campo de aplicação}

Aplica-se em dosimetria de exposição à radiação ultravioleta centrada na região espectral de $330 \mathrm{~nm}$.

\section{C.3 Procedimento}

C.3.1 Inicialmente deve-se "zerar" todas as lâminas dos detectores InLight Dot e InLight numa caixa de luz fluorescente com nível de iluminamento de aproximadamente 26.000 lux. O tempo necessário para "zerar" os detectores é de 30 min a 48 horas ou mais, dependendo da dose recebida.

C.3.2 A manipulação dos detectores $\mathrm{Al}_{2} \mathrm{O}_{3}: \mathrm{C}$ InLight Dot e InLight deve ser feita em ambiente escuro devido à alta sensibilidade desses detectores à luz visível.

C.4 Pré-condicionamento das lâminas dos detectores $\mathrm{Al}_{2} \mathrm{O}_{3}: \mathrm{C}$ InLight Dot e InLight. 
C.4.1 Irradiar com 1Gy $\left({ }^{60} \mathrm{Co}\right)$. Os detectores (invólucros mais lâminas) devem ser irradiados entre placas de Lucite para manter as condições de equilíbrio eletrônico.

C.4.2 Realizar 10 leituras OSL em cada detector. Calcular a média, o desvio padrão e o desvio percentual para cada detector.

C.4.3 Tratar opticamente as lâminas durante 30 min a aproximadamente 26.000 lux na caixa de luz.

C.4.4 Realizar 10 leituras OSL em cada detector. Calcular a média $\left(M_{i}\right)$, o desvio padrão e o desvio percentual de cada detector e a média total $\left(M_{T}\right)$ dos valores médios dos detectores do lote de amostras utilizados.

C.4.5 Calcular o fator de correção para cada detector, que consiste da razão entre a média total das respostas OSL $\left(M_{T}\right)$ e o valor médio das medidas OSL do detector $\left(M_{i}\right)$, sendo:

$$
f_{C}=M_{T} / M_{i}
$$

Cada detector terá um fator de correção que deverá ser aplicado às respostas OSL dos detectores após exposição à RUV. Este fator de correção deverá ser recalculado para cada detector sempre que um lote for tratado opticamente.

\section{C.5 Exposição das lâminas dos detectores $\mathrm{Al}_{2} \mathrm{O}_{3}: \mathrm{C}$ InLight Dot e InLight pré- condicionadas à luz do sistema de RUV da GMR.}

C.5.1 Selecionar o comprimento de onda de $330 \mathrm{~nm}$ no monocromador.

C.5.2 Ligar a lâmpada de Hg.

C.5.3 Conectar o sensor UV ao radiômetro Delta OHM. 
C.5.4 Conectar o radiômetro a um PC compatível no qual foi instalado o software da Delta OHM, para acompanhar e registrar o parâmetro irradiância.

C.5.5 Ligar o radiômetro.

C.5.6 Posicionar o sensor UV no suporte da amostra e na base sobre o trilho do sistema de radiação ultravioleta do laboratório da GMR. Posicionar o sensor numa distância determinada em função da irradiância desejada $\left(0,25 \mathrm{~W} \cdot \mathrm{m}^{-2}\right)$.

C.5.7 Retirar o sensor da base e posicionar o suporte de amostra com a lâmina na base sobre o trilho do sistema de radiação ultravioleta do laboratório da GMR na mesma posição onde estavam a base e o sensor UV.

C.5.8 Expor a lâmina durante 30 min à fonte de RUV, mantendo o comprimento de onda fixo em $330 \mathrm{~nm}$ e a irradiância constante em $0,25 \mathrm{~W} \cdot \mathrm{m}^{-2}$.

C.5.9 Retirar a lâmina do suporte da amostra e colocar no invólucro.

C.5.10 Posicionar novamente o sensor UV na base para verificar se a irradiância permanece constante.

C.5.11 Realizar 10 leituras OSL com cada detector. Calcular a média, o desvio padrão e o desvio percentual e aplicar o fator de correção correspondente de cada detector. 
C.6 Exposição das lâminas dos detectores $\mathrm{Al}_{2} \mathrm{O}_{3}: \mathrm{C}$ InLight Dot e InLight précondicionadas à RUV proveniente de fontes em locais de trabalho

C.6.1 Usar filtro HOYA U 330 sobre a pastilha do detector durante a exposição à fonte de RUV para que a luz do ambiente não interfira no sinal OSL do detector.

C.6.2 Identificar o detector que será utilizado na dosimetria.

C.6.3 Posicionar o detector e o filtro na região dos olhos ou em regiões do corpo sem proteção no trabalhador que estiver executando procedimento que gera RUV e em trabalhadores (sem proteção adequada) que realizam suas atividades próximos a esta fonte de UV.

C.6.4 Anotar o tempo de exposição, os locais onde foram posicionados os detectores (altura e distância) e o tipo de fonte RUV.

C.6.5 Realizar 10 leituras OSL em cada detector. Calcular a média, o desvio padrão e o desvio percentual e aplicar o fator de correção correspondente de cada detector.

C.6.6 Correlacionar os resultados obtidos com a curva de calibração dos detectores pré-condicionados em função da exposição radiante para 330nm, e com os limites de exposição. 


\section{ANEXO I}

\section{Unidades e Grandezas}

Os conceitos dosimétricos e as definições das grandezas de doses para uso da proteção radiológica foram definidos pela International Commission on Radiological Protection [ICRP, 1991] e pela International Commission on Radiation Units and Measurements [ICRU,1993].

\section{- Dose absorvida}

A dose absorvida, $D$, é uma grandeza física básica de interesse particular da proteção radiológica, e é definida pela relação:

$$
D=\frac{d \bar{E}}{d m}
$$

onde $d \bar{E}$ é a energia média depositada pela radiação ionizante no elemento de massa $d m$. A dose absorvida é definida em termos de um ponto específico, mas para o ICRP (1991) significa a dose média absorvida em um tecido ou órgão. A unidade de dose absorvida no Sistema Internacional (SI) é o Joule por quilograma (J.kg-1) e recebe também o nome especial de Gray (Gy).

A taxa de dose absorvida é definida pela unidade de dose absorvida por unidade de tempo. A unidade de taxa de dose absorvida no Sistema Internacional é joule por quilograma por segundo $\left(\mathrm{J} . \mathrm{kg}^{-1} \cdot \mathrm{s}^{-1}\right)$. O nome restrito é Gray por segundo $\left(\right.$ Gy.s $\left.\mathrm{s}^{-1}\right)$ e o nome antigo é rad por segundo $\left(\mathrm{rad} . \mathrm{s}^{-1}\right)$.

\section{- Exposição}

Considerada como a grandeza física mais antiga usada em proteção radiológica, a exposição $(X)$ é definida pela relação: 


$$
X=\frac{d Q}{d m}
$$

onde $d Q$ é o valor absoluto da carga total dos íons de um mesmo sinal, produzidos no ar quando todos os elétrons liberados pelos fótons no ar de massa $d m$ são completamente freados no ar. A unidade de exposição no sistema

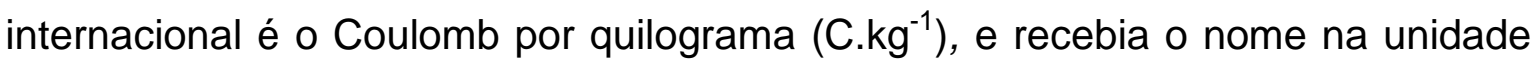
antiga de Roentgen (R).

Além dos valores integrais da grandeza exposição, emprega-se a grandeza taxa de exposição, que é a exposição por unidade de tempo $\left(\mathrm{C}_{\mathrm{kg}} \mathrm{kg}^{-1} \cdot \mathrm{s}^{-1}\right.$ ou R.h $\left.{ }^{-1}\right)($ ICRU,1998).

As grandezas radiométricas são utilizadas para descrever as características de uma fonte ou campo de radiação. Estas grandezas são definidas a seguir [SLINEY, 2007; ICNIRP, 2007]:

- Energia radiante: radiação que se propaga pelo espaço na forma de onda eletromagnética. É a grandeza radiométrica fundamental que indica a quantidade de energia.

- Fluxo radiante: quantidade de energia, num ponto do espaço, durante um intervalo de tempo.

- Intensidade radiante: fluxo radiante emitido pela fonte por unidade de ângulo sólido.

- Radiância: fluxo de energia radiante emitido pela unidade de ângulo sólido e área da fonte.

- Irradiância: quantidade de fluxo radiante recebida por unidade de área em uma superfície.

- Exposição radiante: energia radiante incidente em uma superfície pelo tempo. É a integral do tempo da irradiância. 
$\mathrm{Na}$ TAB. 1 estão apresentadas essas grandezas e suas respectivas unidades radiométricas.

Tabela161 - Grandezas e unidades radiométricas [SLINEY, 2007].

\begin{tabular}{ccc}
\hline Grandezas & Símbolo & Unidade \\
\hline Comprimento de Onda & $\lambda$ & $\mathrm{nm}$ \\
\hline Energia Radiante & $\mathrm{Q}$ & $\mathrm{J}$ \\
\hline Fluxo Radiante & $\phi$ & $\mathrm{W}$ \\
\hline Intensidade Radiante & $\mathrm{I}$ & $\mathrm{W} \cdot \mathrm{sr}^{-1}$ \\
\hline Radiância & $\mathrm{L}$ & $\mathrm{W} \cdot \mathrm{m}^{-2} \mathrm{sr}^{-1}$ \\
\hline Irradiância & $\mathrm{E}$ & $\mathrm{W} \cdot \mathrm{m}^{-2}$ \\
\hline Exposição Radiante & $\mathrm{H}$ & $\mathrm{J} \cdot \mathrm{m}^{-2}$ \\
\hline
\end{tabular}




\section{ANEXO II}

\section{Características do Filtro HOYA U 330}

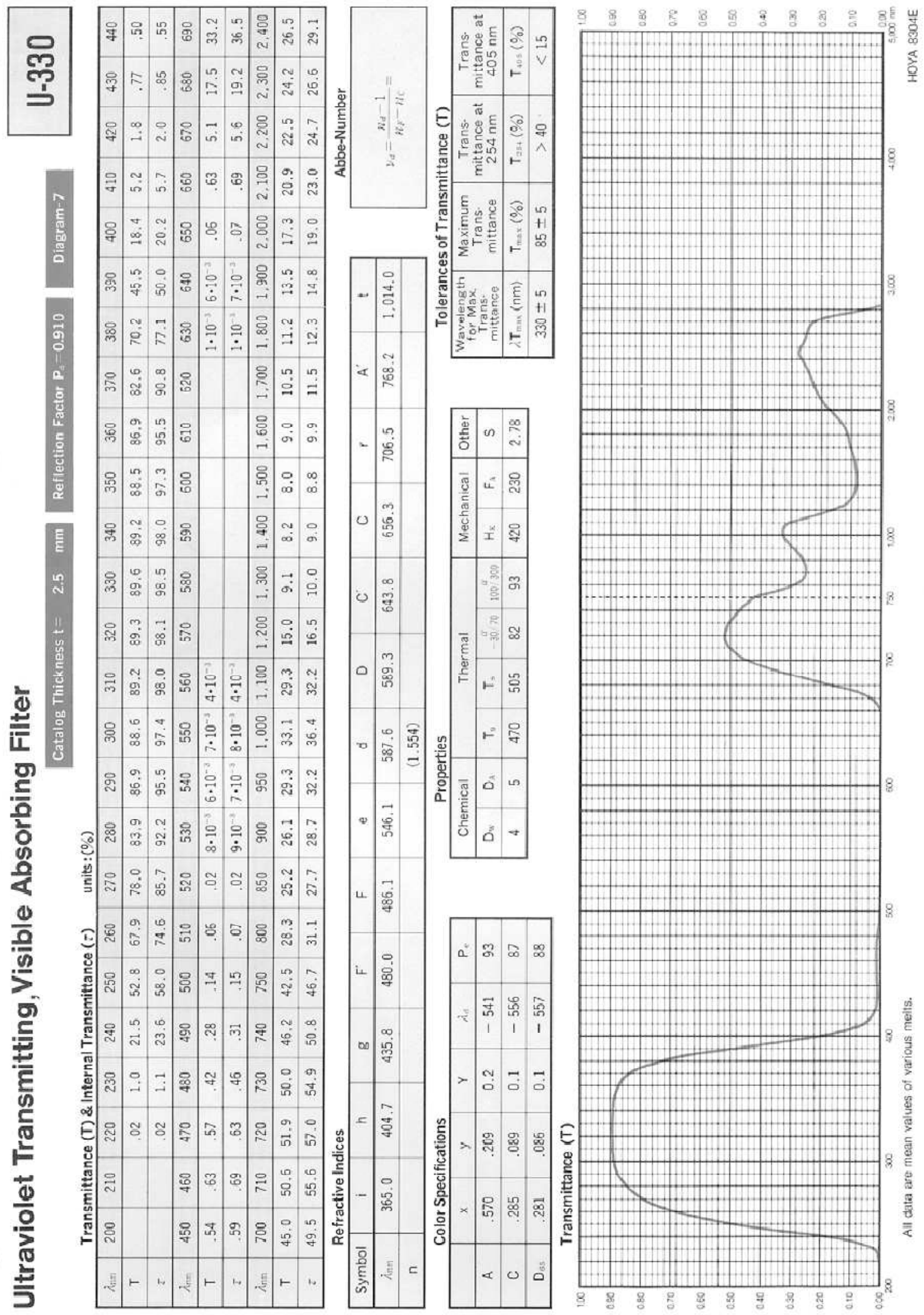




\section{ANEXO III}

\section{Características do Filtro HOYA U 340}

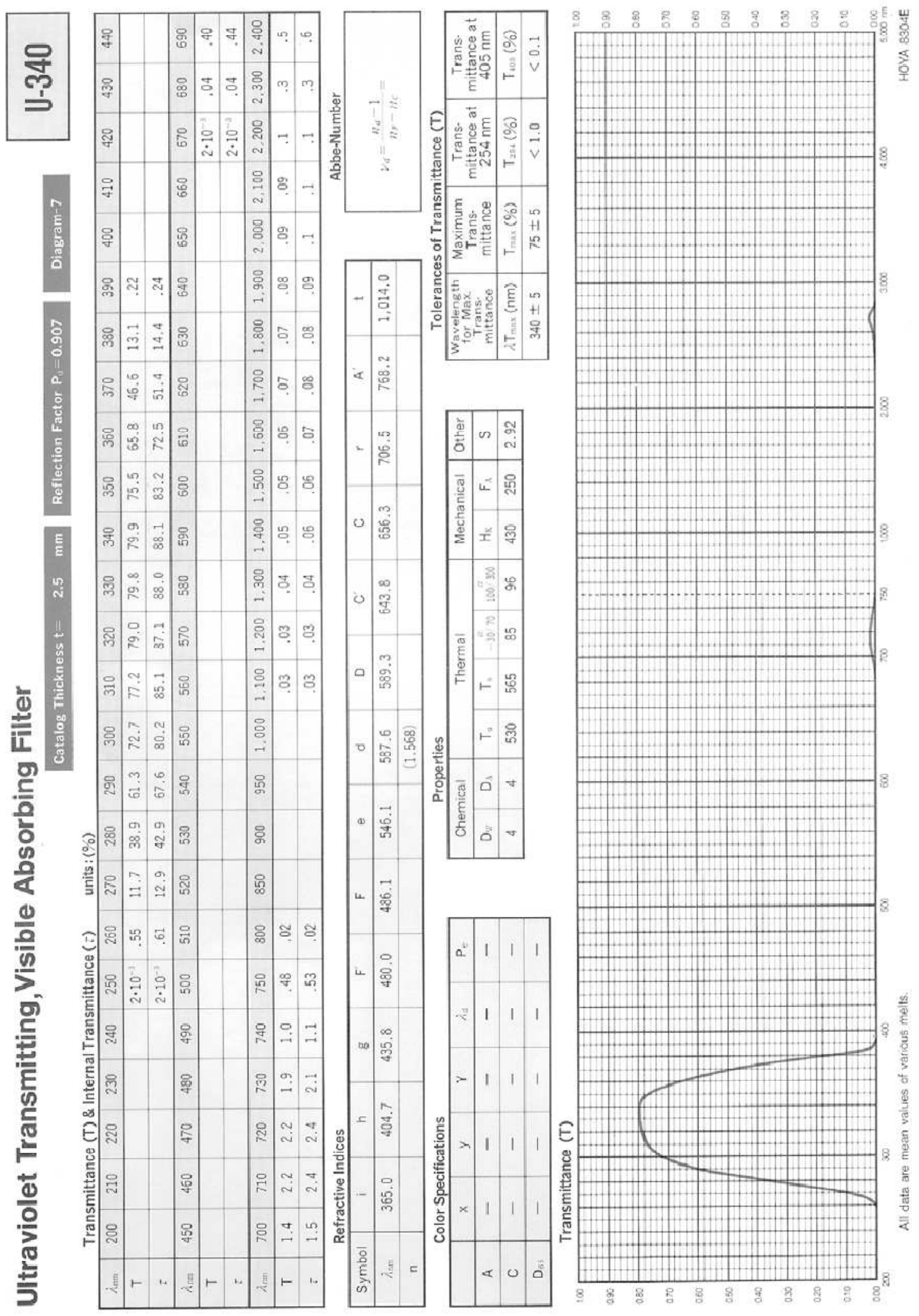




\section{REFERÊNCIAS BIBLIOGRÁFICAS}

AKSELROD, M. S.; BOTTER-JENSEN, L.; McKEEVER, S. W. S. Optically stimulated luminescence and its use in medical dosimetry. Radiat. Meas., v. 41, p. S78 - S99, 2007.

AKSELROD, M. S.; KORTOV, V. S.; GORELOVA, E.A. Preparation and properties of $\alpha-\mathrm{Al}_{2} \mathrm{O}_{3}:$ C. Radiat. Prot. Dosim., v. 47, p. $159-164,1993$.

AKSELROD, M. S.; KORTOV, V. S.; KRAVESTSKY, D. J.; GOTLIB, V. I. Highly sensitive thermoluminescenct anion-defect $\alpha-\mathrm{Al}_{2} \mathrm{O}_{3}: \mathrm{C}$ single crystal detectors. Radiat. Prot. Dosim., v. 33, p. 119 - 122, 1990.

ANTONOV-ROMANOVISKII, V. V.; KEIRUM MARCUS, I. F.; POROSHINA, M.S.; TRAPEZNIKOVA, Z. A. Conference of the Academy of Sciences of the USSR on the Peaceful Uses of Atomic Energy. Moscou, USAEC Report AEC-tr-2435 (pt.1), 239, 1956.

BAKIRTZIS, G.; BRISCOE, C. V.; PEDDIE, C.; RICHES, A. C. Expression of delayed cell death and DNA repair in human epthelial cell lines following exposure to ultraviolet radiation. Radiat. Prot. Dosim., v. 91, n. 1-3, p. 77-80, 2000.

BØTTER-JENSEN, L. Development of optically stimulated luminescence techniques natural minerals and ceramics, and their application to retrospective dosimetry. Riso-R-1211(EN), Denmark, 2000.

BØTTER-JENSEN, L.; McKEVEER, S. W. S.; WINTLE, A. G. Optically stimulated luminescence dosimetry., Elsevier, Amsterdam, 2003.

BRÄUNLICH, P.; SCHÄFER, D.; SCHARMANN, A. A simple model for thermoluminescence and thermally stimulated conductivity of inorganic photoconducting phosphors and experiments pertaining to infra-red stimulated luminescence. Proceedings of the First International Conference on Luminescence Dosimetry, Stanford, USEAC, p.57 - 73, 1967.

CALDAS, L. V. E. Termoluminescência radio e fotoestimulada do LiF;Mg. São Paulo: 1973. Dissertação (Mestrado) - Universidade de São Paulo.

CESARINI, J. P. Impact of ultraviolet radiation on humans. Indoor Built Environ., v. 10, p. $310-316,2001$.

CHANG, C.; LIU, H.; PENG, C.; SHIEH, J.; LAN, C. UVR measurement of a UV germicidal lamp. Health Phys., v. 92, n. 3, p.242 - 250, 2006. 
COLYOTT, L. E.; AKSELROD, M. S.; McKEEVER, S. W. S. An integrating ultraviolet-B dosemeter using phototransferred thermoluminescence from $\alpha$ $\mathrm{Al}_{2} \mathrm{O}_{3}:$ C. Radiat. Prot. Dosim., v. 72, n. 2, p. 87 - 94, 1997.

COLYOTT, L. E.; AKSELROD, M. S.; McKEEVER, S. W. S. Phototransferred thermoluminescence in $\alpha-\mathrm{Al}_{2} \mathrm{O}_{3}$ :C. Radiat. Prot. Dosim., v. 65, n. 1 - 4, p. 263 266, 1996.

COLYOTT, L. E.; McKEEVER, S. W. S.; ASKSELROD, M. S. An integrating UVB dosemeter system. Radiat. Prot. Dosim., v. 85, n. 1 - 4, p. 309-312, 1999.

CORDOBA, C.; AGUIRRE de CARCER, I.; JAQUE, F. Behaviour of the $\alpha-\mathrm{Al}_{2} \mathrm{O}_{3}: \mathrm{C}$ solar ultraviolet dosemeter under environmental conditions. Radiat. Prot. Dosim., v. 85, n. $1-4$, p. 321 - 324, 1999.

CORREA, M. P.; DUBUISSON, P.; PLANA-FATTORI, A. An overview of the ultraviolet index and the skin cancer cases in Brazil. Photochem. Photobiol., v.78, p. $49-54,2003$.

DELTA OHM. DO 9721 Instructions Manual. 2008. Disponível em: <htpp://www.deltaohm.com/ver2008/BR/manuali/DO9721_M_br.pdf>. Acesso em 05 de agosto de 2009.

DIFFEY, B.; HART, G. Ultraviolet and blue ligth phototerapy: principles, sources, dosimetry and safety. The Institute of Physics and Engineering in Medicine, Report no 76 (York: IPEM), 1997.

DIFFEY, L. B. Sources and measurements of ultraviolet radiation. Methods., v. 28, p.4-13, 2002.

DIXON, A. J.; DIXON, B. F. Ultraviolet radiation from welding and possible risk and ocular malignancy. Med. J. Aust., v. 181, p. 155 - 157, 2004.

DOUGTHY, M. J.; OBLAK, E. A clinical assessment of the anterior eye in arc welders. Clin. Exp. Optomet., v.88, n.6, p. 387395, 2005.

DRISCOLL, C. M. H. Solar UVR measurements. Radiat. Prot. Dosim., v. 64, n. 3, p. $179-188,1996$.

GORDON, P. M.; SAUNDERS, P. J.; DIFFEY, B. L.; FARR, P. M. Phototesting prior to narrowband (TL01) ultraviolet B phototherapy. Br. J. Dermatol. v. 139, p. $811-814,1998$.

GROSSI, F. H.; CAMPOS, L. L. Studies of UV Induced Phototransfered thermoluminescence in CaSO4:Dy pellets. Radiat. Prot. Dosim., v. 100, n. 1- 4, p. 421-424, 2002.

GRUIJL, F., R. Biological action spectra. Radiat. Prot. Dosim., v. 91, n. 1 - 3, p. $57-63,2000$. 
HINCE, A. J.; COLLEY, P. A.; TWITCHEN, I.; LOWE, A. Commissioning a narrowband (TL01) ultraviolet B phototherapy cabinet (without getting your fingers... or anything else burnt!). Radiat. Prot. Dosim., v.91, n. 1 - 3, p. 189 192, 2000.

HU, S.; MA. F.; COLLADO-MESA, F.; KIRSNER, R. S. UV radiation, latitude, and melanoma in US hispanics and blacks. Arch. Dermato., v. 140, p 819 - 824, 2004.

HÜLSEN, G.; GRÖBNER, J. Characterization and calibration of ultraviolet broadband radiometers measuring erythemally weighted irradiance. Applied Optics., v. 46, n. 23, p. 5877-5886, 2007

HUNTLEY, D. J.; GODFREY-SMITH, D.I.; THEWALT, M. L. W. Optical dating of sediments. Nature, v. 313, p. $105-107,1985$.

IARC - INTERNATIONAL AGENCY FOR RESEARCH ON CANCER. Monographs on the evaluation of carcinogenics risks to humans. Solar and Ultraviolet Radiation, v. 55, 1992.

ICNIRP - INTERNATIONAL COMMISSION ON NON-IONIZING RADIATION PROTECTION. Guide protecting workers from ultraviolet radiation.

Oberschleibheim, 14/2007.

ICRP- International Commission on Radiological Protection. Recommendations of the international commission on radiological protection. Oxford Pergamon Press, v. 60, 1991.

ICRU - International Commission on Radiation Units and Measurements.

Quantities and units in radiation protection dosimetry. Maryland: ICRU, v. 51, 1993.

ICRU - International Commission on Radiation Units and Measurements.

Fundamental quantities and units for ionizing radiation. Maryland: ICRU, v. 60, 1998.

INCA - INSTITUTO NACIONAL DO CÂNCER. Ministério da Saúde. Estimativa 2008. Incidência de câncer no Brasil. Rio de Janeiro, 2008.

IRD - Instituto de Radioproteção e Dosimetria, Comissão Nacional de Energia Nuclear. Performance of individual monitoring systems: criteria and conditions. CASMIE / IRD / CNEN. Report RT nº 002.01/95, 1995.

ISO - INTERNATIONAL ORGANIZATION FOR STANDARDIZATION. Guia para a expressão da incerteza da medição. Terceira edição brasileira em língua portuguesa. Rio de Janeiro: ABNT, 2003.

JURSINIC, P. A. Characterization of optically stimulated luminescence dosimeters, OSLDs, for clinical dosimetric measurementes. Med. Phys., v.34, p. $4594-4604$, 2007. 
KHAZOVA, M.; O' HAGAN, J.B.; GRAINGER, K. J. L. A new methodology for the assessment of hand protection from ultraviolet exposure. Radiat. Prot. Dosim., v. 121 , n. 3, p. $265-274,2006$.

KIM, E. A.; KIM, B.; YI, C.;KIM, I. G.; CHAE, C.; KANG, S. Macular degeneration in an arc welder. Ind. Health, v. 45, p. $371-373,2007$.

LANDAUER. User manual InLigth Systems, Glenwood, Illinois, 2006.

LAS, W. C. Mecanismos propostos de termoluminescência induzida pela luz UV no $\mathrm{CaF}_{2}$ natural. São Paulo:1975. Dissertação (Mestrado) - Universidade de São Paulo.

LOS, A.; GRÖBNER, J. An assessment of the UV broad band filter radiometer measurement accuracy. Proceedings of WMO Technical Conference on Meteorological and Environmental Instruments and Methods of Observation (TECO - 2005), Bucharest, Romênia, paper 3 (12), 2005.

MacKIE, R. M. Effects of ultraviolet radiation on human health. Radiat. Prot. Dosim., v. 91, n. 1 - 3, p. 15 - 18, 2000.

MARIUTTI, F. G. Rapporteur's report: ultraviolet radiation measurements and sources. Radiat. Prot. Dosim., v. 91, n. 1 - 3, p. 93 - 98, 2000.

McKEEVER, S. W. S. Optically stimulated luminescence dosimetry. Nuclear Instr. Meth. Phys. Res., v. 184, p. 29 - 54, 2001.

McKEEVER, S. W. S.; AKSELROD, M. S.; MARKEY, B. G. Pulsed optically stimulated luminescence dosimetry using $\alpha-\mathrm{Al}_{2} \mathrm{O}_{3}:$ C. Radiat. Prot. Dosim., v. 65, n. $1-4$, p. 267 - 272, 1996.

McKEEVER, S. W. S.; BLAIR, M. W.; BULUR, E.; GAZA, R.; KALCHGRUBER, R.; KLEIN, D. M.; YUKIHARA, E. G. Recent advances in dosimetry using the optically stimulated luminescence of $\mathrm{Al}_{2} \mathrm{O}_{3}:$ C. Radiat. Prot. Dosim., v. 109, n. 4, p. 269 276, 2004.

McKEEVER, S. W. S.; MOSCOVITCH, M. On the advantages and disadvantages of optically stimulated luminescence dosimetry and thermoluminescence dosimetry. Radiat. Prot. Dosim., v. 104, n. 3, p. 263 - 270, 2003.

McKEEVER, S. W. S.; MOSCOVITCH, M.; TOWNSEND, P. D. Thermoluminescence Dosimetry Materials: Properties and Uses. Nuclear Technology Publishing, Ashford, UK, 1995.

MEINANDER, O.; KAZADIS S.; BLUMTHALER, M.; YLIANTTILA, L.; JOHNSEN, B.; LAKKALA, K.; KOSKELA, T.; JOSEFSSON, W. Diurnal discrepancies in spectral solar UV radiation measurements. Appl. Opt., v. 45, p. $5346-5357$, 2006.

MENNO, DI I.; MORICONI, L. M.; MENNO, DI M.; CASALE, R. G.; SIANI, M. A. Spectral ultraviolet measurements by a multichannel monitor and a Brewer 
spectroradiometer: a field study. Radiat. Prot. Dosim., v. 102, n. 3, p. $259-263$, 2002.

MUNNOCH, D. A.; GORST, C. M.; HANCOCK, K. Post laser hyperpigmentation and occupational ultraviolet radiation exposure. Brit. J. Plast. Surg., v. 53, p. 259 - 261, 2000.

NOH, A. B.; AMIM, M. Y.; MAHAT, H. R.; BRADLEY, D. A. Investigation of some commercial TLD chips/discs as UV dosimeters. Radiat. Phys. Chem., v. 61, p. 497 - 499, 2001.

NORVAL, M. Immunosuppression induced by ultraviolet radiation: relevance to public health. Bull. World Health Org., v. 80, n. 11, p. 906 - 907, 2002.

OKUNO, E. Measurement of ultraviolet radiation from welding arcs. Ind. Health, v. 25, p. $147-156,1987$.

OKUNO, E.; VILELA, M. A C. Radiação ultravioleta: características e efeitos. São Paulo: Editora Livraria da Física. p.78, 2005.

OSTER, L.; WEISS, D.; KRISTIANPOLLER, N. A study of photoestimulated thermoluminescence in C-doped $\alpha-\mathrm{Al}_{2} \mathrm{O}_{3}$ crystals. Appl. Phys., v. 27, p. 1732 1736, 1994.

PAGONIS V.; CHEN R.; LAWLESS J. L. A quantitative kinetic model for $\mathrm{Al}_{2} \mathrm{O}_{3}: \mathrm{C}$ :TL response to UV-illumination. Radiat. Meas., v.4, p.175 -179, 2008.

PERKS C. A.; Le ROY G.; PRUGNAUD B. Introduction of the InLight monitoring service. Radiat. Prot. Dosim., v. 125, p. 220 - 223, 2007.

POTIENS, A. J.; CAMPOS, L. L. Ultraviolet and laser radiation dosimetry using phototransferred thermoluminescence in $\mathrm{CaSO}_{4}$ :Dy. Radiat. Prot. Dosim., v. 66, n. 1 - 4, p. 95 - 96, 1996.

PRADHAN, A. S.; DASH SHARMA, P. K.; SHIRVA, V. K. Thermoluminescence response of $\mathrm{Al}_{2} \mathrm{O}_{3}: \mathrm{C}$ to UV and ionizing radiation. Radiat. Prot. Dosim., v. 64, n. 3, p. $227-231,1996$.

SANBORN, E.N.; BEARD, E. L. Sulfides of strontium, calcium, and magnesium in infra-red stimulated luminescence dosimetry. Proceedings of the First International Conference on Luminescence Dosimetry, Stanford, USEAC, p. 183 - 191, 1967.

SCHREDER, J.; GRÖBNER, J. LOS, A.; BLUMTHALER, M. Intercomparison of monochromatic source facilities for the determination of the relative spectral response of erythemal broadband filter radiometers. Opt. Lett., v. 29, p. $1455-$ 1457, 2004.

SGARBI, F. C.; CARMO, E. D.; ROSA, L. E. B. Radiação ultravioleta e carcinogênese. Rev. Ciênc. Méd., v.16. p. 245 -250, 2007. 
SHEEHAN, J. M.; YOUNG, A. R. Ultraviolet radiation induced apoptosis in human skin in vivo. Radiat. Prot. Dosim., v. 91, n. 1 - 3, p. 47 - 50, 2000.

SLINEY, D. H. Radiometric quantities and units in photobiology and photochemistry: Recommendations of the Commission International de l'Eclairage (International Commission on Illumination). Photoch. Photobiol., v. 93, p. $425-$ 432, 2007.

SMETANA, F.; BERGMANN, R.; BRUSL, H.; FUGGER, M.; GRATZL, W.; KITZ, E.; VANA, N. A portable multi-purpose OSL reader for UV dosimetry at workplaces. Radiat. Meas., v. 43, p. 516-519, 2008.

SONO, D. A.; McKEEVER, S. W. S. Phototransferred thermoluminescence for use in UVB Dosimetry. Radiat. Prot. Dosim., v. 100, n. 1 - 4, p. 309 - 312, 2002.

SURAKKA, J.; LINDH, T.; ROSÉN, G.; FISCHER; T. Workers' dermal exposure to UV-curable acrylates in the furniture an parquet industry. Ann. Occup. Hygiene, v. 8 , p. $635-644,2000$.

SWERDLOW, A. J. Epidemiology of chronic disease risks in relation to ultraviolet radiation exposure. Radiat. Prot. Dosim., v. 91, n. 1-3, p. 19 - 23, 2000.

TATUMI, S. H.; GOZZI, G.; YEE, M.; OLIVEIRA, V.I.; SALLUN, A. E. M.; SUGUIO, K. Luminescence dating of quartenary deposits in geology in Brazil. Radiat. Prot. Dosim., v. 119, n. 1-4, p.462 - 469, 2006.

TATUMI, S.H.; PEIXOTO, M. N. O.; MOURAB, J. R. S., MELLO, C. L.,CARMO, I. O.; KOWATA, E. A.; YEE, M.; BRITO, S. L. S M.; GOZZI G.; KASSAB, L. R. P. Optical dating using feldspar from Quartenary alluvial and colluvial sediments from SE Brazilian Plateau, Brazil. J. Luminesc., v. 102 -103, p. 566 - 570, 2003.

WEATHERHEAD, E. C.; WEBB, A. R. International response to the challenge of measuring solar ultraviolet radiation. Radiat. Prot. Dosim., v. 72, n. 3 - 4, p. 223 229, 1997.

WEBB, A. R. Standardisation of data from ultraviolet radiation detectors. Radiat. Prot. Dosim., v. 91, n. 1 - 3, p. $123-128,2000$.

WEELDEN, V.; BAART DE LA FAILLE, H.;YOUNG, E.; VAN DER LEUN, J. A new development in UVB phototheraphy - an effective treatment for psoriasis. $\mathbf{B r}$. J. Dermatol., v. 119, p. 11 - 19, 1988.

WEST, W. G.; KEARFOTT K,. J.; BERNAL, S. M. The sunlight OSL response of a commercially available $\alpha-\mathrm{Al}_{2} \mathrm{O}_{3}: \mathrm{C}$ personnel dosimetry material. Radiat. Prot. Dosim., v. 119, n. 1 - 4, p. 344 - 349, 2006.

WHO - WORLD HEALTH ORGANIZATION. Health and enviromental effects of ultraviolet radiation. A summary of environmental health criteria $\mathbf{1 6 0}$ ultraviolet radiation. Report WHO/EHG/95.16, Geneva, 1995. 
WHO - WORLD HEALTH ORGANIZATION. Solar Ultraviolet Radiation. Global burden of disease from solar ultraviolet radiation. Environmental Burden of Disease Series, No. 13.Geneva, 2006.

WHO - WORLD HEALTH ORGANIZATION. Ultraviolet radiation, environmental health criteria 160. Geneva, 1994.

WINTLE, A. G. Luminescence and ESR dating and allied research. Radiat. Meas., v.27, p. $625-1025,1997$.

XINBO, T.; HONGJUN, L.; YAN, C.; QIANG, T.; LIANGBI, S.; JUN, X. Growth of higly sensitive thermoluminescent crystal $\alpha-\mathrm{Al}_{2} \mathrm{O}_{3}: \mathrm{C}$ by the temperature gradient technique. J. Crystal Growth., v.310, p. $3800-3803,2008$.

YEN, Y. L.; LIN, H. J.; CHEN, C. R.; CHANG, G. H.; GUO, H. R. Photokeratoconjunctivitis caused by different light sources. Am. J. Emerg. Med., v. 22, p. $511-515 ; 2004$.

YOUNG, M. Óptica e lasers. São Paulo. Ed. da Universidade de São Paulo, 1998.

YUKIHARA E. G.; McKEEVER S. W. S.; Optically stimulated luminescence (OSL) dosimetry in medicine. Phys. Med. Biol., v. 53, p. R351 - R379, 2008.

YUKIHARA E. G.; WHITLEY V. H.; McKEEVER S. W. S.; AKSELROD A. E.; AKSELROD M. S. Effect of high-dose irradiation on the optically stimulated luminescence of $\mathrm{Al}_{2} \mathrm{O}_{3}:$ C. Radiat. Meas., v. 38, n. 3, p. $317-330,2004$.

YUKIHARA, E. G.; McKEEVER, S. W. S.; lonizing density dependence of optically and thermally stimulated luminescence from $\mathrm{Al}_{2} \mathrm{O}_{3}:$ C. Radiat. Prot. Dosim., v. 119, n. 1-4, p.206 - 217, 2006.

YUKIHARA, E. G.; WHITLEY, V. H.; POLF, J. C.; KLEIN, D. M.; McKEEVER, S. W. S.; AKSELROD, A. E.; AKSELROD, M. S. The effects of deep trap population on thermoluminescence of $\mathrm{Al}_{2} \mathrm{O}_{3}:$ C. Radiat. Meas., v. 37, p. $627-638,2003$. 